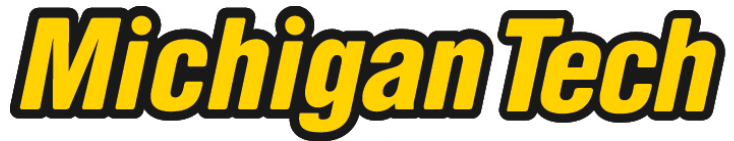 \\ Michigan Technological University Create the Future Digital Commons @ Michigan Tech
}

Dissertations, Master's Theses and Master's Reports - Open

Dissertations, Master's Theses and Master's

Reports

2003

\section{Evaluating the usefulness of soil moisture (forecasts) in streamflow prediction for central Texas}

Mohammed Mahmoud

Michigan Technological University

Follow this and additional works at: https://digitalcommons.mtu.edu/etds

Part of the Civil and Environmental Engineering Commons

Copyright 2003 Mohammed Mahmoud

\section{Recommended Citation}

Mahmoud, Mohammed, "Evaluating the usefulness of soil moisture (forecasts) in streamflow prediction for central Texas ", Master's Thesis, Michigan Technological University, 2003.

https://doi.org/10.37099/mtu.dc.etds/256

Follow this and additional works at: https://digitalcommons.mtu.edu/etds

Part of the Civil and Environmental Engineering Commons 


\title{
Evaluating the Usefulness of Soil Moisture (Forecasts) in Streamflow Prediction for Central Texas
}

\author{
By \\ Mohammed Mahmoud
}

\author{
A THESIS \\ Submitted in partial fulfillment of the requirements \\ for the degree of \\ MASTER OF SCIENCE IN CIVIL ENGINEERING
}

MICHIGAN TECHNOLOGICAL UNIVERSITY

2003 
This thesis, "Evaluating the Usefulness of Soil Moisture (Forecasts) in Streamflow Prediction for Central Texas", is hereby approved in partial fulfillment of the requirements for the degree of MASTER OF SCIENCE IN CIVIL ENGINEERING.

\section{Department of Civil and Environmental Engineering}

Dr. Deborah Nykanen., Thesis Advisor

$\overline{\text { Dr. C. Robert Baillod, Chair, Department of Civil and Environmental Engineering }}$

Date 


\section{Abstract}

The past decade has brought significant advancements in seasonal climate forecasting. However, water resources decision support and management continues to be based almost entirely on historical observations and does not take advantage of climate forecasts. This study builds on previous work that conditioned streamflow ensemble forecasts on observable climate indicators, such as the El Niño-Southern Oscillation (ENSO) and the Pacific Decadal Oscillation (PDO) for use in a decision support model for the Highland Lakes multi-reservoir system in central Texas operated by the Lower Colorado River Authority (LCRA). In the current study, seasonal soil moisture is explored as a climate indicator and predictor of annual streamflow for the LCRA region. The main purpose of this study is to evaluate the correlation of fractional soil moisture with streamflow using the 1950-2000 Variable Infiltration Capacity (VIC) Retrospective Land Surface Data Set over the LCRA region. Correlations were determined by examining different annual and seasonal combinations of VIC modeled fractional soil moisture and observed streamflow. The applicability of the VIC Retrospective Land Surface Data Set as a data source for this study is tested along with establishing and analyzing patterns of climatology for the watershed study area using the selected data source (VIC model) and historical data. Correlation results showed potential for the use of soil moisture as a predictor of streamflow over the LCRA region. This was evident by the good correlations found between seasonal soil moisture and seasonal streamflow during coincident seasons as well as between seasonal and annual soil moisture with annual streamflow during coincident years. With the findings of good correlation between seasonal soil moisture from the VIC Retrospective Land Surface Data Set with observed annual streamflow presented in this study, future research would evaluate the application of NOAA Climate Prediction Center (CPC) forecasts of soil moisture in predicting annual streamflow for use in the decision support model for the LCRA. 


\section{Acknowledgements}

I would like to initially thank the NOAA-NASA GEWEX Americas Prediction Project, GAPP for providing funding for this project and thus allow me to contribute to its intended goals and objectives. The LCRA collaborators on the project Dr. Quentin Martin and Dr. Jobaid Kabir provided useful information in assisting this project towards its anticipated completion. Sara O'Connell provided useful background, materials and previous research to which I am appreciative of. Also, Ed Maurer very kindly provided the VIC data set, which much of the analysis in this thesis is based on, as well as offer assistance in data related questions.

A lot of the work provided in this thesis would not have been possible to perform without the guidance, advise, and motivation of my advisor Dr. Deborah Nykanen, who continuously amazes me with her vast knowledge of the water resources discipline and her dedication to the field. I would also like to show gratitude to Dr. David Watkins who was the lead Principal Investigator on this project. He also has the credit of teaching me almost everything I currently know about water resources and has guided me in the right direction towards furthering my education in graduate school. I would like to thank the rest of the members of my thesis committee Dr. Brian Barkdoll and Dr. Judith Budd for taking time out of their busy schedules to read my thesis and provide feedback on it. I must also show appreciation towards Dr. Alex Mayer, who may not know it, but was the person that attracted me to the water resources field.

I am also very grateful to Andy Carlson, who not only educated me in all things GIS but was always there to help me in solving my GIS problems, no matter how busy or preoccupied he was. My best colleague throughout my graduate experience at Michigan Tech has to be my office-mate Toni Rubert. His support and encouragement during the pursuit of our respective Master's degrees made the work spent on them easier to manage. I have come to know him not only as a good colleague but a great friend and I feel very privileged to have known him and worked with him. I am very thankful to all 
the people that I have gotten to know at Michigan Tech and spent memorable moments with, including members of the Civil and Environmental Engineering department. I also cannot forget to acknowledge my family for their constant love and support. Their contribution to my life has been phenomenal. Finally, I dedicate this work to my Father, Dr. Idris Ahmed Mahmoud, to whom I owe very much and who I always strive to make proud. 


\section{Table of Contents}

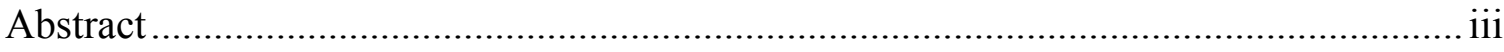

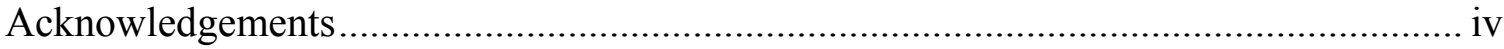

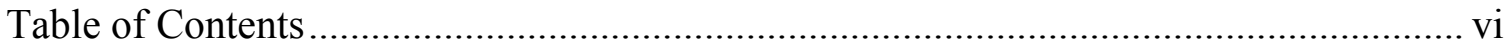

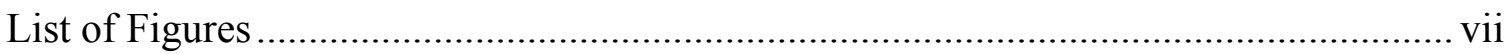

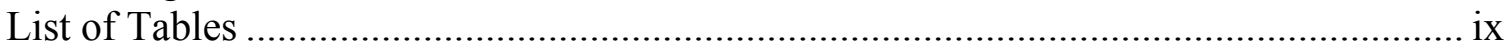

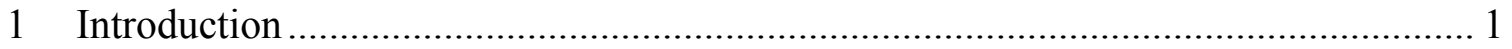

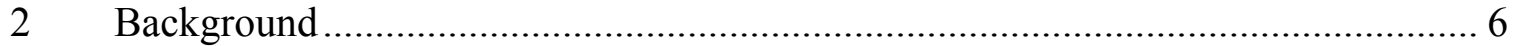

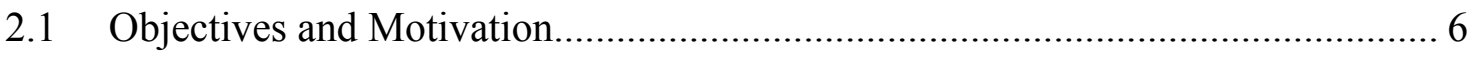

2.2 The Lower Colorado River Authority (LCRA) ……….................................... 8

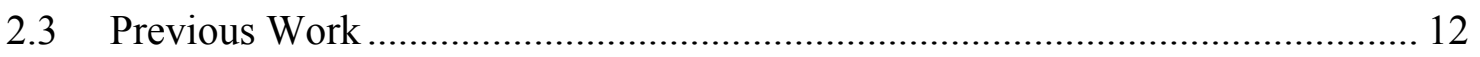

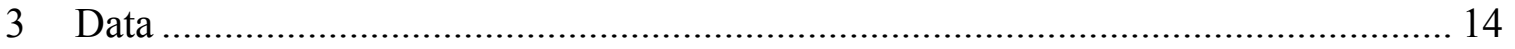

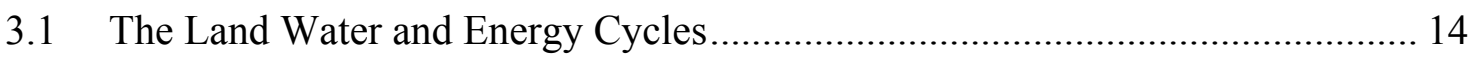

3.2 Variable Infiltration Capacity (VIC) Model ....................................................... 16

3.3 Variable Infiltration Capacity (VIC) Retrospective Land Surface Data Set ....... 19

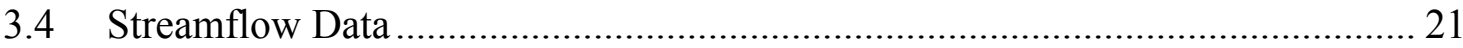

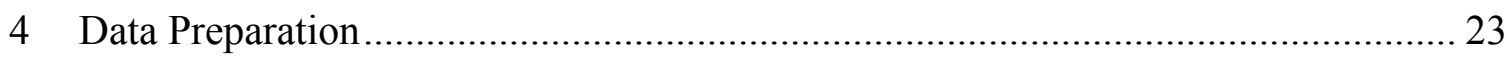

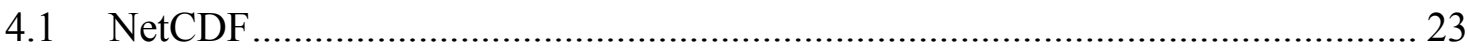

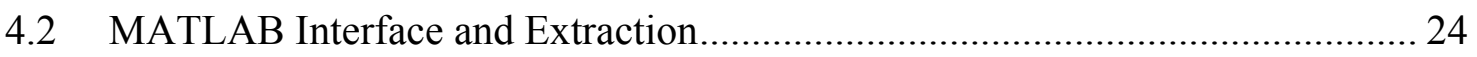

4.3 ArcView GIS Reprojection and Manipulation ................................................ 27

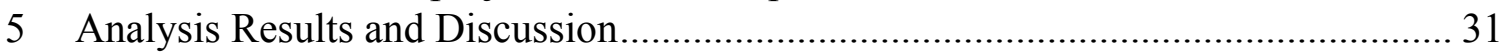

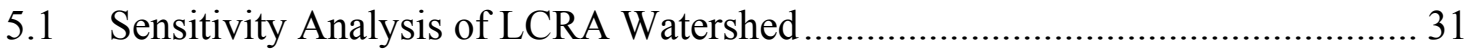

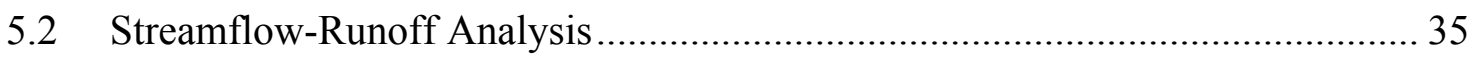

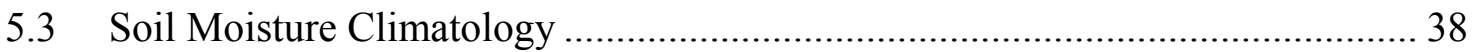

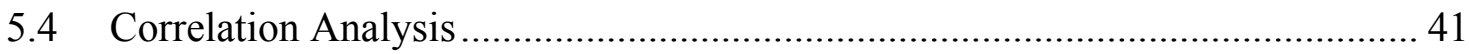

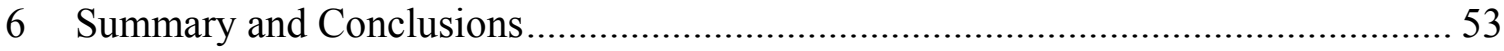

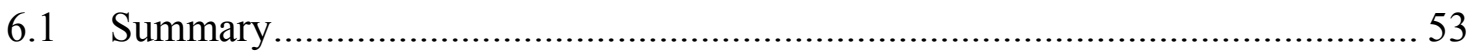

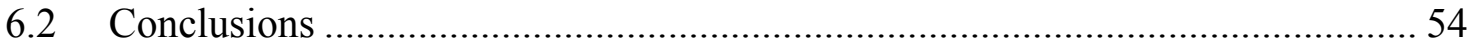

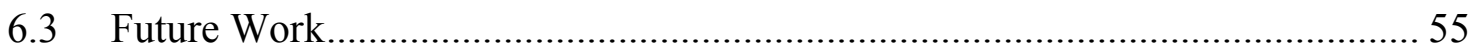

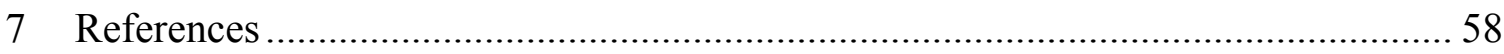

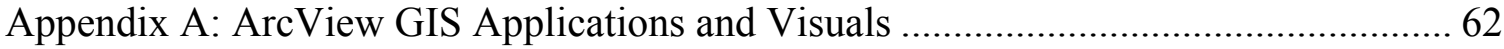

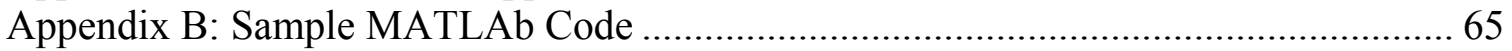




\section{List of Figures}

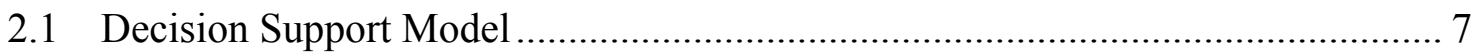

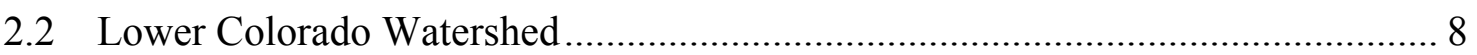

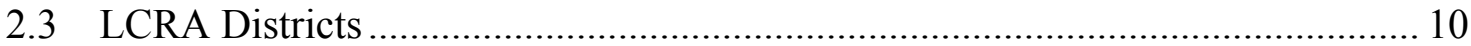

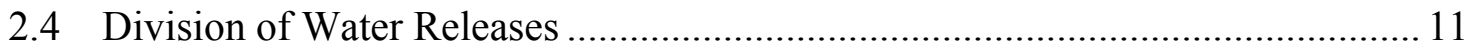

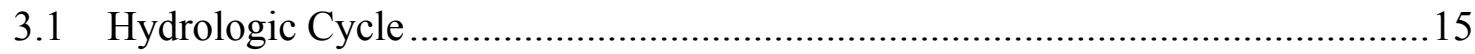

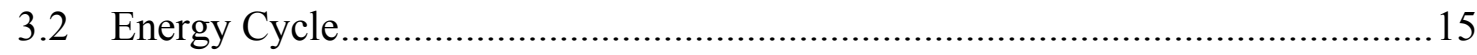

3.3 VIC Retrospective Land Surface Data Set Model .............................................20

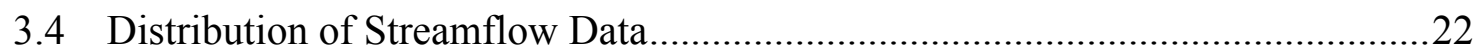

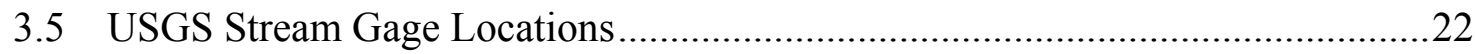

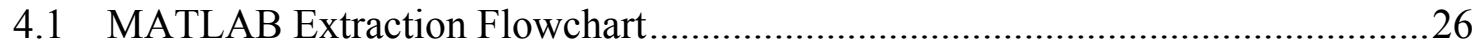

4.2 Reprojection of Shapefiles in ArcView GIS Flowchart .....................................29

4.3 Reliability Check of New LCRA Watershed Shapefile Flowchart .......................30

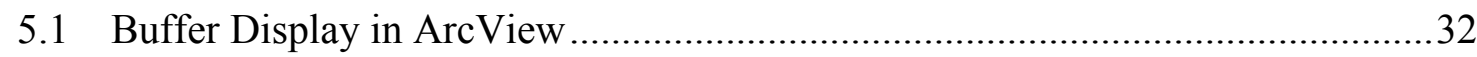

5.2 Average Fractional Soil Moisture Variation Bar Chart ..........................................33

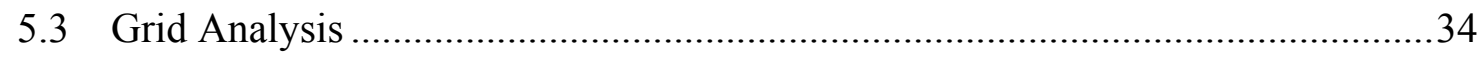

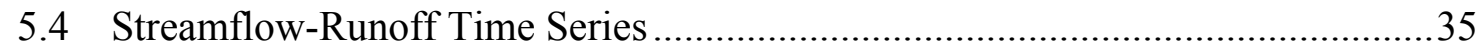

5.5 Monthly Observed Streamflow vs. Monthly Modeled Runoff..............................37

5.6 Annual Observed Streamflow vs. Annual Modeled Runoff....................................37

5.7 Annual Average Fractional Soil Moisture Anomalies and $10^{10}$ Annual AggregateObserved Streamflow Anomalies vs. Time............................................39

5.8 Seasonal Average Fractional Soil Moisture Anomalies and $10^{10}$ Seasonal Aggregate Observed Streamflow Anomalies vs. Time..........................................39

5.9 Seasonal Average Fractional Soil Moisture Anomalies and $10^{10}$ Annual Aggregate Observed Streamflow Anomalies vs. Time............................................40

5.10 October Average Fractional Soil Moisture Correlations ......................................46

5.11 Winter Average Fractional Soil Moisture Correlations .........................................46

5.12 Spring Average Fractional Soil Moisture Correlations …………………….......47

5.13 Summer Average Fractional Soil Moisture Correlations.......................................48

5.14 Fall Average Fractional Soil Moisture Correlations ..............................................48

5.15 Annual Aggregate Observed Streamflow Correlations with 0-Year Lag .............49

5.16 Annual Aggregate Observed Streamflow Correlations with 1-Year Lag ..............50

5.17 Consecutive Seasons Soil Moisture Correlations ................................................50

5.18 Summer Aggregate Observed Streamflow Correlations..........................................51

6.1 Example of NOAA CPC Soil Moisture Outlook ……………..............................56 
6.2 Example of NOAA CPC Precipitation Outlook ............................................56

6.3 Example of NOAA CPC Temperature Outlook ................................................57

A.1 GIS Visual of LCRA Watershed and VIC Data Layer on State of Texas ............63

A.2 GIS Visual of LCRA Watershed and Overlaying VIC Modeled Data Points .......63

A.3 GIS Visual of Kriging on LCRA Watershed ......................................................64 


\section{List of Tables}

4.1 Geographic Projection Information .............................................................28

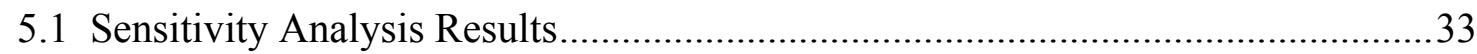

5.2 Correlation Coefficients and Corresponding Statistical Significance ....................44

5.3 Correlation Coefficients and Corresponding Statistical Significance ................... 45 


\section{Introduction}

The management of water resources has become an important issue due to the looming threat of water scarcity. To counter this dilemma, water managers need to make use of all hydrologic and meteorological information available to them, including climate forecasts. However, the current state of water resources decision-making relies to a large extent on historical streamflow observation records and heuristic methods that are geared towards tackling the traditional water resources issues of flood and drought (Hall and Dracup, 1970). There is currently little application of probabilistic forecasts in water resources management and decision-making. Water system operators primarily rely on past experience, observations of current conditions, and professional judgment due to limited experience with hydrologic and meteorological forecasts (Lee, 1999).

Basing water resources decisions on historical observations can be problematic in that climatic patterns of the past may not be the same as the future (Maidment, Ch.2, 1993), and the effect of long-term climate variability neglected. Other associated problems that result from this practice are heavy bias by recent outcomes on water resources decisions, and a lack of decision makers with pertinent experience because of changing objectives for system management and the downsizing of water management agencies.

The inclusion of climate forecasts could assist in the decision-making process, but climate forecasts are not being used to the fullest extent possible for optimal water resources management. Water managers are skeptical about using seasonal climate forecasts due to their uncertainty (Conley et al., 1999; Institute for the Study of Planet Earth, 2000; Pagano et al., 2000, 2001, 2002), and the widespread perception that the quality of forecasts is generally poor (Changnon, 1990). Water managers are hesitant to apply new information and methods, like climate forecasts, that could expose them to greater liability. There is limited knowledge and understanding of climate processes and prediction capabilities among potential climate forecast users. Forecast users feel that they need two main questions answered regarding forecast accuracy: 1) What is the 
probability that climate forecasts will warn of climate extremes? and 2) Given an increased likelihood of an event, what is the probability that it will actually occur? (Hartmann et al., 2002). Climate forecasts themselves are not without limitations that make water managers resistant to using them. Noise in climate signals, inaccuracies in forecasts, and the unpredictability of many aspects of the climate (Maidment, Ch.2, 1993) limit the potentially useful application of climate forecasts and prediction models. The perceived complexity involved in using forecasts and the lack of extensive records and forecasts hint at a need for developing new tools and management strategies to use forecasts advantageously. Developing these tools and strategies can also prove discouraging for water managers who may want to use climate forecasts.

The use of climate forecasts would eliminate the need of decision makers to mostly depend on personal and professional judgment and experience, and reduce statistical bias attributed to recent and current meteorological and hydrological observations and conditions. This is now possible due to advancements and improvements in forecasting capabilities and can bring about better water resources management and water systems operation. The incorporation of climate forecasts in decision-making can provide leadtime in managing and planning for climatic events. This would reduce the vulnerability of water managers and planners to the climate by being more informed and prepared (Hartmann et al., 2002). Climate forecasts improve on water resources planning and management by providing information that could assist in the allocation of water supplies to users, and maintain environmental flows (Piechota et al., 2001).

Climate forecasts have been employed in various situations to yield successful results. The National Weather Service (NWS) possesses a NWS River Forecast System (NWSRFS) that utilizes the NWS Extended Streamflow Prediction (ESP) program. The ESP procedure was first used in California during the early 1970s by the NWS California-Nevada River Forecast Center (RFC) and the State of California. The NWS Hydrologic Research Laboratory began to develop an ESP program in 1975. Since then the ESP procedure and program have been used by RFCs in California-Nevada, the Colorado Basin, and Alaska. It was also used to assess severity of drought in 
Washington, D.C. in 1977. Currently, it is being used nationwide. The ESP program became an essential part of the NWSRFS in 1984. This program aimed to provide more accurate probabilistic forecast information related to streamflow that can yield economic savings, reduced error in water management decisions, and input for multi-purpose reservoir operations (Day, 1985). ESP has been extended further to produce long-range streamflow forecasts by incorporating nonparametric statistical procedures with hydrologic models and data. Long-range forecasts can coincide with hydrologic and meteorological processes with significant persistence that has time scales up to a number of months. Evidence shows that climatic information can provide improvements to longrange streamflow forecasts (Redmond and Koch, 1991). Results also suggest that soil moisture information is of more value than climate information for forecasting, although climate information is useful for long-range forecasting of water-balance variables (Smith et al., 1992).

Another beneficial application of climate forecasts is the Coupled Model Project (CMP) that was founded at the National Meteorological Center (NMC) to develop a multi-season forecast system based on coupled ocean-atmosphere General Circulation Models (GCMs). Studies have shown that ocean-atmosphere interactions account for much of the climatic variability on seasonal and inter-annual time scales. Significant forecast skill was produced, with up to two seasons of lead-time according to the CMP (Ji et al., 1994). Also in the Colombia River basin, climate forecasts helped produce useful streamflow forecasts with a six-month lead. This lead-time has resulted in improved system operating performance for the Colombia River reservoir system. The use of long-lead forecast information improved hydropower production and consequently increased revenue (Hamlet et al., 2002).

Specific climatic events tend to exhibit patterns and properties, some of which can depend on geographic location, that can allow for longer lead-time predictions. These behaviors and patterns are generally associated with particular climate indicators, and it has become evident that the use of climate indicators and predictors has assisted in the production of meaningful forecasts of streamflow. Climate indicators include: streamflow 
persistence, soil moisture, land surface temperatures, and large-scale recurrent teleconnective patterns such as El-Niño Southern Oscillation (ENSO), Pacific Decadal Oscillation (PDO), Tropical Atlantic Variability (TAV), and North Atlantic Oscillation (NAO). These climatic indicators and predictors can provide long lead-times for streamflow forecasts with a better accuracy and prediction skill and therefore greatly improve upon the management of water resources.

Climate indicators and predictors have been widely used to assist in climate forecasting. It has been found that the use and incorporation of ENSO and PDO into extended streamflow forecasts have increased prediction lead-times to about a year (Hamlet and Lettenmaier, 1999; Piechota et al., 2001). An example is a study conducted for longrange streamflow forecasting using ENSO indicators (Southern Oscillation Index-SOI and Wright Sea Surface Temperatures-SSTs) as predictors of Spring-Summer runoff (Piechota and Dracup, 1999). In the country of Colombia, strong and significant correlations between ENSO and streamflow in certain rivers suggest the feasibility of streamflow predictions with a long lead-time (Gutierrez and Dracup, 2001). Rainfall and runoff forecasts in Australia using ENSO indicators have proven to be reliable and useful for local water resources management by forecasting streamflow (Chiew et al., 1998; Piechota et al., 1998).

Another type of indicator that has been used as a climate indicator in examining climate change (in Lebanon) is soil moisture (Bou-Zeid and El-Fadel, 2002). In many regions, soil moisture itself has great persistence as a climatic indicator and therefore is being studied to determine its potential as a climate indicator and predictor. Previous work (O'Connell, 2002), which this current work expands on, dealt with the manipulation of teleconnective patterns as climate indicators and predictors. Several of the potential predictors examined by O'Connell, such as SOI and NAO, were weakly correlated with streamflow and suggested modest potential for streamflow prediction. In O'Connell's work, recommendations were made to investigate other possible climatic predictors for the same purpose. The next step in climate forecasting is using soil moisture not only as a 
climate indicator but also as a climate predictor to promote the use of climate forecasts for streamflow prediction.

Equation Chapter 2 Section 1 


\section{Background}

This chapter discusses the objectives and motivations of the overall project and the specific objectives of this research. The collaborating Lower Colorado River Authority (LCRA) is described and the geographic location of this study in central Texas defined. Previous work by O'Connell (2002) is also highlighted, and connections between both research studies are mentioned.

\subsection{Objectives and Motivation}

The overall goal of the project is to improve the operation and management of a multireservoir system in central Texas. This is to be done by incorporating climate indicators, which can also be used as predictors, and climate forecasts into a decision support model geared for the multi-reservoir system (see Figure 2.1). The decision support model aims to assist in the planning and management of the multi-reservoir system and is based on a stochastic (ensemble-based) model of the reservoir system (Watkins et al., 2000). The model predictions will supplement standard critical planning information. The model itself could reveal different decision results and evaluate them for a range of possible inflows (i.e., streamflow scenarios that are statistically similar to historical conditions).

Climate indicators can add predictive skill to the decision support model for the improvement of the operation and management of the multi-reservoir system. Climate indicators include streamflow persistence, land surface temperature, soil moisture, and large-scale recurrent teleconnective patterns such as El Niño-Southern Oscillation (ENSO), Pacific Decadal Oscillation (PDO), Tropical Atlantic Variability (TAV), and North Atlantic Oscillation (NAO). These climate indicators could be used as long-lead indicators and predictors of regional streamflow. Previous studies have already shown an existing strong relationship between Southern Oscillation Index (SOI), temperature, and precipitation patterns in central Texas, where the multi-reservoir system is located (Ropelewski and Halpert, 1986; Piechota and Dracup, 1996). The overall project will 
look at the usefulness of climate forecasts by assessing the value of seasonal and annual climate forecasts with respect to water resources management. The project intends to encourage water managers to utilize hydrologic and meteorological information that is readily available to them, such as seasonal climate forecasts, instead of just using historical observations.

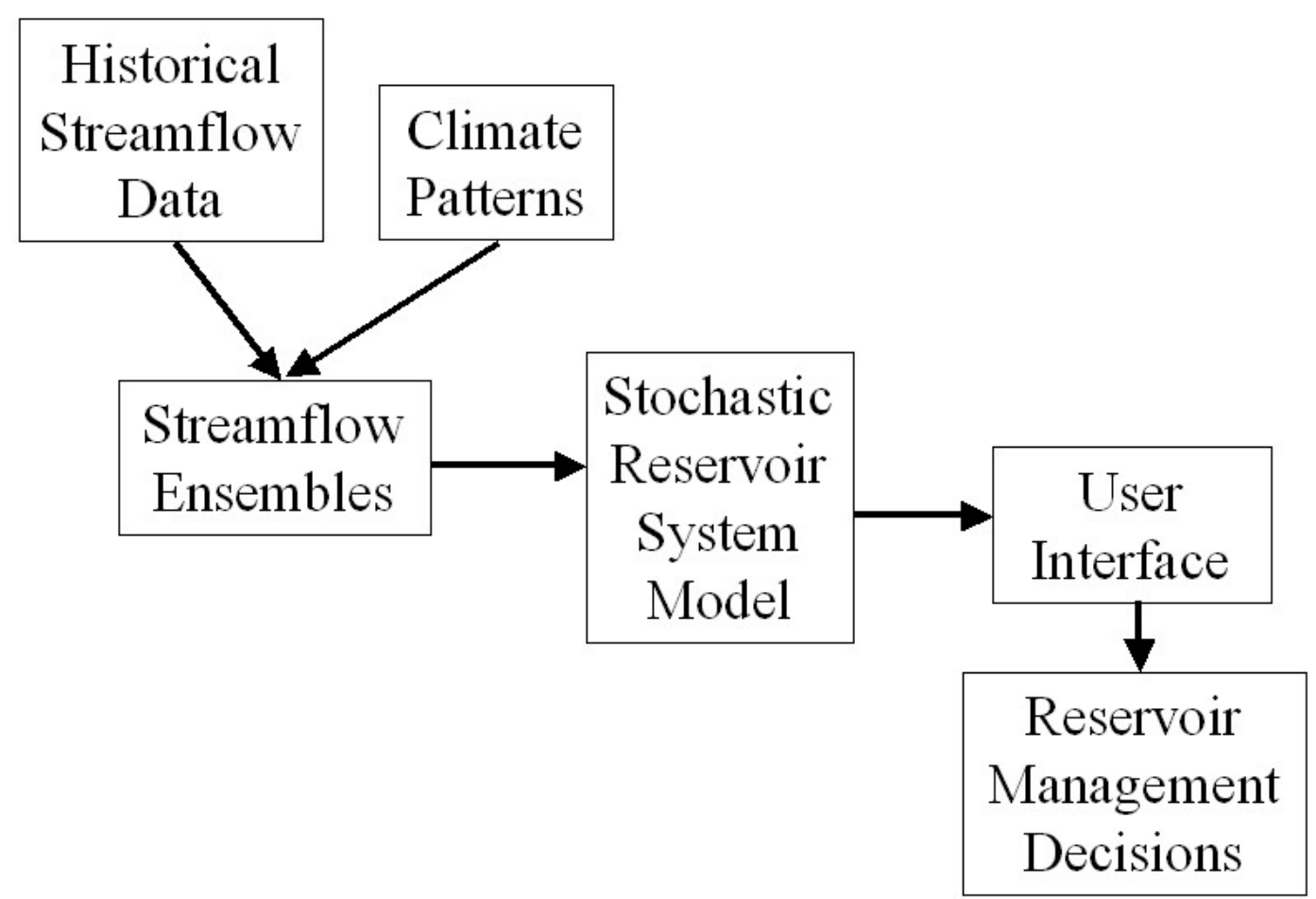

Figure 2.1: Decision Support Model (Watkins et al., 2000; Kracman, 2002)

The specific objective of this thesis research is to explore soil moisture as a potential climate indicator and predictor of streamflow over the area of study in central Texas. Quantifying the correlation of soil moisture with streamflow over the study area will be used to evaluate the feasibility of soil moisture as a climatic predictor. Seasonal climate forecasts could then be used for the operation of the reservoir system by deriving optimal forecasts based on the streamflow correlations found using soil moisture. With the possible application of climate forecasts, the National Oceanic and Atmospheric Administration (NOAA) Climate Prediction Center (CPC) forecasts of soil moisture anomalies should be evaluated for adjusting streamflow probabilities to use in the decision support system. 


\subsection{The Lower Colorado River Authority (LCRA)}

The multi-reservoir system in central Texas is managed by the Lower Colorado River Authority (LCRA). The LCRA is a water conservation and reclamation district that provides water supply and flood control to a 33-county area including the City of Austin and several rice irrigation districts along the Texas Gulf Coast. It produces wholesale power for a 53-county service area and provides water resources for lake recreation activities and in-stream flow maintenance. The LCRA also operates the Highland Lakes system in central Texas, a series of six lakes/reservoirs along with six dams in the Lower Colorado River Basin. As part of its duties, the LCRA fulfills multiple purposes in flood control, water supply, power, irrigation, recreation, and the environment.
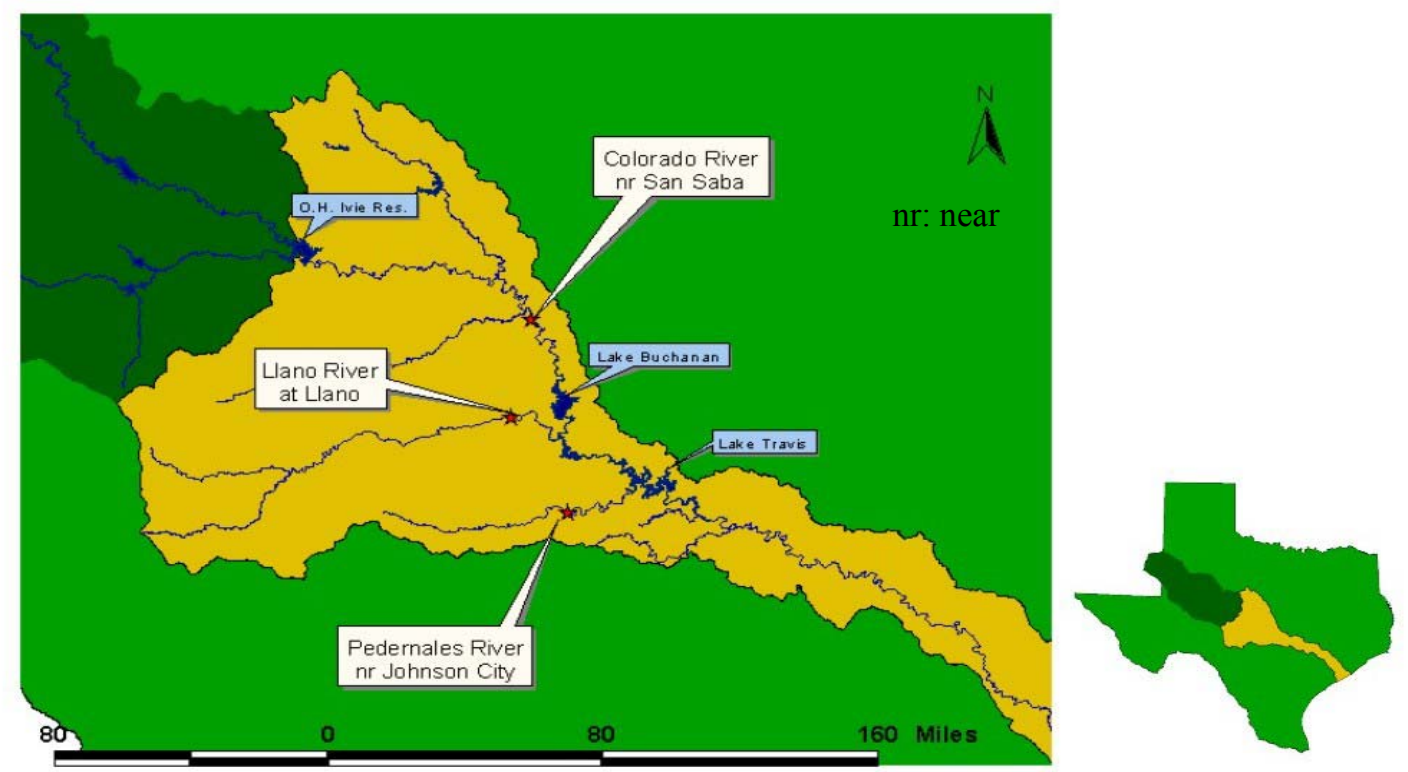

Figure 2.2: The Lower Colorado River Watershed (O’Connell, 2002)

The Colorado River of Texas runs from Southwest New Mexico, across Texas to the Matagorda Bay on the Gulf of Mexico. The river's watershed covers 39,900 square miles, and the river itself flows an approximate 600 miles. The watershed contains a variety of land types that include the hilly central Texas area and the flat Coastal Plain. Land use varies as well, with areas of high development such as the City of Austin, smaller 
residential and agricultural regions, wetlands, and community parks. Perennial rivers exhibit a large range of flows that subject the region to frequent droughts and flooding (Kracman, 2002). The Lower Colorado River starts in San Saba County (central Texas). It is legally separated from the upper segment of the river by legislation that gave the LCRA jurisdiction over the Lower Colorado River Watershed (see Figure 2.2)

The Lower Colorado River Watershed is home to a series of six reservoirs, dams, and lakes known as the Highland Lakes system. The Owen H. Ivie Reservoir marks the upstream boundary of the Lower Colorado River, and is a dam with releases upon which the Lower Colorado River flows depend. The Lower Colorado River joins with the Pecan Bayou just below the Owen H. Ivie Reservoir, and as it progresses deeper into San Saba County it joins a major tributary, the San Saba River. The flow continues into Lake Buchanan, one of two lakes with capacity for water storage, which was formed by Buchanan Dam and has a capacity of approximately 918,000 acre-feet. Right below Lake Buchanan is the smaller Inks Lake at a capacity of 17,500 acre-feet. Downstream, the Lower Colorado River meets the Llano River and then flows into Lake Lyndon B. Johnson, a 138,500 acre-feet reservoir formed by Wirtz Dam. Lake Lyndon B. Johnson is followed by Starcke Dam, which formed Lake Marble Falls, the smallest of the six reservoirs $(8,760$ acre-feet). The river then reaches Lake Travis, which was created by the Mansfield Dam, a 748,502 acre-feet structure (Kracman, 2002). The Mansfield Dam is the only flood control structure for the Lower Colorado River Basin. The Pedernales River, an important tributary, flows into Lake Travis as well. Lake Travis itself, the other lake with capacity for water storage, holds 1,170,750 acre-feet, and with Lake Buchanan can hold about 2 million acre-feet of conservation storage. The sixth reservoir, Lake Austin (21,000 acre-feet) is right below Lake Travis and owes its formation to the Tom Miller Dam. The LCRA operates Lake Austin but does not own it; the dam is leased to the LCRA by the City of Austin. This region of the Lower Colorado River Basin from San Saba County to Lake Austin is considered the Texas Hill Country. 


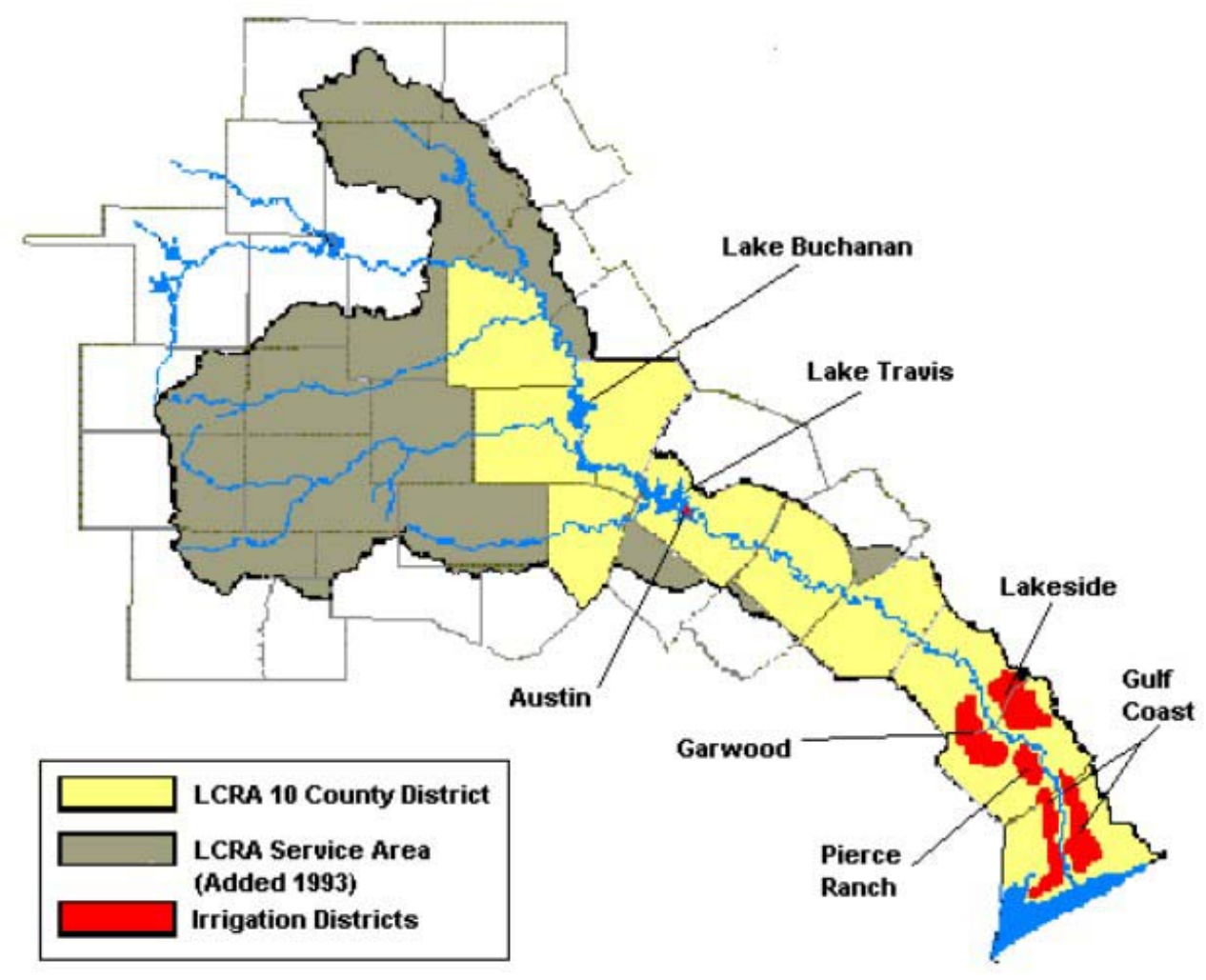

Figure 2.3: LCRA Districts (Kracman, 2002)

Downstream of the Tom Miller Dam and out of the Highland Lakes system is Town Lake. Town Lake was formed by Longhorn Dam and is controlled by the City of Austin. The Lower Colorado River joins with other small tributaries south of Austin before reaching Matagorda Bay where outflows to the Gulf of Mexico average 2,600 cubic feet per second. Near the downstream end of the river, on the Texas Gulf Coastal Plain, an abundance of agricultural land resides. These agricultural lands are composed primarily of rice farms that require generous supplies of water. The water demand of rice farming is met by four main irrigation districts (see Figure 2.3) in this region: Lakeside, Garwood, Pierce Ranch, and Gulf Coast. Over half the water releases go to irrigation districts (see Figure 2.4). 


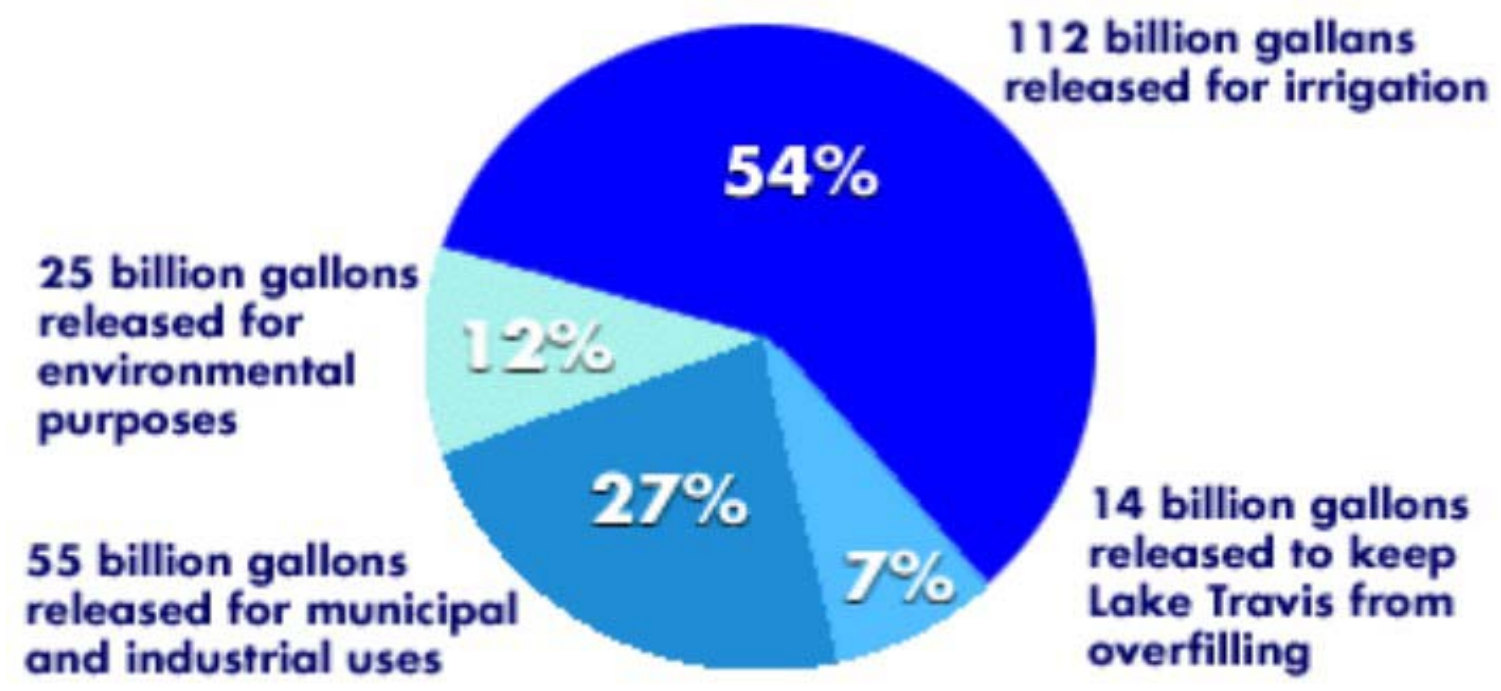

Figure 2.4: Division of Water Releases (LCRA, n.d.)

The LCRA's initial goals were to moderate droughts and floods. With the construction of the dams and the Highland Lakes system these goals were better realized, as well as providing a stable water supply and a source of hydroelectric power that encourages growth in the region. The LCRA strives to maximize and equalize benefits for its competing users by employing a water management plan. This plan gives consideration to private rights holders, recreational, environmental, and hydroelectric interests. It also caters to two types of customers, those who have firm contracts and those who sign yearly interruptible contracts. Firm water is diverted from storage under contract by the LCRA to high priority users (e.g. City of Austin, municipal and industrial entities) and is a guaranteed water right during repetition of drought of record. Interruptible water contracts are issued on a yearly basis (contracts signed in November) with the condition that water supplies may be interrupted in the event that firm water supplies risk depletion. Irrigation districts are the main customers of interruptible contracts. If the availability of interruptible water exceeds irrigation needs, other entities (mainly recreation) get some preference in the distribution of interruptible water. The LCRA currently uses beginningof-year storage levels to determine the amount of water available to meet firm and interruptible water demands in the coming year (Martin, 1991). The LCRA water management plan also gives consideration to recreation and tourism as part of the 
LCRA's public interest responsibilities (LCRA, 1999). Twenty-five parks exist on LCRA-owned land and they receive over one million visitors per year. Tourism on the lakes in the Lower Colorado River Basin brings in over $\$ 90$ million annually to the region (Kracman 2002). The LCRA also employs a drought management plan and a conservation plan, the latter of which targets large users (municipalities and irrigation districts) and aims to reduce demand, decrease water use, and increase crop yield in irrigation districts (LCRA, 1999). The LCRA has also invested interest in environmental concerns through voluntary monitoring programs and sewage disposal inspections, as well as examining pollutant sources.

\subsection{Previous Work}

This current work builds on previous research done by O'Connell (2002). Previous work focused on the generation and development of synthetic streamflow scenarios using historical streamflow data. It proposed the conditioning of streamflow ensemble forecasts on observable climate indicators for predictions. This incorporation of forecast data was to be used for inflows to the Highland Lakes multi-reservoir system in central Texas operated by the LCRA. It was also to be used in the associated decision support model.

Inter-annual climate anomalies were investigated for their suitability as local streamflow predictors and climate indicators. The trends of three wide-scale teleconnection patterns, ENSO, NAO, and PDO, were considered as forecasters. The advantages of using these climate signals to predict streamflow for this multi-reservoir system were examined. ENSO and NAO were found to be the best candidates for forecasting in this region (central Texas). Streamflow persistence was also examined as a potential predictor. The combination of these three indicators was expected to improve the usefulness of the basin's decision support system.

Reasonable synthetic streamflow scenarios were generated and developed for the stochastic reservoir system model of the Lower Colorado River Basin by the software package SPIGOT (Grygier and Stedinger, 1999). An optimal linear combination of forecast indices including those related with ENSO and NAO was developed. The skill 
(degree to which forecasts corresponded with observed historical flows) of each forecast was tested based on a ranked probability score.

Results of the study showed that several of the potential predictors (SOI, NAO, and October flow) were weakly correlated with annual streamflow in the Lower Colorado River Basin. The streamflow indicators were able to improve the predictive ability of scenarios to a small degree using a method that incorporated nonparametric density estimation and Bayesian probability updating techniques. The optimal linear combination of ENSO and NAO predictors demonstrated a small improvement in ranked probability score. The persistence of December flows was strongly correlated with the subsequent annual streamflow. Unfortunately, the insufficient lead-time associated with it did not allow for the predictions to be practically beneficial (O'Connell, 2002). This previous work demonstrated the potential for management improvement of the multi-reservoir system with climate indicators/predictors and climate forecasts, but did not produce substantially effective results using the selected indicators.

Equation Chapter 3 Section 1 


\section{Data}

The data utilized in furthering the project objective comes from two main sources: historical streamflow data obtained from the United States Geological Survey (USGS) records, and derived Retrospective Land Surface Data from the Variable Infiltration Capacity (VIC) hydrologic model. The science behind the VIC model is based on the fundamental principles of the hydrologic (water) cycle and the energy cycle.

\subsection{The Land Water and Energy Cycles}

The hydrologic cycle comprises the interactions and exchanges of water between the land surface and the atmosphere (see Figure 3.1). It continuously operates through a series of processes that are powered by the solar energy of the sun and gravity. The processes of evaporation and transpiration transport water from open water bodies, bare soil, and vegetation on the earth's surface to the atmosphere, where it circulates as water vapor. Transpiration is the complex route water takes from deep root zone layers in the soil through trees and vegetation to reach the atmosphere as water vapor. This water vapor then precipitates to the land surface mainly in the form of rain or snow, where it may be intercepted by a vegetative canopy. If not intercepted, this form of water may either infiltrate into the earth's soil, where it can recharge underlying groundwater, or advance on the land surface as runoff and possibly discharge back into water bodies. This water may then begin to evaporate or transpire and repeat the cycle again (Maidment, 1993).

The hydrologic cycle is explicably tied to the energy cycle of the earth. The thermal equilibrium of the earth is maintained by the recycling of energy between the earth's surface and atmosphere in the forms of radiant energy, sensible heat flux, and latent heat flux (see Figure 3.2). Sensible heat flux is heat transported by the processes of conduction and convection. Latent heat flux is the energy absorbed in the process of evaporating water. It is the latent heat that provides the key link between the water and energy cycles (Maidment, 1993). 


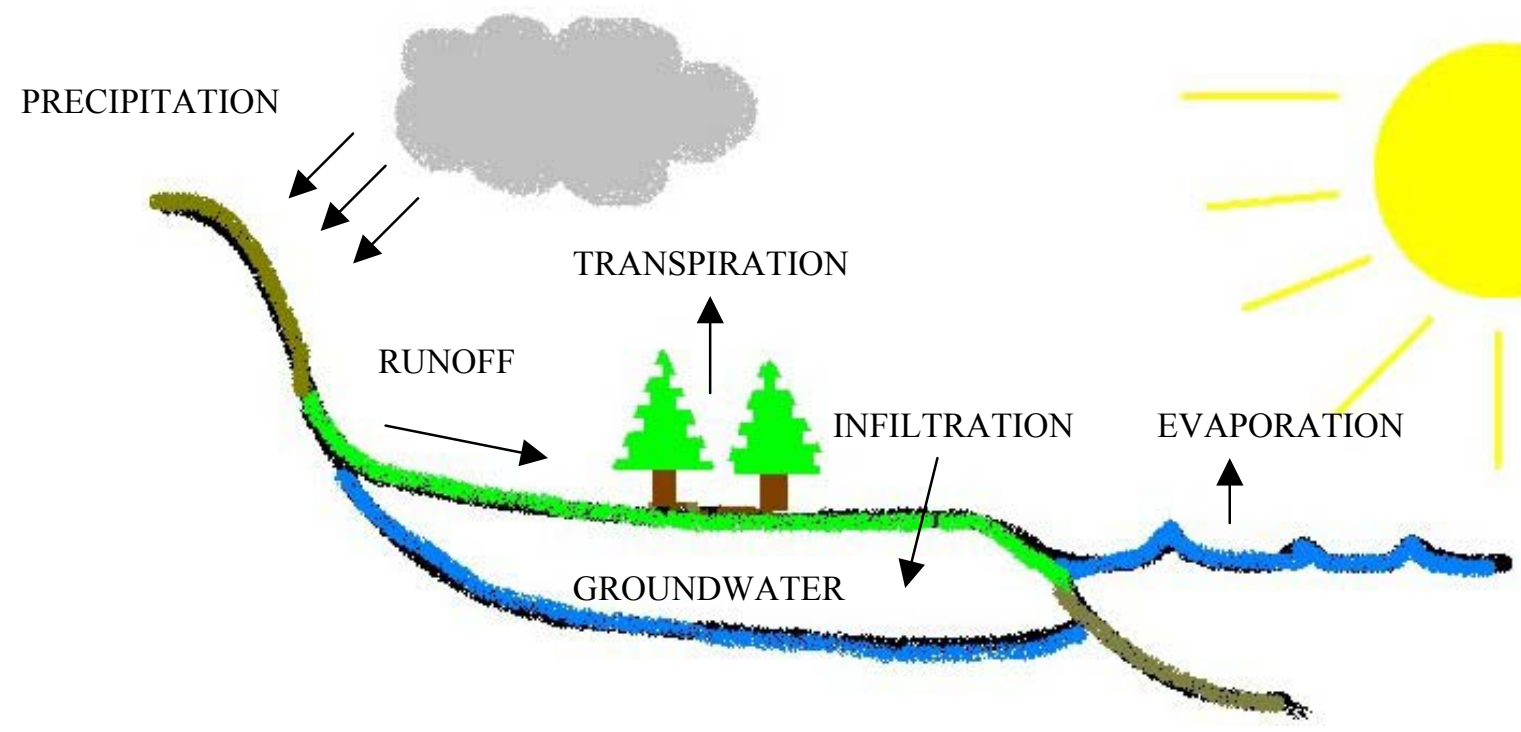

Figure 3.1: The Hydrologic Cycle

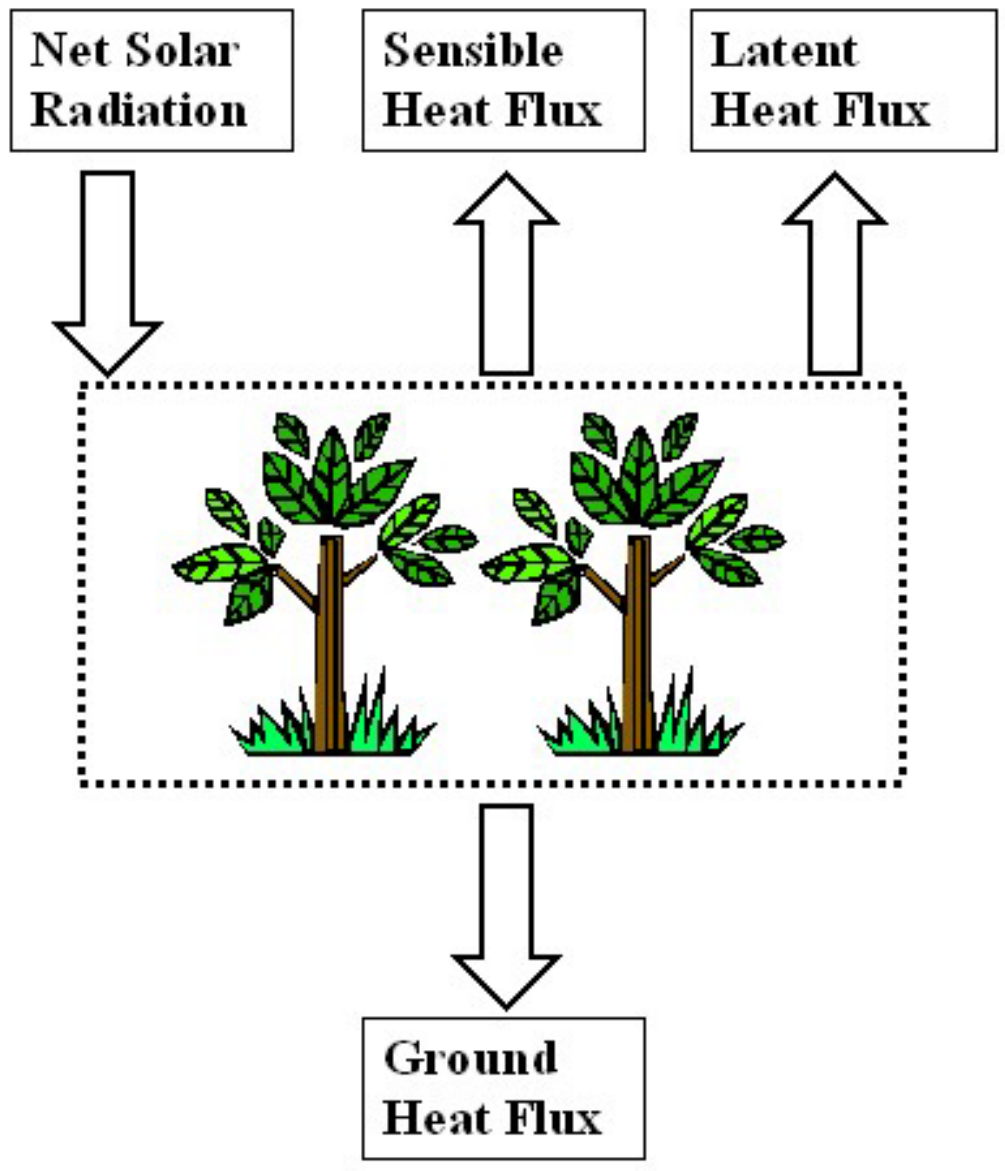

Figure 3.2: The Energy Cycle 


\subsection{Variable Infiltration Capacity (VIC) Model}

The generation of General Circulation Models (GCMs) depended on 'bucket' algorithms to represent land-surface hydrology, e.g. Budyko's 'bucket' model (Manabe et al., 1965). The disadvantages of 'bucket' models are that they tend to simplify hydrologic processes too much and they do not directly consider vegetation, as well as assuming constant soil moisture capacity. One alternative was the application of biosphere-atmosphere models, but their limitation was the need to estimate too many parameters, and some of the data and methods needed for those parameters have not even been fully developed. Another problem with all these models is that they fail to account for is the inclusion of spatial variability in a GCM grid (primarily with respect to infiltration). Another alternative for GCMs that tackles these issues is the Variable Infiltration Capacity (VIC) water balance model. This model has its roots from the Nanjing model, named after the investigators who first suggested its usage for catchment rainfall-runoff modeling at the Water Resources Institute, Nanjing, People's Republic of China (Institute of Hydrology, 1985; Chenlai, 1990). The original model was updated to include an evapotranspiration expression to assist in forecasting water supply for extended periods. This VIC model estimates parameters of infiltration and evaporation, and a baseflow recession coefficient. The model is represented by a single soil layer and because of the nature of its spatial distribution, is represented by grids. It assumes that infiltration capacity, runoff generation, and evapotranspiration vary within a grid because of topography, soil, and vegetation variations. Hydrological processes are considered for each grid and based on the physical conditions on a given grid, meteorological parameters and variables are determined. Ultimately this preliminary form of the VIC model proved more dynamic than any 'bucket' model (Wood et al., 1992).

The next practical application of this land surface hydrological model was a generalization of the single soil layer VIC model previously developed. The difference between it and earlier VIC models was the number of soil layers (two instead of one) and the explicit representation of vegetation in the surface energy flux. Two main soil layers exist in this version of the model: upper zone (Soil Layer 1) and lower zone (Soil Layer 
2), in addition to a single canopy layer. The first soil layer exhibits dynamic soil column responses to rainfall events and its drainage proceeds directly to the second layer without being attributed to surface runoff. Slow-changing soil moisture behavior is characterized by Soil Layer 2, and it distinguishes subsurface flow by only responding to rainfall if soil layer 1 was completely wetted. An aerodynamic flux representation of latent and sensible heat fluxes is utilized: latent heat flux is computed and the surface temperature is solved for by incorporating the 2-layer model, energy balance, and soil thermal properties. With surface temperature found, sensible and ground heat fluxes can then be determined. This process is repeated at every time step. Each grid in the model is split into different land surface cover types and thus presents many types of vegetation. Hence a spatial distribution of soil capacities is available. The types of evaporation considered are canopy layer evaporation and transpiration associated with each vegetation class, and bare soil evaporation. Spatial variability in precipitation is not accounted for. Overall, good model performance existed with replicating stream flow and soil water budget simulation (Liang et al., 1994).

Problems associated with the VIC-2L were: 1) Low soil moisture and underestimated evaporation in the upper layer due to no diffusion mechanism in the model to allow water movement upwards from the lower layer to the upper layer, and 2) Dynamic soil moisture behavior is not captured on the surface, as evidenced by underestimated soil water content. A modified version implemented corrective measures such as allowing soil moisture and water diffusion between layers and including a top thin layer above the upper layer. The results for the modified version included: 1) Soil moisture results were more realistic due to implemented diffusion parameterization; 2) The top thin layer was able to capture near-surface soil dynamics better than the upper layer by itself; and 3) The model was sensitive to soil layer depths, which should not be arbitrary but relevant to root distribution (Liang et al., 1996a). The incorporation of subgrid spatial variability of precipitation into the 2-layer VIC model provided additional improvements in model performance (Liang et al., 1996b). 
A grid network version of the 2-layer VIC macroscale model (VIC-2L) was applied along with a routing model for streamflow prediction on the Weser River, Germany. The model grid was spaced on a rotated grid at 1/6 degree $(\sim 18 \mathrm{~km})$, and the model itself ran off-line while comparing data on daily, monthly, and yearly time steps. Results determined that streamflow predictions were accurate, although important measurements such as that of soil thickness and moisture content were not considered (Lohmann et al., 1998). The term offline refers to model simulations that are driven by observed surface meteorological data (e.g. precipitation and temperature) and estimated radiative forcing that are not predicted by the land surface model. Offline models are also described as uncoupled, meaning the water and energy balances of the land surface are separate from the water and energy balances of the atmosphere. Online simulations, on the other hand, include the land surface scheme directly into the GCM.

Some of the problems associated with the VIC-2L model that were found when a grid network version was run off-line (Nijssen et al., 1997) included the exclusion of groundwater recharge and drainage to streams, and the absence of an explicit mechanism for infiltration excess flow prediction, which subsequently led to poor model performance. The routing of the model also assumed that grid flow proceeded in one direction, an assumption that can prove erroneous depending on the nature of the subbasin. Soil moisture estimations using the VIC model have yielded a larger spatial and temporal range than other studies (e.g. climatology of Mintz and Serafini, 1992) as well as producing spatial and temporal soil moisture patterns that have compared well to soil moisture observations (Nijssen et al., 2001). These findings and developments on the VIC model have led to its current improvement for application in producing a useful data set. 


\subsection{Variable Infiltration Capacity (VIC) Retrospective Land Surface Data Set}

The VIC Retrospective Land Surface Data Set was developed to address the need for data sets that evaluate water balance components interaction over large regions for long periods. To create the data set, the model ran on a 3-hour time step with balanced water and energy budgets at each time step. It was visualized on a 1/8-degree grid spatial resolution $\left(\sim 140 \mathrm{~km}^{2}\right)$ and it represented the entire continental United States. The data set spanned the period of January 1950 to July 2000, and the VIC model (VIC-3L) it was derived from utilized a 3-layer soil column (see Figure 3.3). The data set was produced using the VIC-3L model forced with observed meteorological data (precipitation, temperature, wind, vapor and air pressure, long and short wave radiation). The data set, unlike many other global and continental data sets, included the effects of varying soil properties. The fractional soil moisture monthly data accounted for necessary scaling up (matching) of volumetric soil moisture to represent relative wetness. This scaling up was necessary because the soil porosity of each grid cell is determined based on local soil texture and derived soil depths. Fractional soil moisture is equal to the volumetric soil moisture divided by the product of porosity and soil depth. In addition, the data set matched observed runoff quite well in large basins and therefore represented the surface water balance parameters (e.g. soil moisture) well (Maurer et al., 2002).

The long data time span, the large geographical representation of data, and the uncommon use of a full energy balance formulation were key factors in deciding to incorporate the VIC Retrospective Land Surface Data Set as the main data source in this research. This data set was also specifically chosen to explore the potential of soil moisture as a climate indicator and predictor of streamflow over the LCRA region because of the good representation of water balance terms like soil moisture and the proper reproduction of relative wetness with scaled up fractional soil moisture. The matching of simulated and observed runoff of the data set also shows promise in using its soil moisture data for the purpose of streamflow prediction. 


\section{Grid Cell Vegetation Coverage}

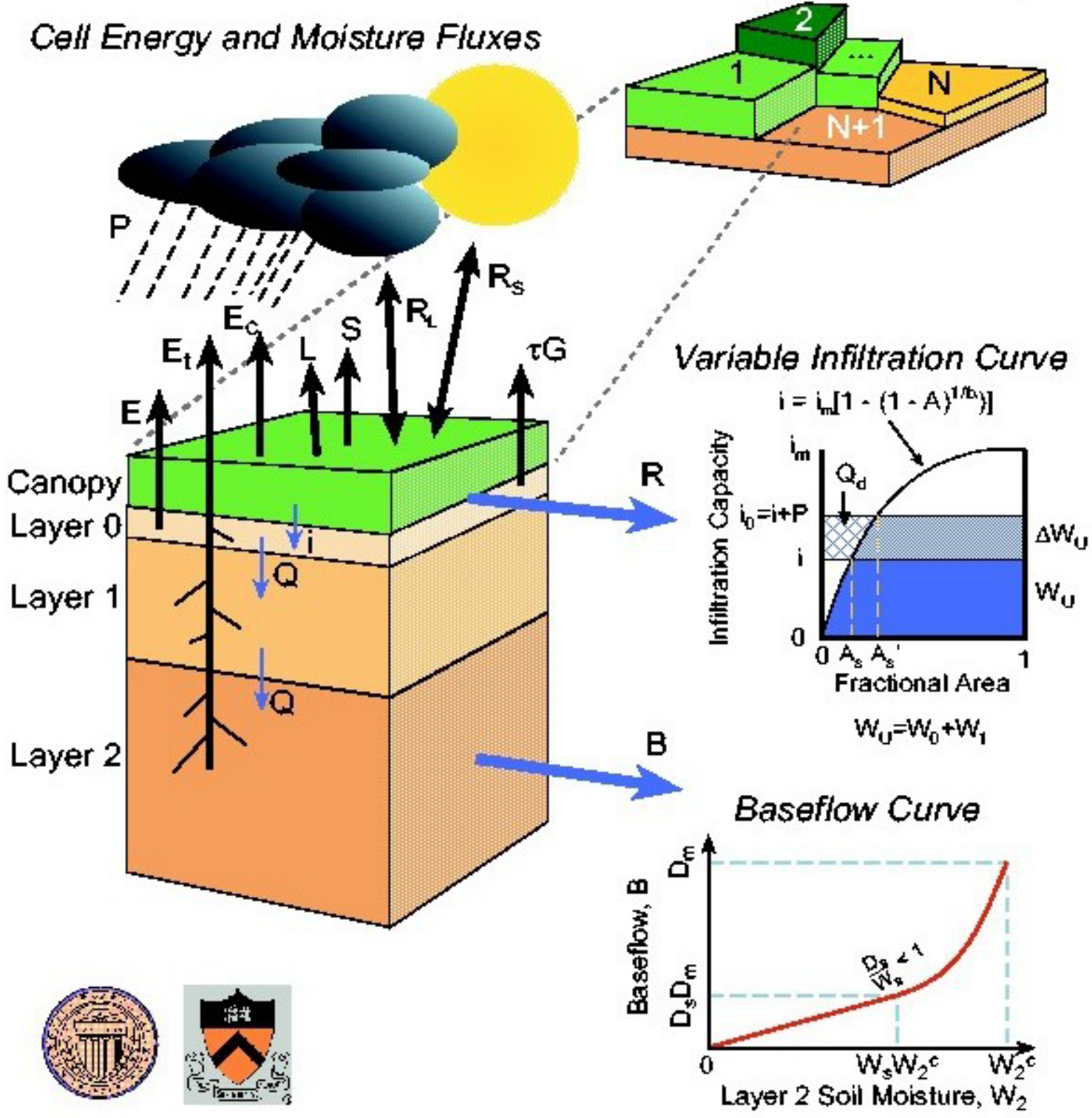

Figure 3.3: Retrospective Land Surface Data Set VIC Macroscale Hydrologic Model (http://www.hydro.washington.edu/Lettenmaier/Models/VIC/VIChome.html) 


\subsection{Streamflow Data}

Observed streamflow data was obtained from USGS historical records and was used as a comparison to the VIC modeled data to show existing flow conditions in the study area (see Figure 3.4). The streamflow data used was in monthly format and collected from stream gages. The units of the streamflow data were converted from the USGS standard of cubic feet per second to acre-feet per month, the preferred units of the LCRA. Three stream gage sites were selected to obtain data based on the stream size, location, and the availability of historical data. These three stream gage sites were chosen due to the USGS not having enough stream gages at every ideal location along the Lower Colorado River Watershed, and due to some stream gages not having continuous records. The gage sites are located on the Colorado River near San Saba, the Llano River at Llano, and the Pedernales River near Johnson City (see Figure 3.5). The Colorado, Llano, and Pedernales Rivers flow into Lakes Buchanan, Lyndon B. Johnson, and Travis, respectively. Data from the three sites were available for 1915-1999, 1940-1999, and 1940-1999, respectively. Therefore considering the time span of the VIC Retrospective Land Surface Data Set, the final study period was 1950-1999.

The streamflow data from the gage sites was scaled up to account for parts of the watershed not represented by the sum of the three selected gages. Monthly flows were therefore scaled up according to the full drainage area of each lake the stream gages flow into, and were also adjusted to account for the operation of the Owen H. Ivie Reservoir. Details on the scaling up procedure can be found in O'Connell (2002). Accordingly, Lake Lyndon B. Johnson flows from the Llano River site were scaled up by $19 \%$, and Pedernales flows were scaled up by $114 \%$. The $8 \%$ scaling up factor found for the Colorado River gage was considered negligible compared to the adjustments made to account for the operation of the Owen H. Ivie Reservoir (O'Connell, 2002). 


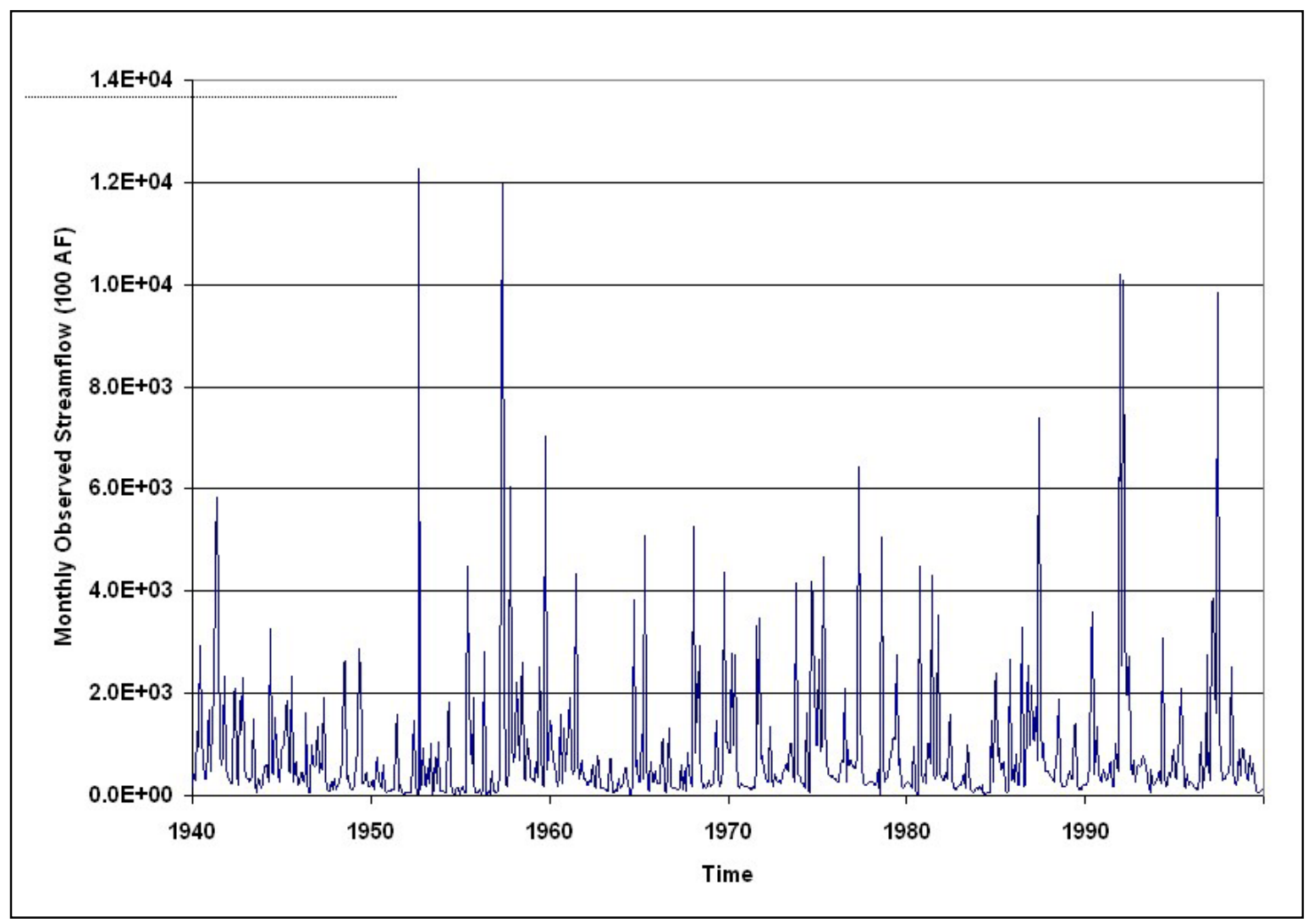

Figure 3.4: Distribution of Streamflow Data

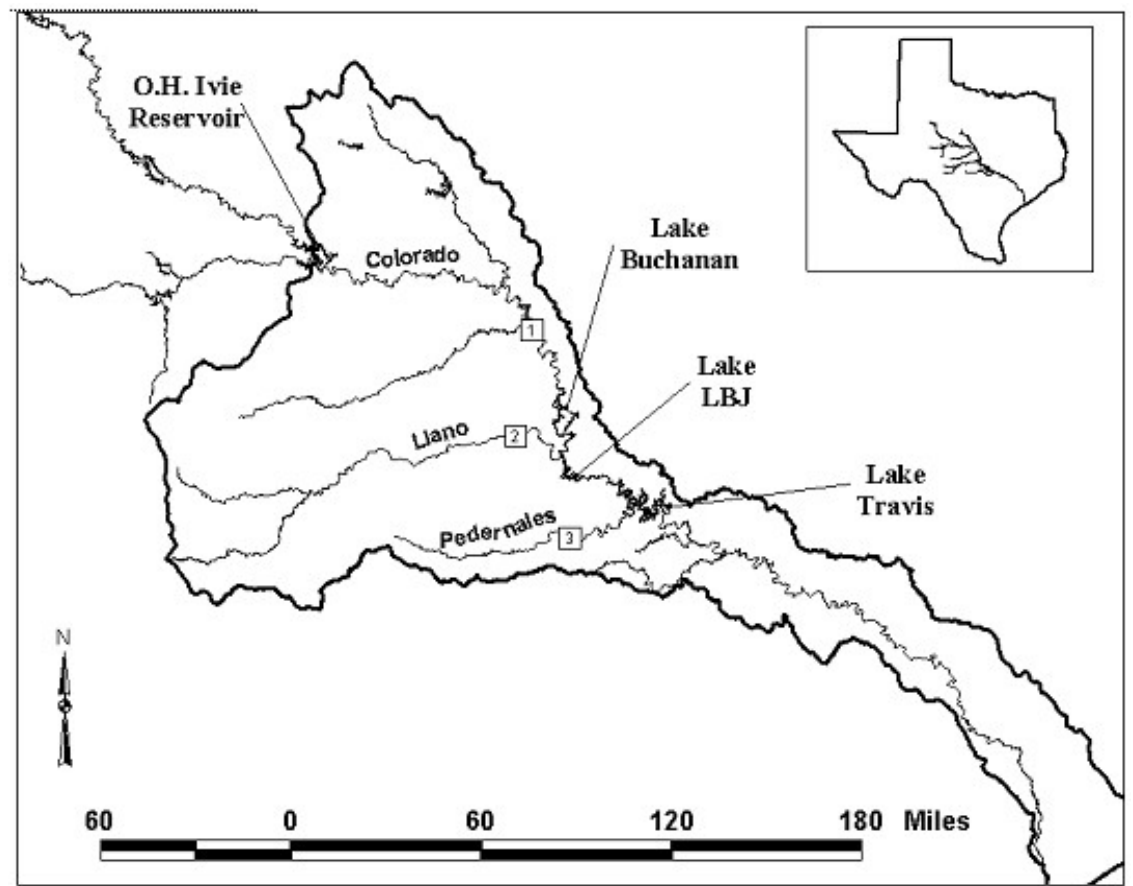

Figure 3.5: USGS Stream Gage Locations (O’Connell, 2002) Equation Chapter 4 Section 1 


\section{Data Preparation}

This chapter gives an overview of the methods and programs used to manipulate the data from its original form to a data set useful for fulfilling the research goals. The transformation of the VIC data from its NetCDF format, incorporation of MATLAB, and the preparation of the data through ArcView GIS are included.

\subsection{NetCDF}

The Variable Infiltration Capacity (VIC) Retrospective Land Surface Data Set was archived in NetCDF (Network Common Data Form) format. NetCDF is software that: (1) stores and retrieves scientific data by acting as an interface for array-oriented data access, and (2) includes a freely distributed collection of libraries that provide interface implementations. The software is widely used by various research centers within the National Oceanic and Atmospheric Administration (NOAA), the National Aeronautics and Space Administration (NASA), and the National Center for Atmospheric Research (NCAR), as well as other agencies and program centers. The software itself was developed at the University Corporation for Atmospheric Research (UCAR) Unidata Program Center in Boulder, Colorado. The Unidata NetCDF software package is available for downloading by users at no cost. NetCDF features self-describing data, with information about the data stored as attributes related to each respective variable. Data is described in a machine independent format that supports its creation, access, and sharing. Therefore, different types of computers can access data without the need for any data conversion or manipulation, just as data stored using a certain programming language may be retrieved using another programming language. Small subsets of data can be easily, efficiently, and directly accessed without reading or going through previous data. The NetCDF format allows for data to be readily accessed by the writer(s) and reader(s), encouraging data sharing between various researchers and disciplines. Data can be added to an existing NetCDF dataset without the need to redefine or copy the dataset since data storing is independent of the computer architecture, and hence reduces the effort related to dealing with data formats. 


\subsection{MATLAB Interface and Extraction}

The VIC Retrospective Land Surface Data was formatted in a monthly summary time step. The model derived water balance variables, acquired primarily for relevant research application, were fractional soil moisture (total soil column) and runoff. Other modelderived meteorological water balance variables, obtained as supplemental data information, were the soil moisture and soil moisture tendencies for each respective layer (Layer 1, Layer 2, and Layer 3). To manipulate and display the data, it had to be extracted from its NetCDF form using compatible software. Of the available options for compatible software, a MATLAB interface was chosen due to the fact that it was easier to use and quicker to learn than other alternatives. MATLAB itself provides a powerful programming language that allows the user to compute and visualize data in a mathematically user-friendly and compliant environment. The specific MATLAB interface employed was the NetCDF Toolbox for MATLAB-5 (http://woodshole.er.usgs.gov/staffpages/cdenham/public_html/MexCDF/nc4ml5.html). This interface combines NetCDF-3 and MATLAB-5 to perform MATLAB operations on NetCDF entities. It is the improved and extended version of the MEXCDF interface with MATLAB-4; an interface that is now practically obsolete. The NetCDF Toolbox for MATLAB interface significantly simplifies operations on NetCDF files within MATLAB and primarily does so with the use of a NetCDF file browser that allows the user to preview the NetCDF files along with their attributes and characteristics before retrieving them.

The VIC Retrospective Land Surface Data of interest stored in NetCDF format had 607 time steps (each month being one time step, since it was monthly summary data), from January 1950 to July 2001, and encompassed 76,576 grids in the spatial representation of the continental United States. The data was stored in a matrix form. The average fractional monthly soil moisture combined all three soil layers and was represented as volumetric soil moisture divided by the product of porosity and soil depth, it has no quantitative units. The average monthly surface runoff rate was represented in units of kilograms per meter squared per second $\left(\mathrm{kg} / \mathrm{m}^{2} / \mathrm{s}\right)$. Both these data had to be extracted 
from their NetCDF format using MATLAB before any data manipulation could occur. This was done by developing and writing a comprehensive MATLAB code that outputted each respective data attribute (fractional soil moisture and runoff) along with its respective longitude and latitude spatial location. The data that was outputted was partitioned at ten-year intervals (1950-1999: 1950-1959, 1960-1969, etc.) to accommodate extraction of the large quantity of data. The data extracted using the MATLAB code was spatially based on the entire state of Texas. Since the Lower Colorado River Authority (LCRA) study region is near the center of Texas, using the entire state as a data boundary ensured that the necessary data was extracted. A longitude and latitude map locator was employed to determine the spatial boundaries of the state of Texas and hence their position in the stored data matrix, to allow for simple extraction via the MATLAB code.

This extracted VIC modeled data was then stored and saved in ten-year segments along with the historical observed streamflow data. The observed streamflow data was specific to the LCRA region of interest. The time period of the observed data was from 1940 to 1999. Since the VIC modeled data temporal range was from 1950 to 2001, the common time frame of 1950 to 1999 for both data sets defined the study period of the project. The observed streamflow data remained in its original units of 100 acre-feet. The VIC modeled runoff data units needed to be converted from a rate to a measure of volume. This conversion was done by multiplying the average monthly surface runoff rate by time (number of seconds in a given month) and area of each grid, as well as dividing by the density of water $\left(\sim 1,000 \mathrm{~kg} / \mathrm{m}^{3}\right)$. The VIC model estimates the $1 / 8$-degree grid spacing to be equivalent to approximately $140 \mathrm{~km}^{2}$, but this is the average grid size over the continental United States. Selecting adjacent spatial grid points (where each grid point of data represents a point within the exact center of the given grid) from the extracted VIC data for the state of Texas, and using their longitude and latitude information and attributes, an average grid size of approximately $174 \mathrm{~km}^{2}(12.5 \mathrm{~km}$ by $13.9 \mathrm{~km})$ was estimated. Since this area is more representative of Texas than the average grid size for the whole VIC data set $\left(140 \mathrm{~km}^{2}\right)$, it was selected as the average grid size for this study and was used for all area-related calculations (including the runoff rate unit conversion). 

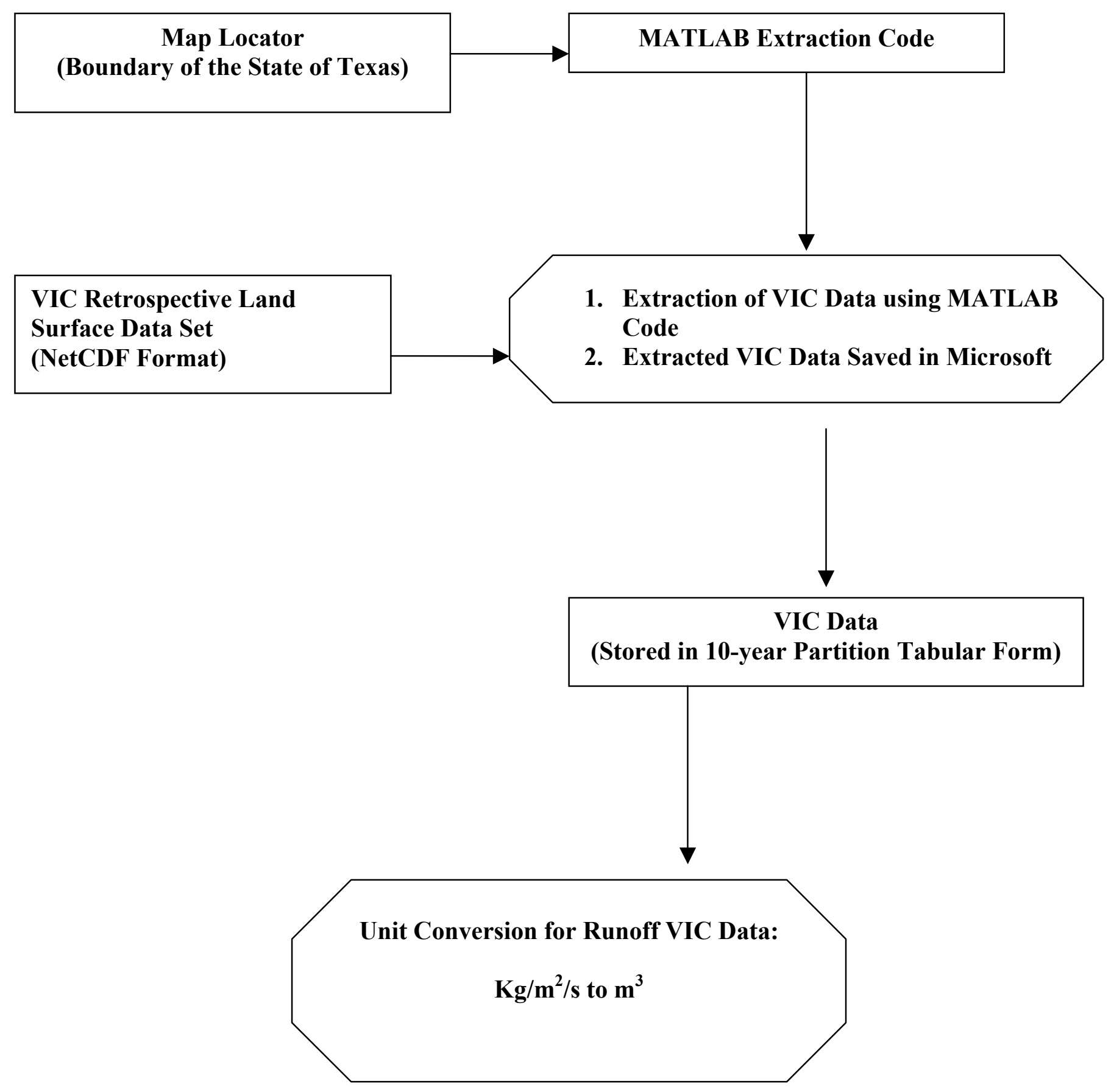

Figure 4.1: MATLAB Extraction Flowchart 


\subsection{ArcView GIS Reprojection and Manipulation}

The next step in refining the data to suit the specific needs of the project involved the usage of Geographic Information System (GIS) applications in the form of ArcView GIS. ArcView GIS is a versatile desktop GIS software with user-friendly graphical interface that allows for spatial and tabular data representation as maps, tables, and charts. It permits the user to input data, store it, and manage it, as well as transform it to create new information from existing data. ArcView GIS also provides handy tools for data editing, analyzing, visualizing, querying, and exploring.

Previously created shapefiles for the geographic boundaries of Texas, State watersheds, and the LCRA watershed region were provided by O'Connell (2002). In order to make minor adjustments to exterior and interior boundaries, the LCRA watershed shapefile was duplicated through manual onscreen digitizing. This type of digitizing involved graphically 'tracing' the boundaries of the existing shapefile to produce a polygon of the same size and shape as the original watershed shapefile. Digitizing was done at a scale of 1:10,000 to ensure an acceptable level of accuracy.

Both VIC data sets (fractional soil moisture and runoff volume) were imported into ArcView and then displayed visually via the data's locational attribute (longitude and latitude) as grid points representing the center of each grid. This grid point overlay and any data layer graphically visualized is referred to as a theme. Each respective data set was then promptly converted to and saved as a shapefile (ArcView's file format). Importing the VIC fractional soil moisture and runoff volume data had to be done in tenyear subsets, much like the ten-year intervals it was stored in, due to the number of records. To be able to bring these two different types of data (imported VIC data and duplicated LCRA shapefile) together for analysis, they needed to share the same geographic coordinate system. Therefore, the VIC data's original geographic projection had to be georeferenced to that of the current LCRA watershed shapefile so that they would share the same geographic projection information (see Table 4.1). 
For the VIC fractional soil moisture and runoff volume data to be georeferenced to the coordinate system of the LCRA watershed shapefile, an ArcView extension tool named the MI DNR Projection Wizard was utilized. The MI DNR Projection Wizard reprojected the VIC data's coordinate system to that of the LCRA watershed shapefile by inputting the georeference information of each coordinate system and the desired output geographic coordinate system.

With both sets and types of data finally sharing the same geographic reference, analysis on the LCRA region with respect to the given data was able to commence. Analysis operations and commands in ArcView GIS that assist in data processing and theme enhancement include Dissolve (aggregating features with the same value for a specified attribute), Merge (appending features of two or more themes into a single theme), and Clip (using a clip theme like a cookie cutter on another overlaying theme). These tools are available via the Geoprocessing Wizard or Xtools extensions from within ArcView GIS.

\begin{tabular}{|c|c|c|}
\hline & LCRA Watershed Shapefile & VIC Data \\
\hline Projection & Lambert Conformal Conic & Longitude/Latitude \\
\hline Spheroid & GRS 1980 & - \\
\hline $\mathbf{1}^{\text {st }}$ Standard Parallel & 27.417 & - \\
\hline $\mathbf{2}^{\text {nd }}$ Standard Parallel & 34.917 & - \\
\hline Central Meridian & -100.000 & - \\
\hline Reference Latitude & 31.167 & - \\
\hline False Easting & $1,000,000$ & Decimal Degrees \\
\hline False Northing & $1,000,000$ & - \\
\hline Map Units & Meters & - \\
\hline
\end{tabular}

Table 4.1: Geographic Projection Information (Datum: NAD 1927)

To check the reliability of the newly created duplicate LCRA watershed shapefile, a tenyear fractional soil moisture subset (e.g. 1950-1959) was clipped with both the original 
and duplicate LCRA watershed shapefile. The average fractional soil moisture for each location for that decade was computed with the aid of arithmetic operations on the existing attribute (average fractional soil moisture) by viewing the attribute table of the theme. The result was that each geographical location within the LCRA watershed had a single average fractional soil moisture value. Both files were then compared to determine whether there were statistical differences. By using the statistics summary option in ArcView for each watershed shapefile, it was determined that the number of grid points and the total average fractional soil moisture of the entire watershed were the same, therefore statistical integrity was preserved, and the digitizing accuracy of the duplicate shapefile was verified.

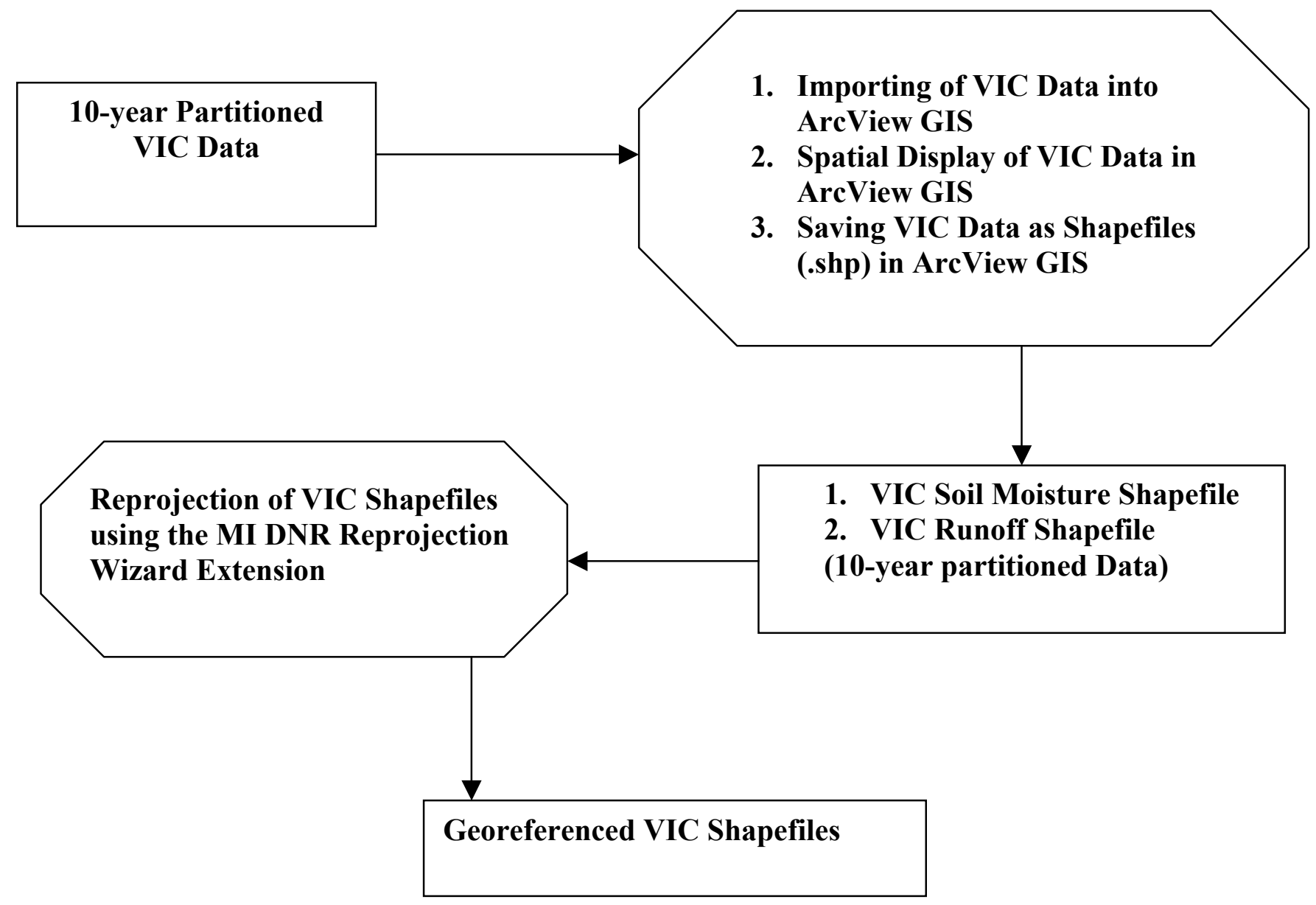

Figure 4.2: Reprojection of Shapefiles in ArcView GIS Flowchart 


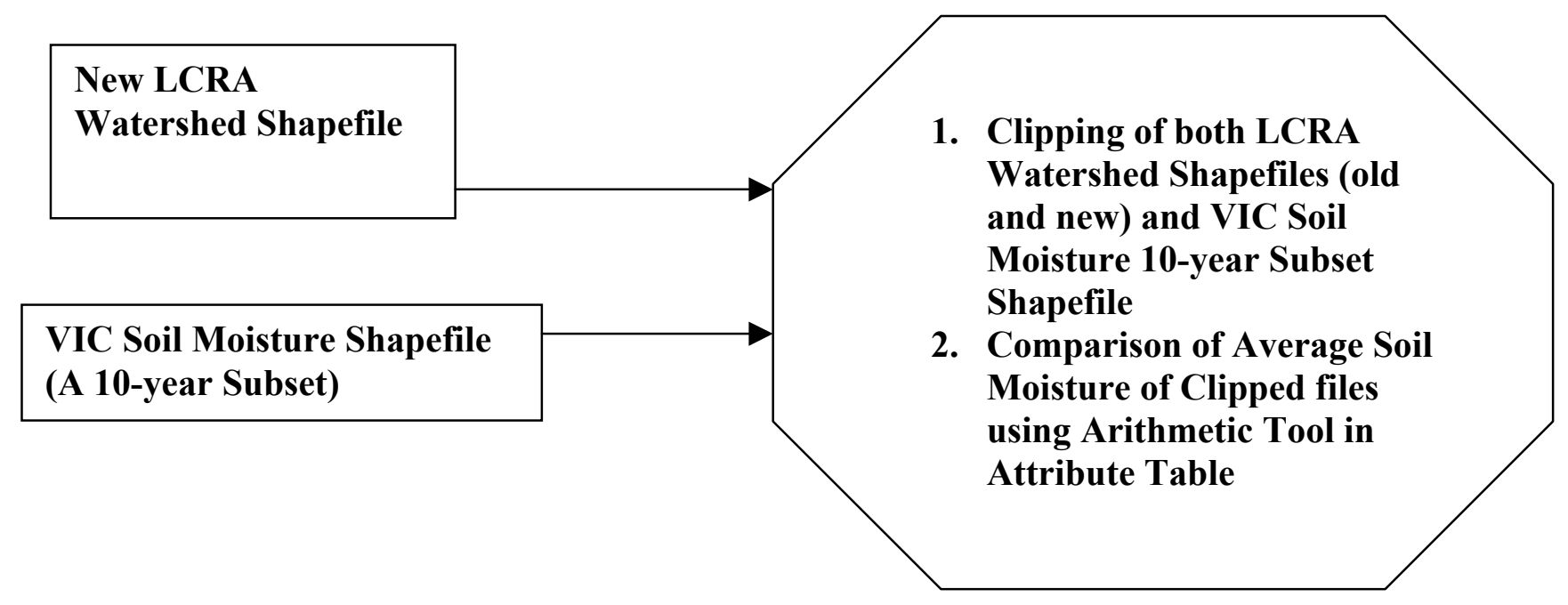

Figure 4.3: Reliability Check of New LCRA Watershed Shapefile Flowchart

Equation Chapter 5 Section 1 


\section{Analysis Results and Discussion}

All relevant analyses performed in this research are detailed in this chapter. The analyses include sensitivity analysis of LCRA Watershed, streamflow-runoff analysis, correlation analysis, and the establishing of climatology. The results of said analyses are presented and discussed in an interpretive manner relevant to the objectives of this study.

\subsection{Sensitivity Analysis of LCRA Watershed}

To prepare for sensitivity analysis, a procedure was repeated much like what was done to determine the reliability of the newly recreated LCRA shapefile (see section 4.3). The average fractional soil moisture for the entire study period (1950-1999) was calculated for each spatial location (grid point), thus giving each spatial location a single average fractional soil moisture value for the years 1950-1999. This geographical theme representation was saved as a shapefile in Arc View GIS for further use in the sensitivity analysis.

The purpose of the sensitivity analysis was to test the effect on the total average fractional soil moisture within the LCRA watershed if the size of the watershed increased or decreased by a specified buffer size. This information will then enable us to choose an ideal final LCRA watershed size that takes into account attribute variability if it is significant. Variability across the watershed is not expected to be considerable but this analysis is necessary to verify that assumption. Attribute variability may be a factor to consider since the spatial grids used to represent the VIC-3L modeled data does not align exactly with the boundaries of the LCRA watershed. To facilitate the tasks of performing this analysis, an ArcView GIS extension tool called Xtools was put to use. Xtools primarily performs shape conversion functions, provides table management tools, and performs basic analysis functions (e.g. clipping, merging, buffering, etc.).

The effect of size changes for the LCRA watershed was established by creating buffers around the original watershed size that projected both inside and outside with respect to the original watershed boundary. Xtools can create such buffers by offsetting a buffer 
(inwards or outwards) by a certain distance from the original watershed boundary (Figure $5.1)$.

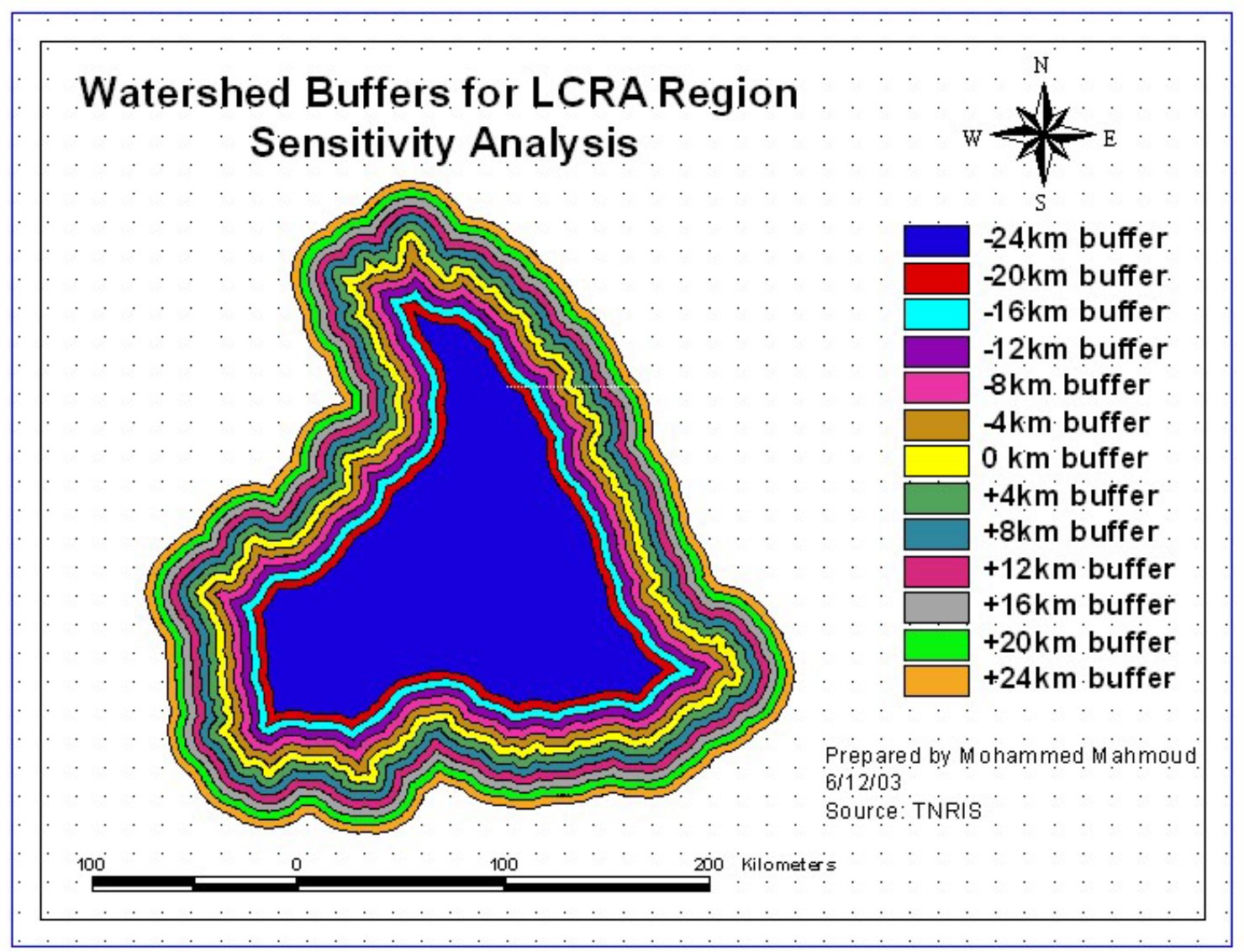

Figure 5.1: Buffer Display in ArcView

Given the approximate size of the grid $(12.5 \mathrm{~km}$ by $13.9 \mathrm{~km})$, a $4-\mathrm{km}$ buffer increment was selected. The increments increased from 4 to $24 \mathrm{~km}$ outside and inside the watershed clip boundary. The saved shapefile displaying the average fractional soil moisture grid points for 1950-1999 was then clipped with each successive buffer that was created including the original watershed clip. Using a statistical summary in the attribute table information, the number of grid points and average fractional soil moisture within each respective buffer polygon were determined. These results, along with the percent change in the average fractional soil moisture from the original watershed clip polygon, can be found in Table 5.1 and Figure 5.2. An increase in the buffer size leads to an increase in 
the value of the average fractional soil moisture for each successive buffer size. The opposite effect is encountered with decreasing buffer sizes (Figure 5.2).

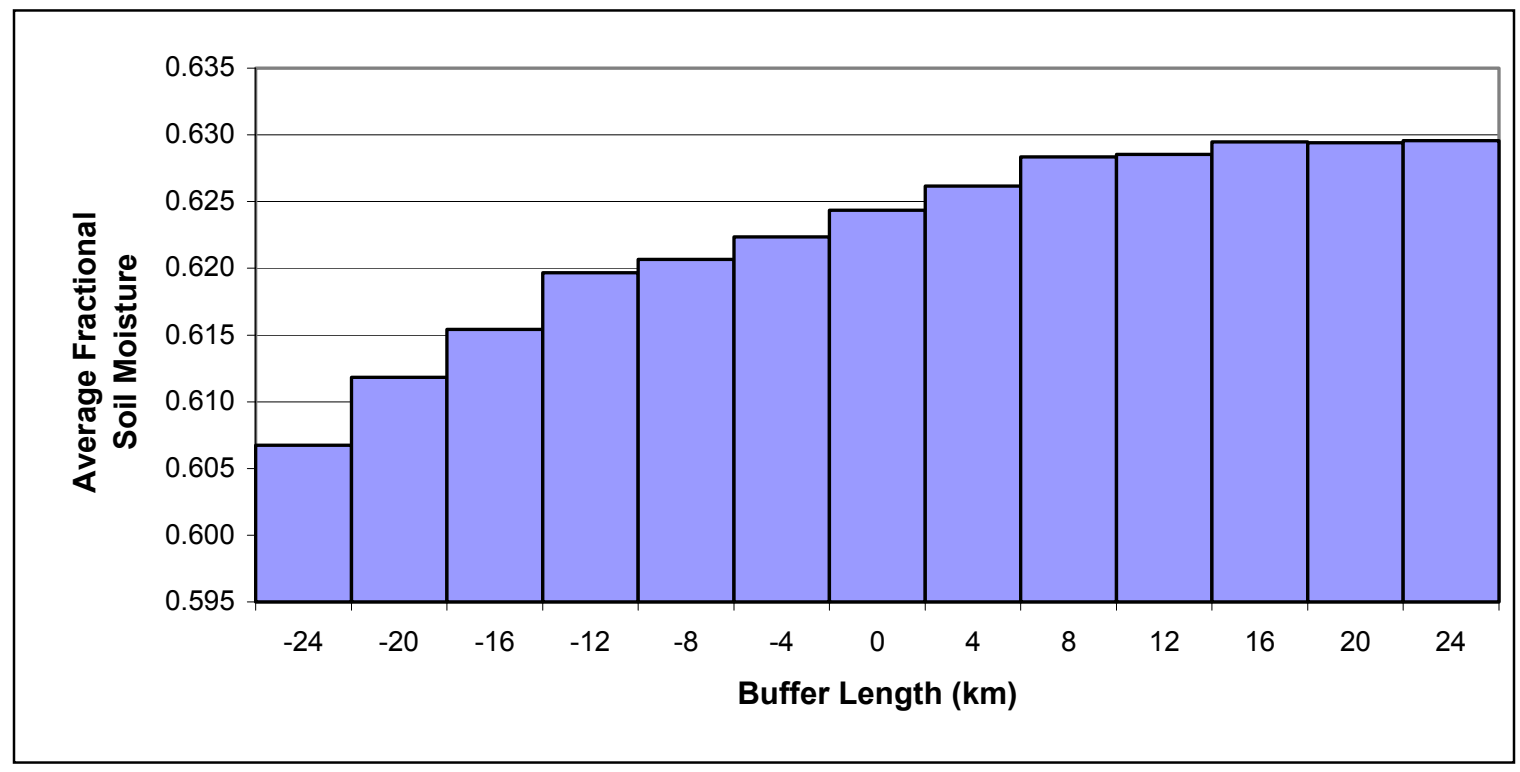

Figure 5.2: Average Fractional Soil Moisture Variation Bar Chart

\begin{tabular}{|c|c|c|c|}
\hline Buffer Size $\mathbf{( k m )}$ & No. of Grid Points in Buffer & Average Fractional Soil Moisture & $\%$ Change \\
\hline-24 & 108 & 0.607 & -2.820 \\
\hline-20 & 125 & 0.612 & -2.002 \\
\hline-16 & 144 & 0.615 & -1.430 \\
\hline-12 & 167 & 0.620 & -0.748 \\
\hline-8 & 181 & 0.621 & -0.590 \\
\hline-4 & 202 & 0.622 & -0.317 \\
\hline 0 & 232 & 0.624 & 0.000 \\
\hline 4 & 251 & 0.626 & 0.293 \\
\hline 8 & 282 & 0.628 & 0.640 \\
\hline 12 & 301 & 0.629 & 0.669 \\
\hline 16 & 325 & 0.629 & 0.821 \\
\hline 20 & 353 & 0.629 & 0.810 \\
\hline 24 & 379 & 0.630 & 0.838 \\
\hline
\end{tabular}

Table 5.1: Sensitivity Analysis Results

In selecting the final size for the LCRA watershed shapefile, a few factors needed to be considered. An alteration in the original watershed size must be justified by a logical reason, such as a marked difference in the fractional soil moisture between successive 
increasing and/or decreasing watershed buffers. Even if that is the case, then such a difference must be reasonably explained by providing supporting evidence (e.g. adjacent watersheds contributing to systematic soil moisture biases because of bordering streams and tributaries). The results indicated that the maximum percent change of average fractional soil moisture, based on the original watershed size, was small $(\sim 2.8 \%)$.

Negative (inward) buffers were neglected as an option for watershed size change since they reduced the number of grid points representing the LCRA watershed and excluded data points that actually fell within the watershed. Likewise, larger buffer sizes such as the 24-km buffer encompassed land area that fell well outside the watershed. Ultimately what was desired was the best representation possible of the LCRA region. For a grid to be considered in a buffer, its centroid (grid point) had to fall within the watershed region. With that in mind, it was decided to select either the $+4-\mathrm{km}$ buffer or the original watershed clip ( $0-\mathrm{km}$ buffer). Since the grid is $12.5 \mathrm{~km}$ by $13.9 \mathrm{~km}$, the distance from the center of the grid to its corners is $9.35 \mathrm{~km}$ (Figure 5.3). Therefore, if only part of an exterior grid fell within the $0-\mathrm{km}$ buffer, then this grid would be included in the watershed if the $+4-\mathrm{km}$ buffer was used. But since it was decided to only consider a grid if its centroid was within a given buffer, and no significant attribute variability was found, the original clip ( $0 \mathrm{~km}$ buffer) was selected as the best choice.
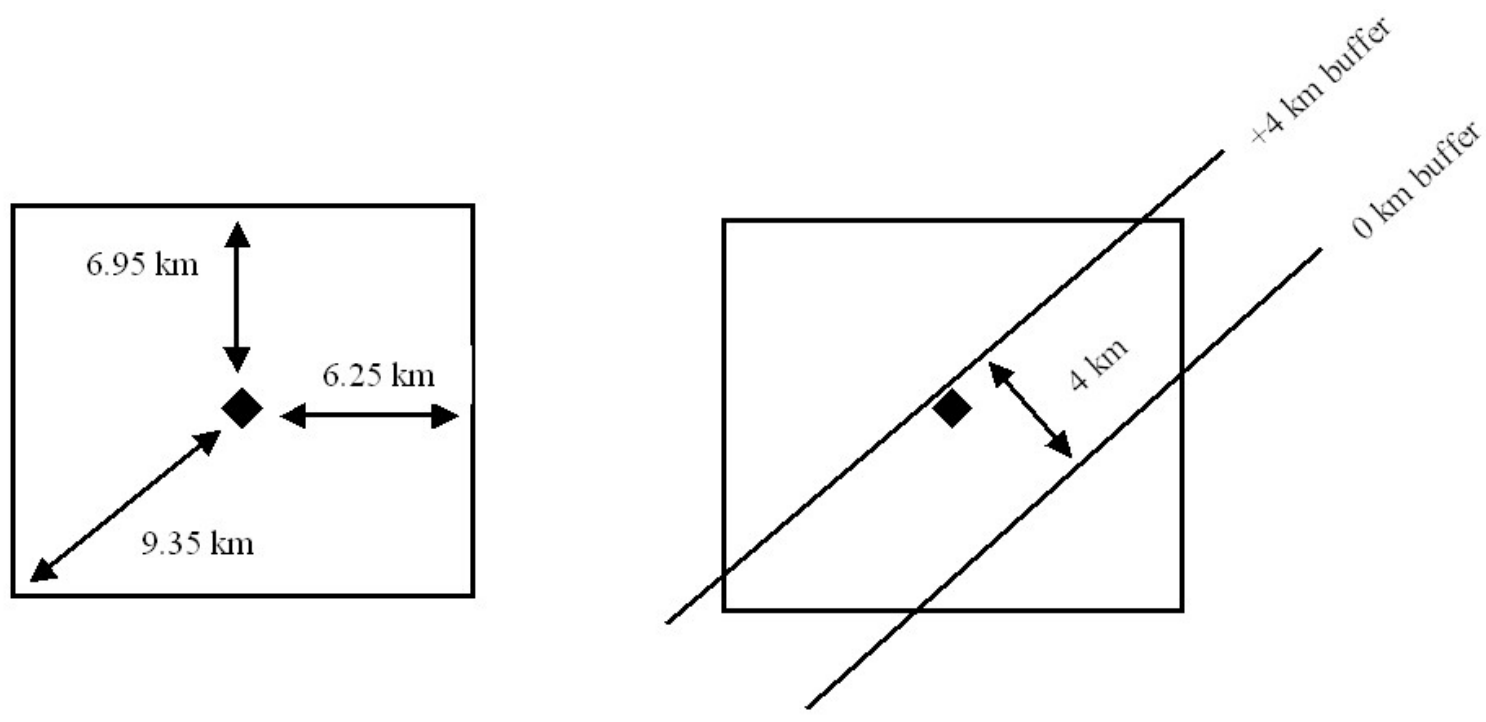

Figure 5.3: Grid Analysis 


\subsection{Streamflow-Runoff Analysis}

The streamflow-runoff analysis provided an initial view at how well the VIC modeled data tracked observed data of the same characteristic (streamflow/runoff). It compared modeled runoff volume data obtained from the VIC data set to observed historical streamflow for the LCRA watershed region (Figure 5.4). The observed streamflow data units needed to be converted from 100 acre-feet to cubic meters, the units of the VIC runoff volume data, so that comparisons could be made.

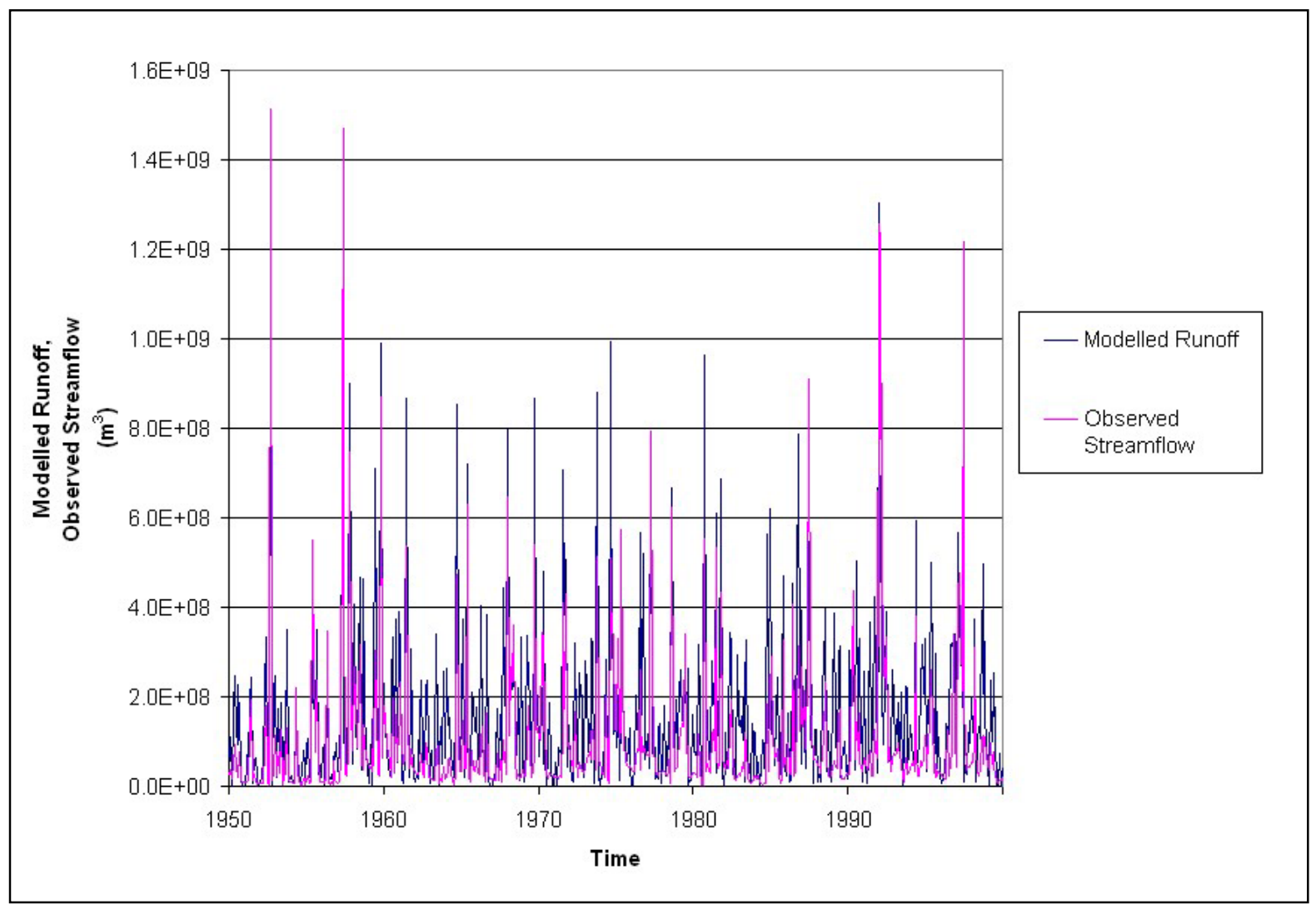

Figure 5.4: Streamflow-Runoff Time Series

Graphical plots were produced, encompassing the study period of 1950-1999. One graph plotted monthly observed streamflow vs. monthly simulated runoff (Figure 5.5). The other graph plotted annual observed streamflow vs. annual simulated runoff (Figure 5.6). A linear watershed response was assumed to determine the correlation between the two parameters, and linear trend lines that passed through the origin were added. Ideally, 
streamflow and runoff are meant to be the same type of hydrological parameter and should thus reflect each other proportionally (in a true zero scale where zero runoff equals zero streamflow). Hence the constraint of the linear trend line passing through the origin was applied.

As shown in Figures 5.5 and 5.6, the correlations between the modeled and observed parameters for annual and monthly comparisons were found to be approximately 0.75 and 0.80 respectively. Runoff and streamflow are technically the same parameter (albeit from two different sources), therefore in an ideal scenario the graphical results should produce a linear trend line with an equation of $y=x$. in this case the relationship is different than expected. It is evident that the volume magnitudes of modeled runoff and observed streamflow are not directly proportional to each other. The observed streamflow data is not necessarily underestimating streamflow since observed streamflow data was scaled up to account for key locations of the watershed that did not have gages (see section 3.4). Streamflow data from the gages was scaled up to represent the full drainage area of the flow-contributing lakes: Buchanan, Lyndon B. Johnson, and Travis (O’Connell, 2002).

It is likely that the VIC modeled data is overestimating simulated runoff. The simulated runoff produced by the VIC model is considered the rainfall excess at each grid surface and does not account for baseflow (a separately modeled parameter). The simulated runoff used in this analysis is not routed but rather is a sum of all the grids within the watershed. This overestimation is likely due to the fact that the VIC-3L model used was not calibrated exclusively for the LCRA watershed. Despite the fact that the two parameters do not exactly match each other in a quantitative sense, they seem to follow a proportionate trend (evident from the resulting correlation coefficients). Overall, runoff and streamflow tracked each other well, giving confidence in the quality of the VIC Retrospective Land Surface Data Set as a data source for this research analysis. 


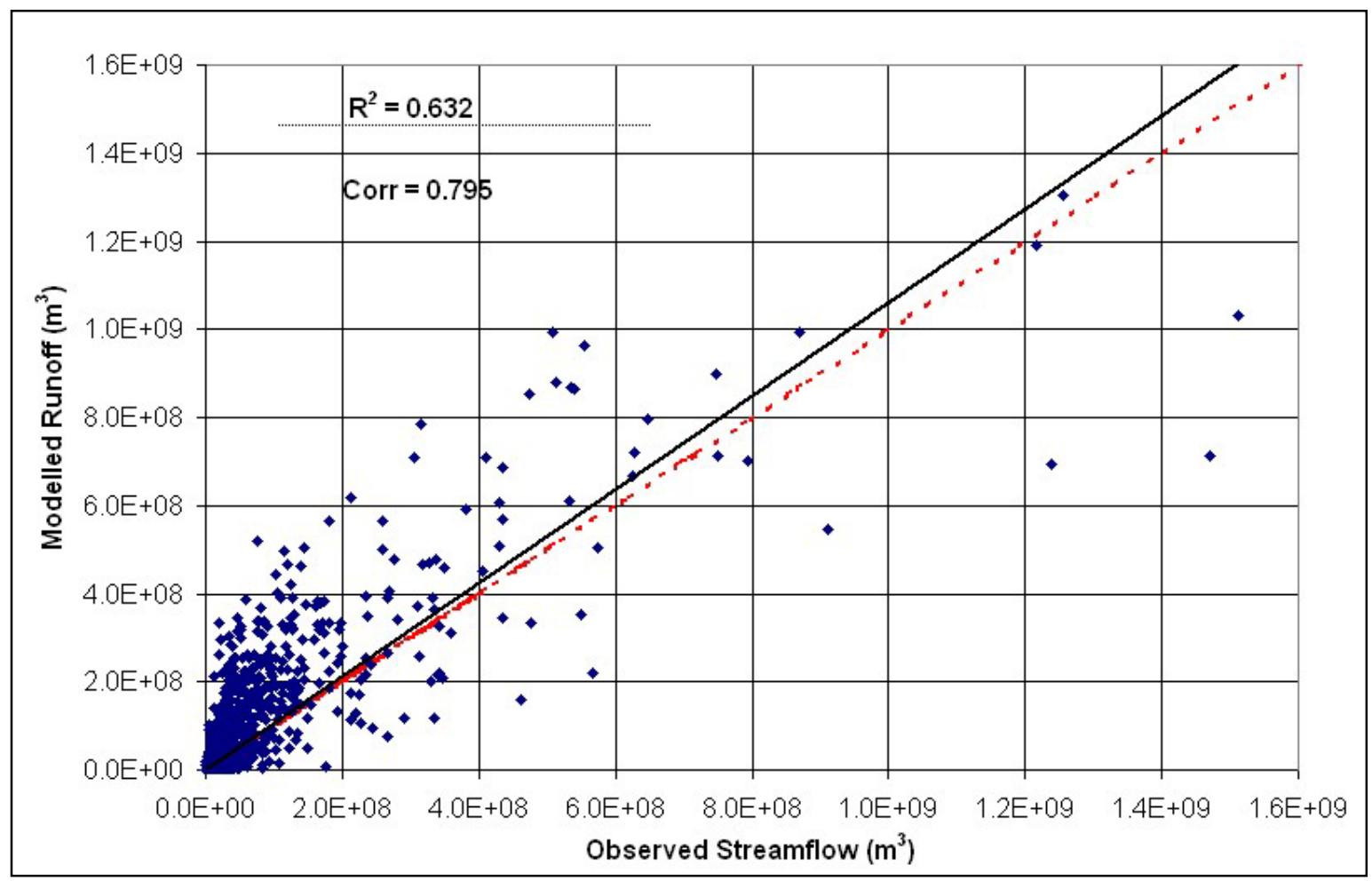

Figure 5.5: Monthly Observed Streamflow vs. Monthly Modeled Runoff (1950-1999)

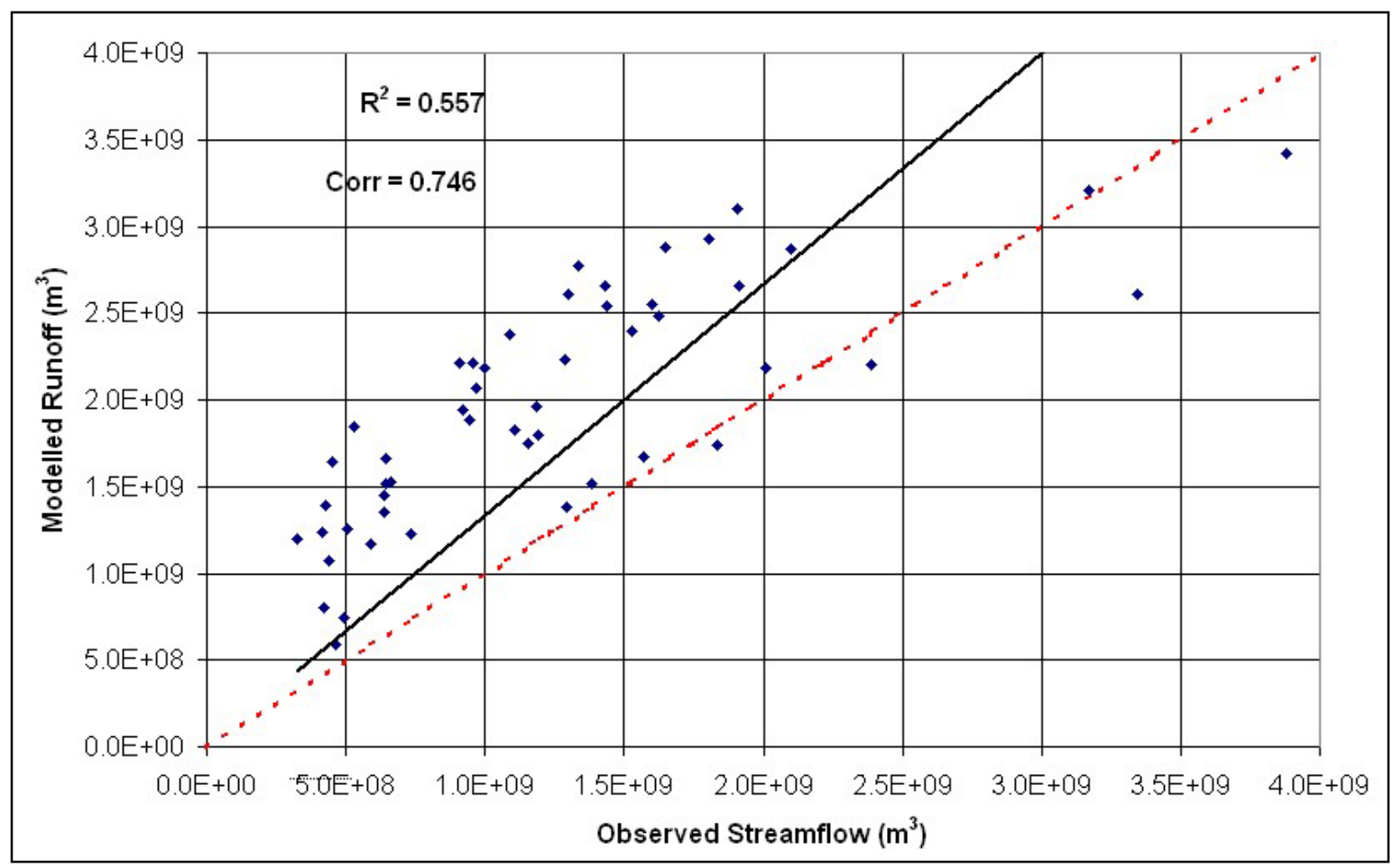

Figure 5.6: Annual Observed Streamflow vs. Annual Modeled Runoff (1950-1999) 


\subsection{Soil Moisture Climatology}

Climatology refers to the setting up of an average temporal climate for the data set and study period from which certain data parameters can then be analyzed in reference to. Soil moisture climatology was established to quantify relationships that might exist between the modeled average fractional soil moisture and the observed (historically recorded) streamflow. Data trends and patterns were explored by considering fractional soil moisture and observed streamflow deviations from their temporal average. These deviations are called anomalies. The temporal periods of significance for forecasting purposes are annual and seasonal periods. Seasons were defined as Winter (January, February, March), Spring (April, May, June), Summer (July, August, September), and Fall (October, November, December).

The annual fractional soil moisture climatology was determined by subtracting the average fractional soil moisture of the entire study period (1950-1999) from each year's average fractional soil moisture value. This procedure was repeated for observed streamflow. Seasonal climatology repeated the same procedure using seasonal averages rather than annual averages. The magnitude and sign of the resulting values indicated the range of the anomalies. A positive value denoted a wetter than average year or season, and a negative value denoted a drier than average year or season. Time series of annual and seasonal anomalies of fractional soil moisture and observed streamflow were examined and plotted (see Figures 5.7-5.9). 


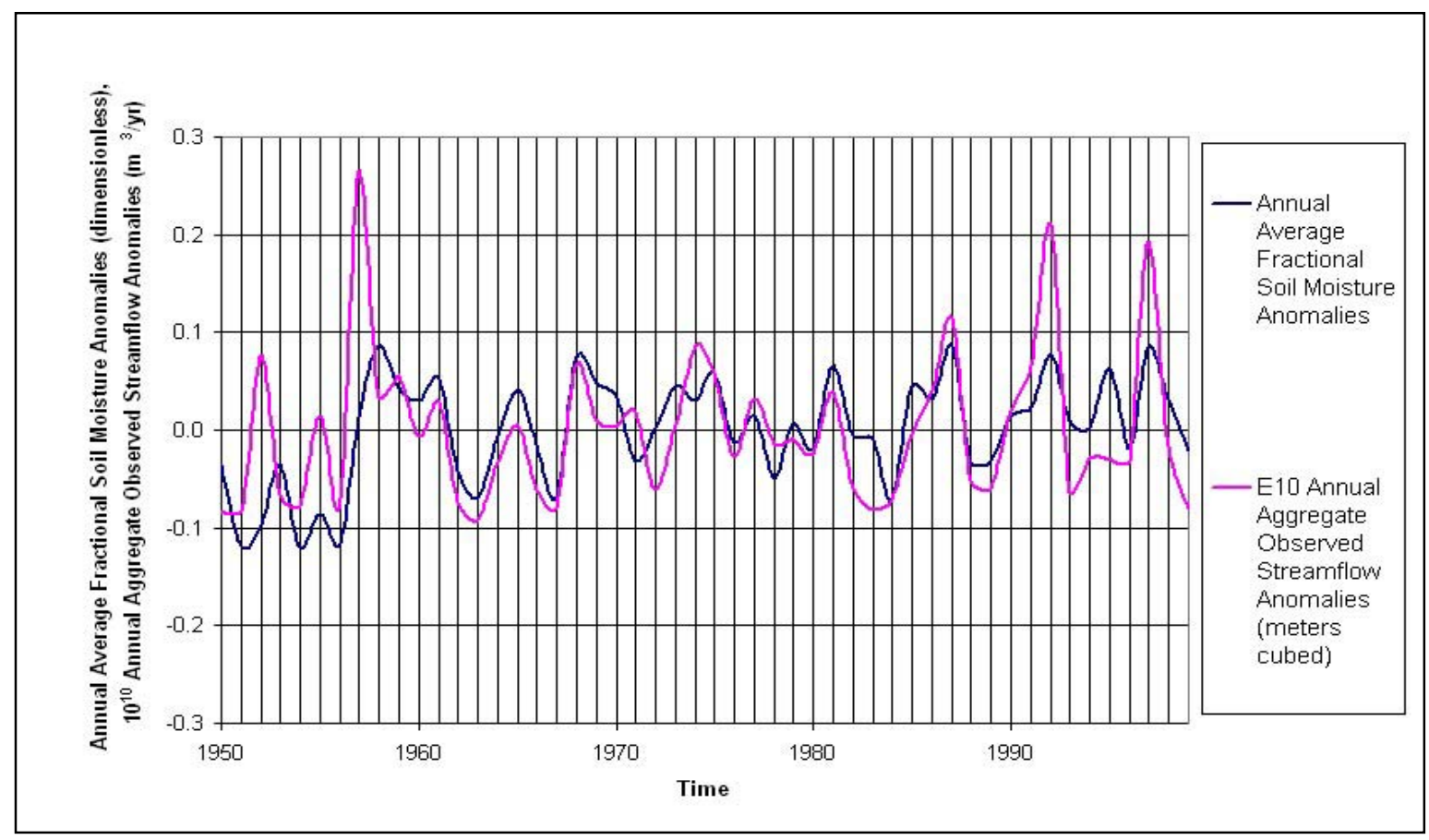

Figure 5.7: Annual Average Fractional Soil Moisture Anomalies and $10^{10}$ Annual Aggregate Observed Streamflow Anomalies vs. Time (1950-1999)

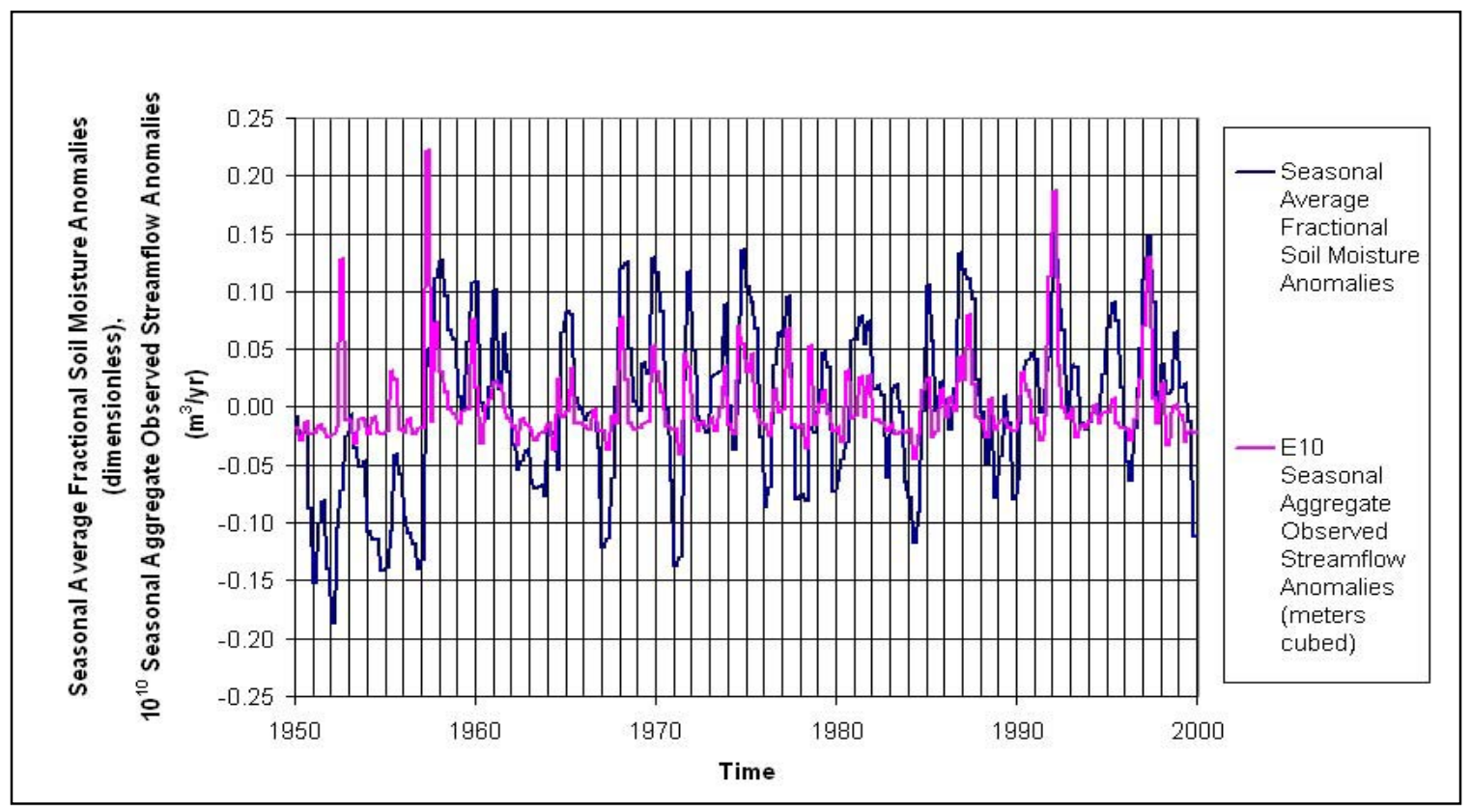

Figure 5.8: Seasonal Average Fractional Soil Moisture Anomalies and $10^{10}$ Seasonal Aggregate Observed Streamflow Anomalies vs. Time (1950-1999) 


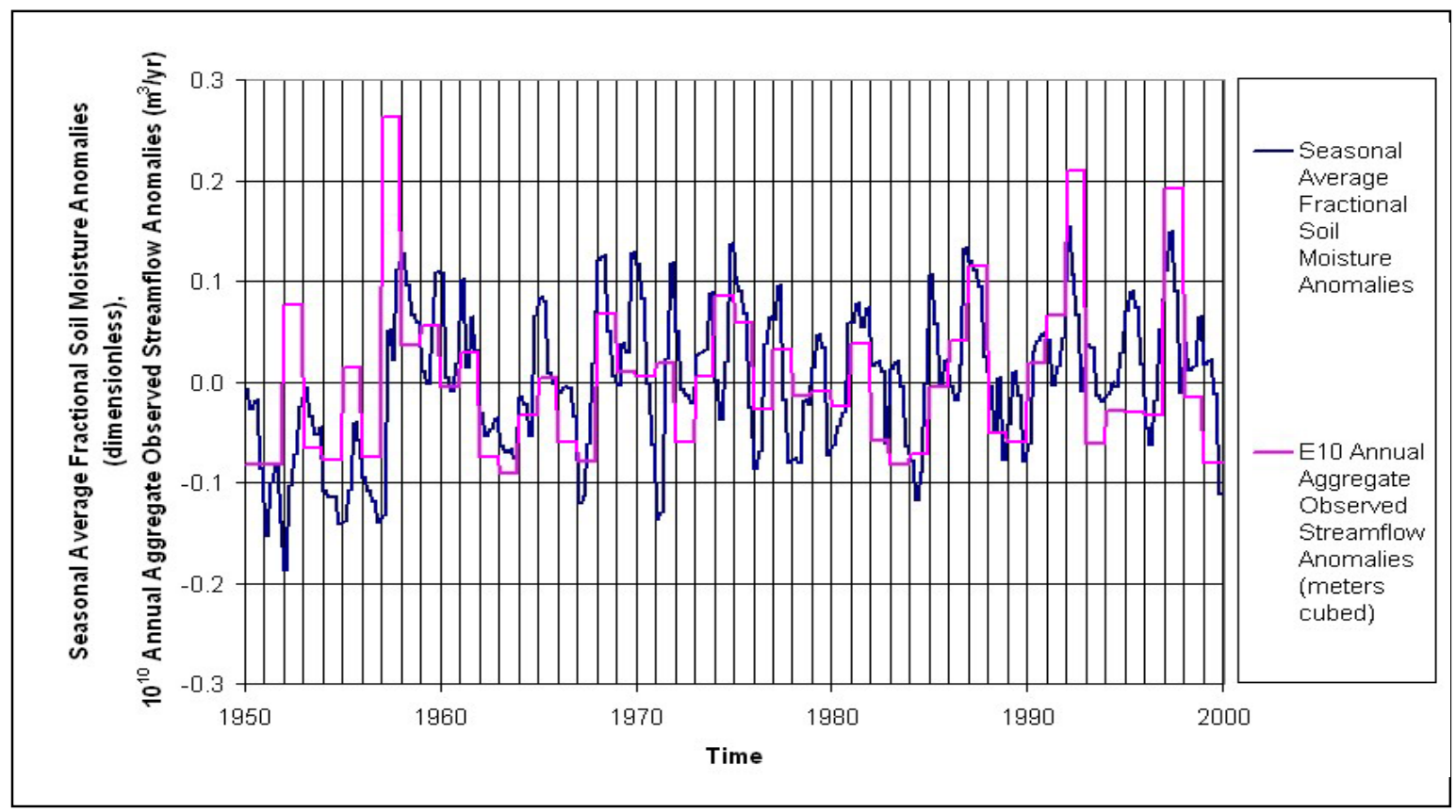

Figure 5.9: Seasonal Average Fractional Soil Moisture Anomalies and $10^{10}$ Annual Aggregate Observed Streamflow Anomalies vs. Time (1950-1999)

The statistics obtained from the climatology revealed an approximately equal split between dry and wet periods. Climatology on fractional soil moisture yielded 27 wet years and 23 dry years, as well as 98 wet seasons and 102 dry seasons. Observed streamflow climatology produced 22 wet years and 28 dry years. Seasonal observed streamflow displayed a significant shift towards drier seasons with a resulting 143 dry seasons to 57 wet seasons. The soil moisture and streamflow patterns exhibited in the climatology plots seem consistent in their behavior in that an increase or decrease in fractional soil moisture was mirrored in observed streamflow. This behavior tends to be more obvious during the later period of 1950-1999 than in the beginning. Trend shifts are well represented between the anomalies of both parameters. These results demonstrate the potential of soil moisture as a climate indicator of streamflow over the LCRA region. 


\subsection{Correlation Analysis}

Correlation analysis of fractional soil moisture and observed streamflow was applied to different combinations of annual and seasonal time periods to evaluate soil moisture's potential in predicting streamflow. The value of correlation between two parameters is determined by the correlation coefficient (see Equations 5.1-5.3)

$\rho_{x, y}=\frac{\operatorname{Cov}(x, y)}{\sigma_{x} \sigma_{y}}$

Where:

$\operatorname{Cov}(x, y)=\frac{1}{n} \sum_{i=1}^{n}\left(x_{i}-\mu_{x}\right)\left(y_{i}-\mu_{y}\right)$

(Equation 5.2)

And:

$\sigma_{x}=\frac{1}{n} \sum_{i=1}^{n}\left(x_{i}-\mu_{x}\right)^{2}$

$\sigma_{y}=\frac{1}{n} \sum_{i=1}^{n}\left(y_{i}-\mu_{y}\right)^{2}$

(Equation 5.3)

Covariance $(\operatorname{Cov}(\mathrm{x}, \mathrm{y}))$ and the correlation coefficient $\left(\rho_{\mathrm{x}, \mathrm{y}}\right)$ measure how closely two variables are related in a linear manner. The range of the correlation coefficient is between 1 and -1 . When the correlation coefficient value is between 0 and 1 , both parameters are positively and linearly correlated. If the correlation coefficient is exactly 1 then it is perfectly, linearly, and positively correlated. When the correlation coefficient value is between 0 and -1 , both parameters are negatively and linearly correlated. If the correlation coefficient is exactly -1 then it is perfectly, linearly, and negatively correlated. If the value of the correlation coefficient is zero then both parameters are absolutely linearly uncorrelated. The further the correlation coefficient value is from zero, the more significant the linear correlation is, whether it be positive or negative. Only linear 
correlation was tested since all graphical plots with fractional soil moisture and observed streamflow appeared linear in nature and assuming linearity was a simple first approach to use in this investigative study. All correlations were linear to maintain consistency between the various correlation combinations.

The correlation coefficients calculated for temporal period combinations between fractional soil moisture and observed streamflow are in Table 5.2. For correlation between two parameters with a lag year (e.g. annual average soil moisture (t) vs. annual aggregate stream flow $(\mathrm{t}+1)$ ), the leading years were 1950-1998 and the lagged years were 1951-1999. For seasonal lag correlations, all 50 years were used.

To determine the statistical significance of the correlation coefficients calculated, the ttest was applied. The null hypothesis for this test was that the correlation, $r$, of soil moisture and streamflow is equal to zero $\left(\mathrm{H}_{0}: \mathrm{r}=0\right)$. A two-tailed (or two-sided) interval test was applied to determine whether the correlation coefficient values were either larger or smaller than the value denoted in the null hypothesis. For testing the significance of correlation, the t-statistic is given by:

$$
t=\left|\frac{r \sqrt{N-2}}{\sqrt{1-r^{2}}}\right|
$$

Where:

$$
\begin{aligned}
& \mathrm{N}=\text { Data Population Size } \\
& \mathrm{df}=\mathrm{N}-2=\text { Degrees of Freedom }
\end{aligned}
$$

Performing a t-test on the data with the significance levels outlined for the correlation coefficients depended on quantiles of the t-distribution. The t-test was based on 49 or 50 data points and 47 or 48 degrees of freedom. Three significance levels $(\alpha)$ were tested to verify the significance of the correlations found. For levels of $0.01,0.05$, and 0.1 , t-values 
needed to exceed $2.682,2.011$, and 1.678 respectively to be deemed statistically significant.

Table 5.2 is organized by sets of different seasonal and annual fractional soil moisture correlations with various periods of observed streamflow. The six sets are mainly correlations of October, Fall, Winter, Spring, Summer, and Annual fractional soil moisture with observed streamflow respectively. The three highlighted colors in the table indicate to what degree of statistical significance a correlation may have. The color yellow indicates statistical significance at the 0.01 level, green indicates statistical significance at the 0.05 level, and blue indicates statistical significance at the 0.1 level. 


\begin{tabular}{|c|c|c|c|c|c|c|c|}
\hline \multirow{2}{*}{ Set } & \multirow{2}{*}{$x$} & \multirow{2}{*}{$\mathrm{Y}$} & \multirow{2}{*}{$\begin{array}{l}\text { Correlation } \\
\text { Coefficient }\end{array}$} & \multirow{2}{*}{$\begin{array}{c}\mathrm{t} \\
\text { value }\end{array}$} & \multicolumn{3}{|c|}{ Statistically Significant? } \\
\hline & & & & & $\alpha=0.01$ & $\alpha=0.05$ & $\alpha=0.1$ \\
\hline \multirow{7}{*}{1} & October Soil Moisture (t) & Fall Streamflow $(\mathrm{t}+1)$ & 0.083 & 0.575 & No & No & No \\
\hline & October Soil Moisture (t) & Winter Streamflow $(t+1)$ & 0.227 & 1.615 & No & No & No \\
\hline & October Soil Moisture (t) & Spring Streamflow $(t+1)$ & -0.049 & 0.339 & No & No & No \\
\hline & October Soil Moisture (t) & Summer Streamflow $(\mathrm{t}+1)$ & -0.193 & 1.362 & No & No & No \\
\hline & October Soil Moisture (t) & Annual Streamflow (t) & 0.451 & 3.500 & Yes & Yes & Yes \\
\hline & October Soil Moisture (t) & Annual Streamflow $(\mathrm{t}+1)$ & 0.038 & 0.262 & No & No & No \\
\hline & October Soil Moisture (t) & Fall Streamflow (t) & 0.648 & 5.899 & Yes & Yes & Yes \\
\hline \multirow{7}{*}{2} & Fall Soil Moisture (t) & Winter Streamflow $(t+1)$ & 0.380 & 2.846 & Yes & Yes & Yes \\
\hline & Fall Soil Moisture (t) & Spring Streamflow $(t+1)$ & 0.060 & 0.420 & No & No & No \\
\hline & Fall Soil Moisture $(\mathrm{t})$ & Summer Streamflow $(t+1)$ & -0.246 & 1.758 & No & No & Yes \\
\hline & Fall Soil Moisture (t) & Fall Streamflow $(\mathrm{t}+1)$ & 0.053 & 0.368 & No & No & No \\
\hline & Fall Soil Moisture (t) & Annual Streamflow (t) & 0.472 & 3.714 & Yes & Yes & Yes \\
\hline & Fall Soil Moisture $(\mathrm{t})$ & Annual Streamflow $(\mathrm{t}+1)$ & 0.144 & 1.005 & No & No & No \\
\hline & Fall Soil Moisture (t) & Fall Streamflow (t) & 0.716 & 7.104 & Yes & Yes & Yes \\
\hline \multirow{7}{*}{3} & Winter Soil Moisture (t) & Winter Streamflow $(t+1)$ & -0.047 & 0.327 & No & No & No \\
\hline & Winter Soil Moisture (t) & Spring Streamflow (t) & 0.189 & 1.335 & No & No & No \\
\hline & Winter Soil Moisture $(\mathrm{t})$ & Summer Streamflow (t) & -0.321 & 2.346 & No & Yes & Yes \\
\hline & Winter Soil Moisture (t) & Fall Streamflow (t) & -0.029 & 0.202 & No & No & No \\
\hline & Winter Soil Moisture $(\mathrm{t})$ & Annual Streamflow (t) & 0.290 & 2.099 & No & Yes & Yes \\
\hline & Winter Soil Moisture $(\mathrm{t})$ & Annual Streamflow $(t+1)$ & -0.149 & 1.046 & No & No & No \\
\hline & Winter Soil Moisture (t) & Winter Streamflow (t) & 0.665 & 6.163 & Yes & Yes & Yes \\
\hline \multirow{7}{*}{4} & Spring Soil Moisture (t) & Winter Streamflow $(t+1)$ & -0.109 & 0.759 & No & No & No \\
\hline & Spring Soil Moisture (t) & Spring Streamflow $(t+1)$ & -0.370 & 2.755 & Yes & Yes & Yes \\
\hline & Spring Soil Moisture (t) & Summer Streamflow (t) & -0.276 & 1.988 & No & No & Yes \\
\hline & Spring Soil Moisture (t) & Fall Streamflow $(\mathrm{t})$ & -0.007 & 0.045 & No & No & No \\
\hline & Spring Soil Moisture $(\mathrm{t})$ & Annual Streamflow (t) & 0.516 & 4.178 & Yes & Yes & Yes \\
\hline & Spring Soil Moisture (t) & Annual Streamflow $(t+1)$ & -0.174 & 1.222 & No & No & No \\
\hline & Spring Soil Moisture (t) & Spring Streamflow (t) & 0.559 & 4.673 & Yes & Yes & Yes \\
\hline \multirow{7}{*}{5} & Summer Soil Moisture (t) & Winter Streamflow $(t+1)$ & 0.041 & 0.283 & No & No & No \\
\hline & Summer Soil Moisture (t) & Spring Streamflow $(t+1)$ & -0.342 & 2.518 & No & Yes & Yes \\
\hline & Summer Soil Moisture (t) & Summer Streamflow $(t+1)$ & -0.113 & 0.791 & No & No & No \\
\hline & Summer Soil Moisture (t) & Fall Streamflow (t) & 0.249 & 1.782 & No & No & Yes \\
\hline & Summer Soil Moisture $(\mathrm{t})$ & Annual Streamflow (t) & 0.609 & 5.318 & Yes & Yes & Yes \\
\hline & Summer Soil Moisture $(\mathrm{t})$ & Annual Streamflow $(t+1)$ & -0.193 & 1.360 & No & No & No \\
\hline & Summer Soil Moisture (t) & Summer Streamflow (t) & 0.037 & 0.259 & No & No & No \\
\hline \multirow{6}{*}{6} & Annual Soil Moisture (t) & Winter Streamflow $(t+1)$ & 0.079 & 0.550 & No & No & No \\
\hline & Annual Soil Moisture (t) & Spring Streamflow $(t+1)$ & -0.290 & 2.102 & No & Yes & Yes \\
\hline & Annual Soil Moisture (t) & Summer Streamflow $(t+1)$ & -0.109 & 0.762 & No & No & No \\
\hline & Annual Soil Moisture (t) & Fall Streamflow $(\mathrm{t}+1)$ & 0.172 & 1.213 & No & No & No \\
\hline & Annual Soil Moisture (t) & Annual Streamflow $(t+1)$ & -0.112 & 0.780 & No & No & No \\
\hline & Annual Soil Moisture (t) & Annual Streamflow (t) & 0.578 & 4.911 & Yes & Yes & Yes \\
\hline
\end{tabular}

Table 5.2: Correlation Coefficients and Corresponding Statistical Significance 
The t-test for significance of correlation assumes that the paired variables considered (soil moisture and streamflow) are sampled independently. But this t-test assumption is not accurate when considering that the two parameters in question are soil moisture and streamflow, two hydrologic variables that demonstrate persistence. To examine the persistence of soil moisture, its respective annual and seasonal (1-lag) autocorrelations were calculated and tabulated in Table 5.3.

\begin{tabular}{|c|c|c|c|c|c|}
\hline & \multicolumn{5}{|c|}{ Fractional Soil Moisture } \\
\hline & Winter (t) & Spring (t) & Summer (t) & Fall (t) & Annual (t) \\
\hline Spring (t) & 0.843237 & - & - & - & - \\
\hline Summer (t) & - & 0.75503 & - & - & - \\
\hline Fall (t) & - & - & 0.5114805 & - & - \\
\hline Winter ( $(+1)$ & - & - & - & 0.801 & - \\
\hline Annual $(\mathrm{t}+1)$ & - & - & - & - & 0.343697 \\
\hline
\end{tabular}

Table 5.3: Soil Moisture 1-Lag Autocorrelations

Based on the correlation results obtained from the analysis, various correlation combinations with definitive trends were plotted in bar charts (see Figures 5.10-5.18). Correlation bar plots are arranged with correlation parameters on the $\mathrm{x}$-axis in order of increasing lag time, followed by annual aggregate stream flow correlation. The t notation on the correlation bar plots refers to the current year and the $t+1$ notation refers to a 1 year lag. The colored lines in the bar charts also denote the level of statistical significance. The yellow, green, and blue colors denote the same significance levels as in Table 5.2.

Besides looking at seasonal and annual correlations, it was of interest to look at the correlation between October fractional soil moisture and various observed streamflow periods (see Figure 5.10). This would be useful to the LCRA since interruptible contracts for the next year are signed in November. If water managers had knowledge of the upcoming year's streamflow, then those water contracts can be signed with greater confidence and reliability. However, as shown in Figure 5.10, the October soil moisture 
which would be observable before signing contracts in November is significantly correlated only with the Fall streamflow and does not provide any predictive skill for annual or lagged seasonal streamflow.

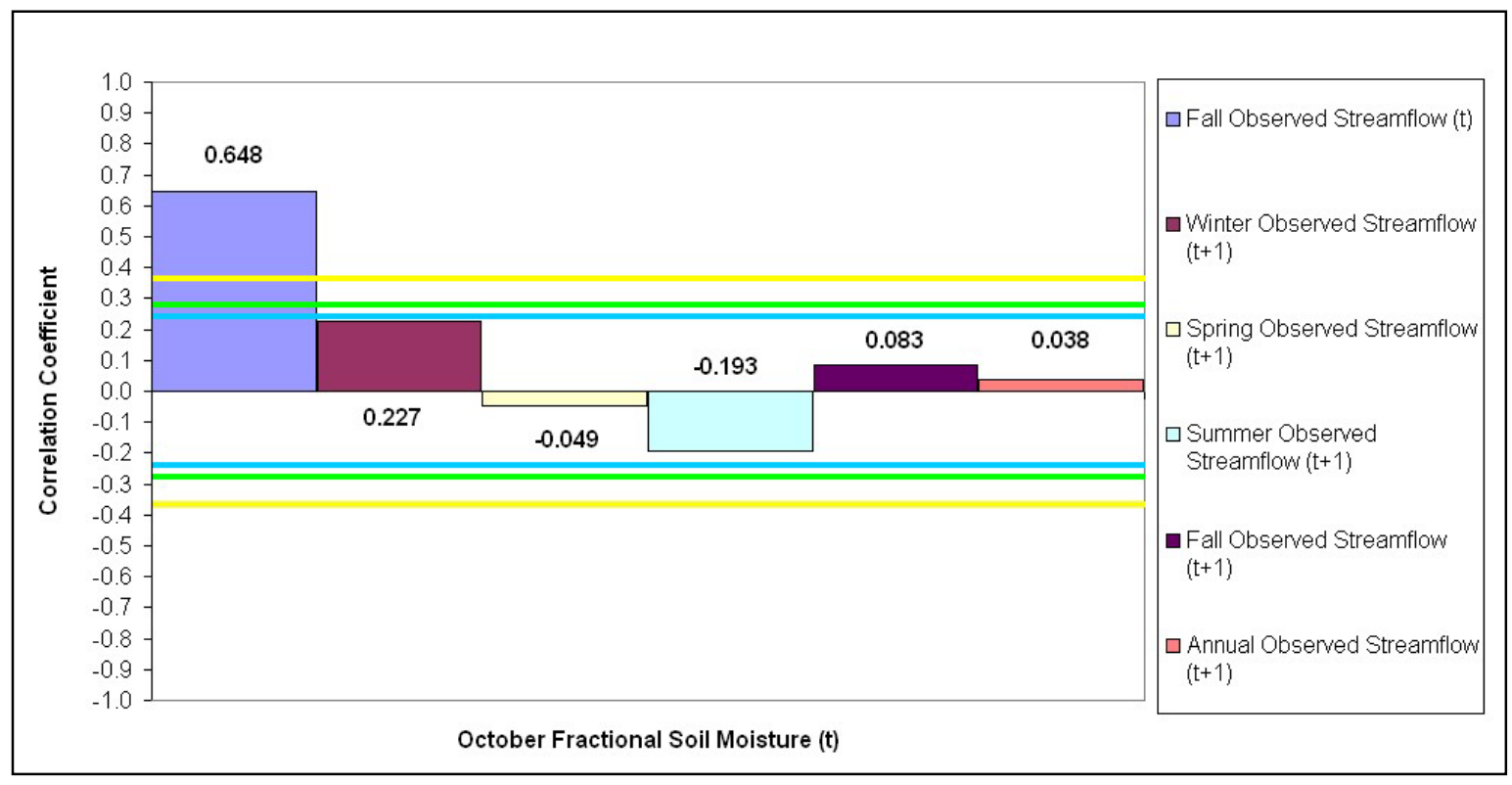

Figure 5.10: October Average Fractional Soil Moisture Correlations

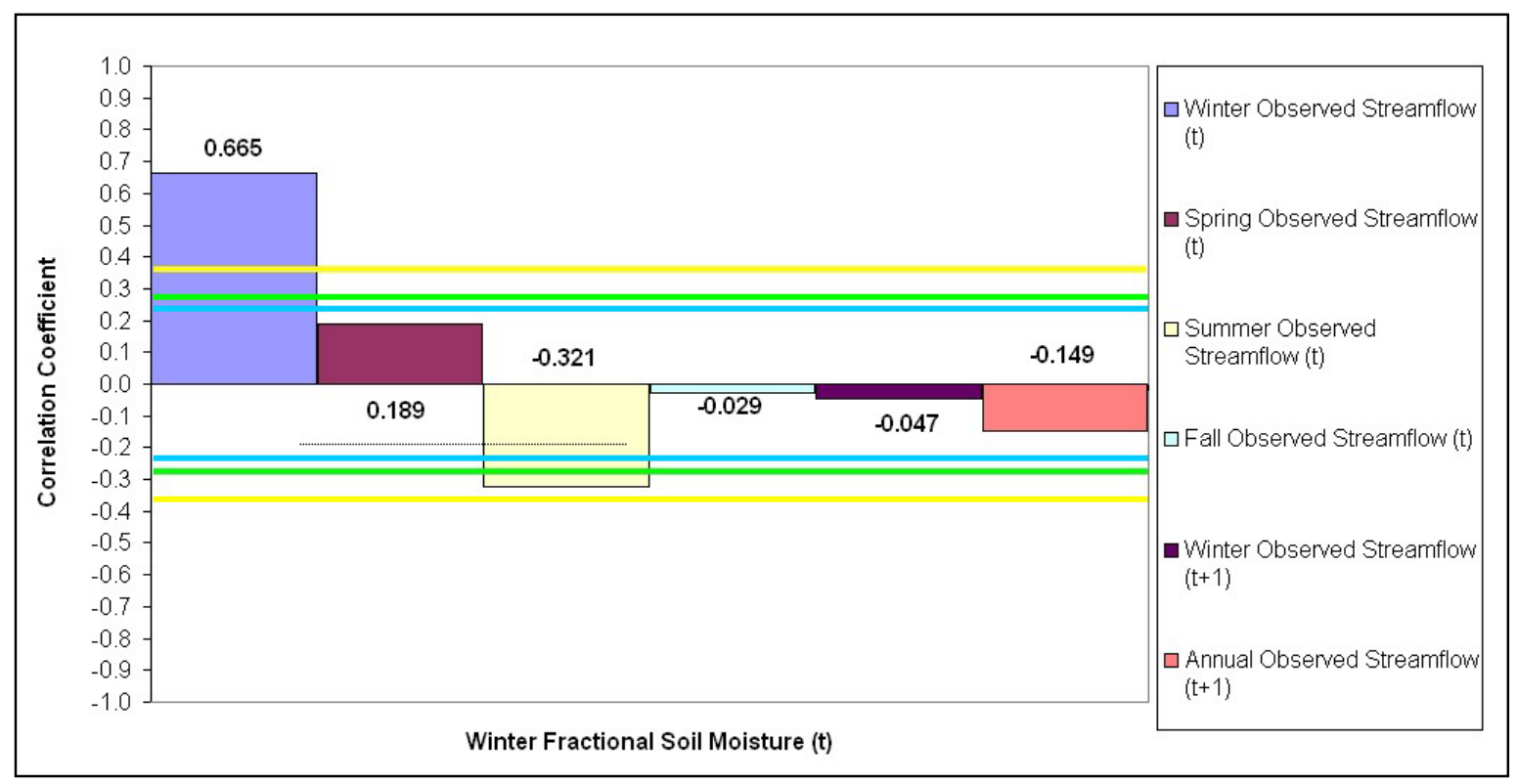

Figure 5.11: Winter Average Fractional Soil Moisture Correlations 


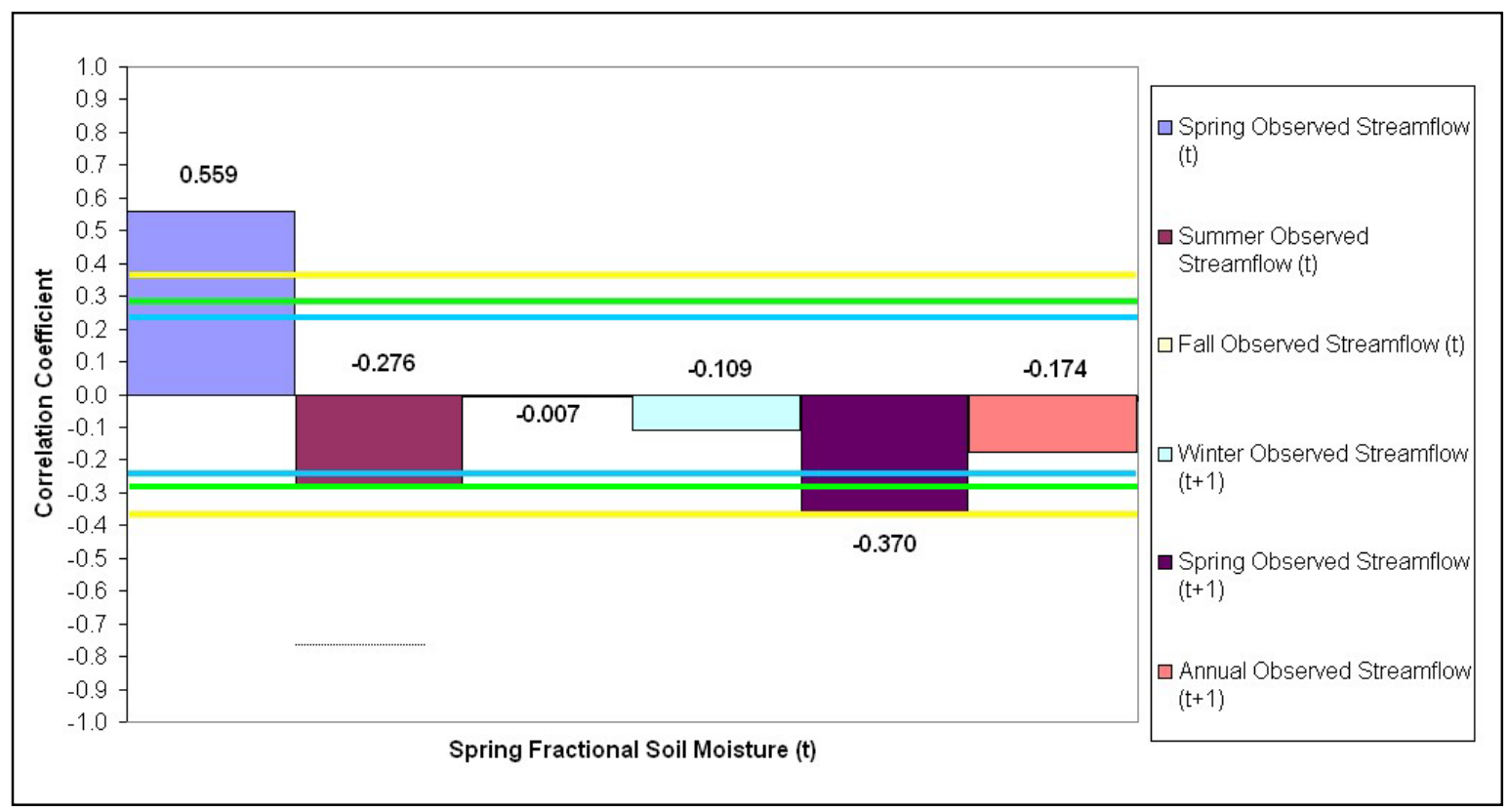

Figure 5.12: Spring Average Fractional Soil Moisture Correlations

Correlations between fractional soil moisture and observed streamflow are greatest during the same season of the same year and the correlations decrease as the lag increases (see Figures 5.11-5.14). Summer fractional soil moisture is the only exception to this trend. The behavior exhibited with Summer correlations is most likely attributed to the effect of convective thunderstorms that are active during the Spring and Summer in the area of the Gulf Coast. These storms may tend to produce an inverse relationship between soil moisture and runoff/streamflow. Convective rainfall that results from this phenomenon is mainly due to strong vertical air motions and is characterized by a warm and unstable air mass. This precipitation develops at a fast rate and as such can lead to surface flooding (Maidment, 1993). Summer (convective) thunderstorms are usually of high intensity and span a short duration (Fernandez et al., 1999). In effect, the soil cannot capture much of the precipitation that has been produced by the thunderstorm, and that precipitation goes directly into surface runoff. Due to the high temperatures and solar radiation of the Summer months, the little water that has been absorbed by the soil is evaporated quickly. With the exception of Summer, seasonal fractional soil moisture was generally a good indicator of seasonal streamflow over the LCRA region. Spring fractional soil moisture may provide additional forecast information. Not only was there good correlation between Spring soil moisture and observed streamflow within the same 
year, there was also good correlation between both parameters with a 1-year lag (Figure 5.12). This behavior was only apparent with the Spring fractional soil moisture. Since the Spring season promotes the greatest amount of surface runoff annually, it is likely for this significant correlation to be evident between two subsequent Spring seasons reflecting the persistence of interannual climate signals.

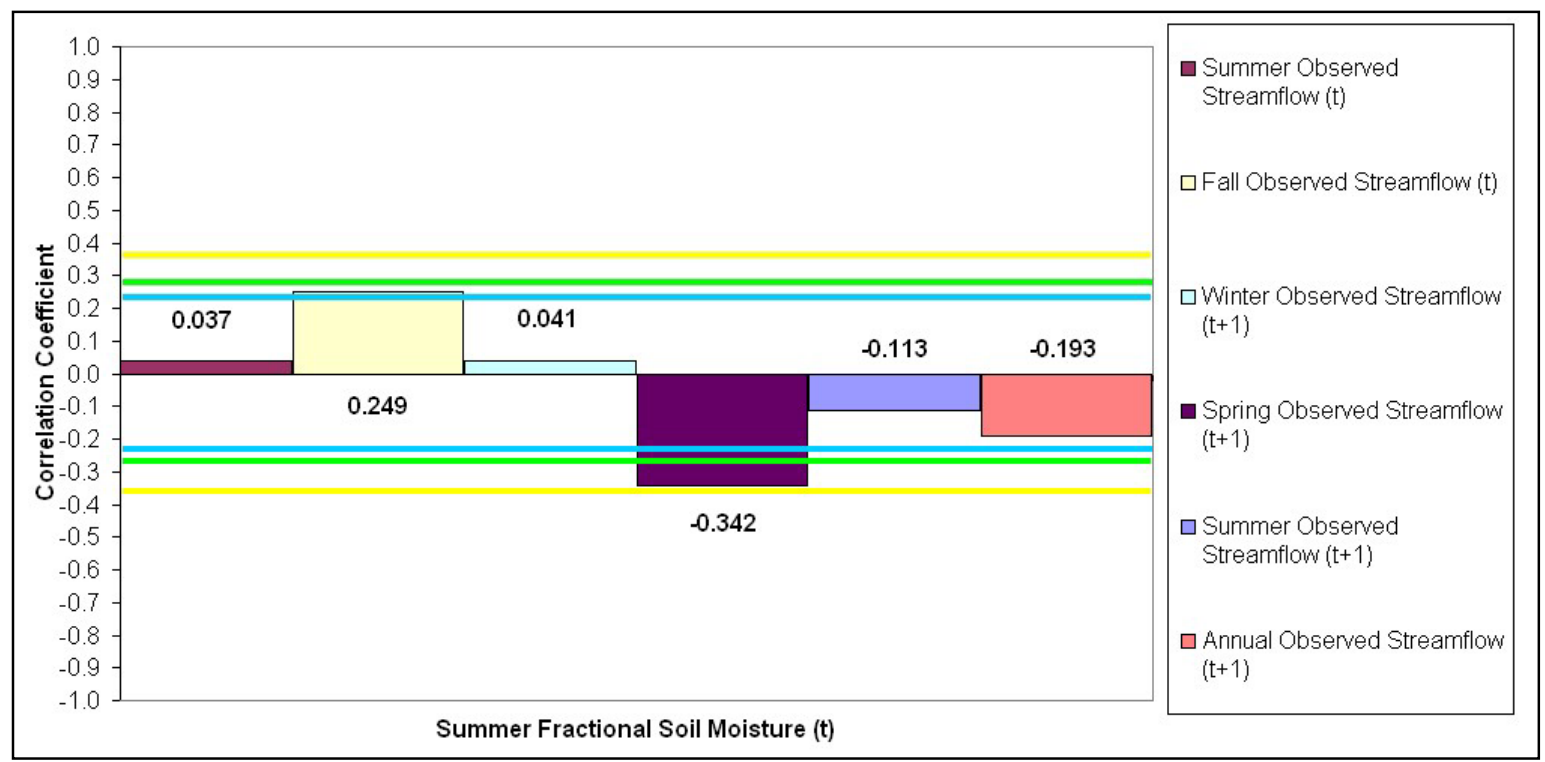

Figure 5.13: Summer Average Fractional Soil Moisture Correlations

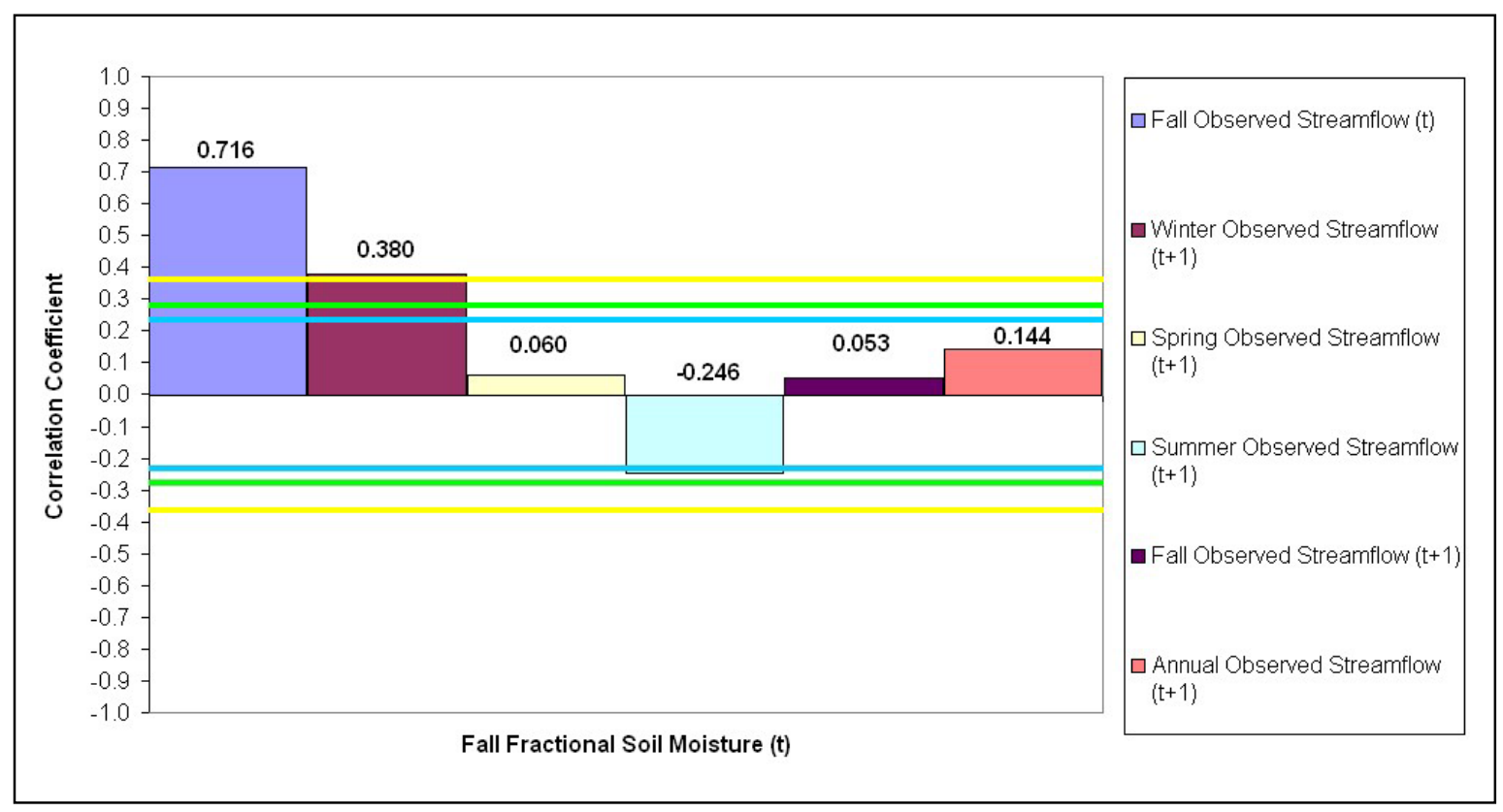

Figure 5.14: Fall Average Fractional Soil Moisture Correlations 
All temporally averaged values of fractional soil moisture annually and seasonally yielded a significant correlation with annual observed streamflow (see Figure 5.15). Consequently, seasonal and annual fractional soil moisture was a good indicator of annual observed streamflow over the LCRA region for coincident years. Correlation between fractional soil moisture and observed streamflow was significantly higher for 0 year lag (within the same year) than for 1-year lag (the following year) as shown in Figures 5.15 and 5.16. Thus soil moisture does not appear useful as a predictor of annual streamflow at the 1-year lag. As will be discussed later, this highlights the need for skillful soil moisture forecasts that would enable 0 -year lag prediction of streamflow.

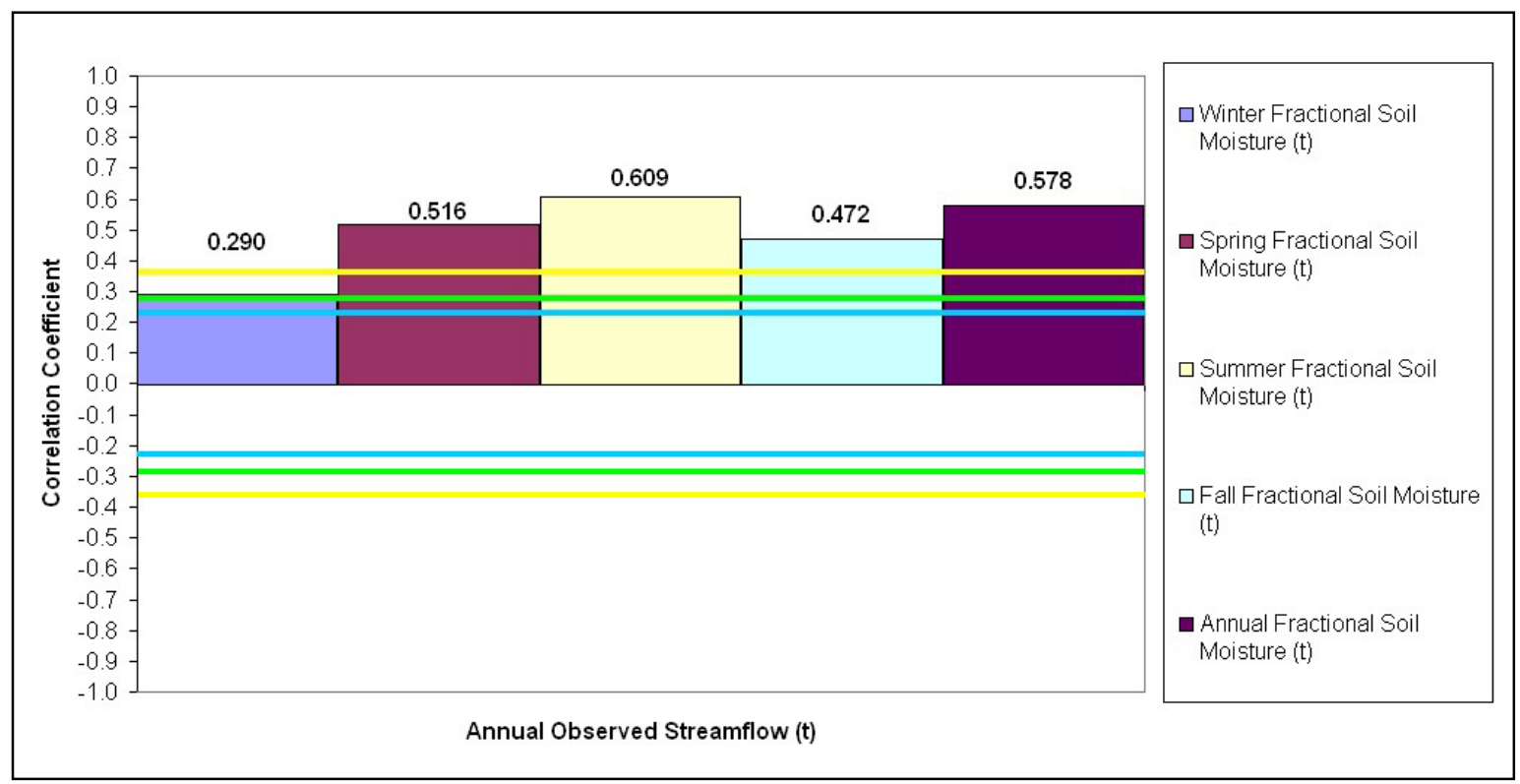

Figure 5.15: Annual Aggregate Observed Streamflow Correlations with 0-Year Lag 

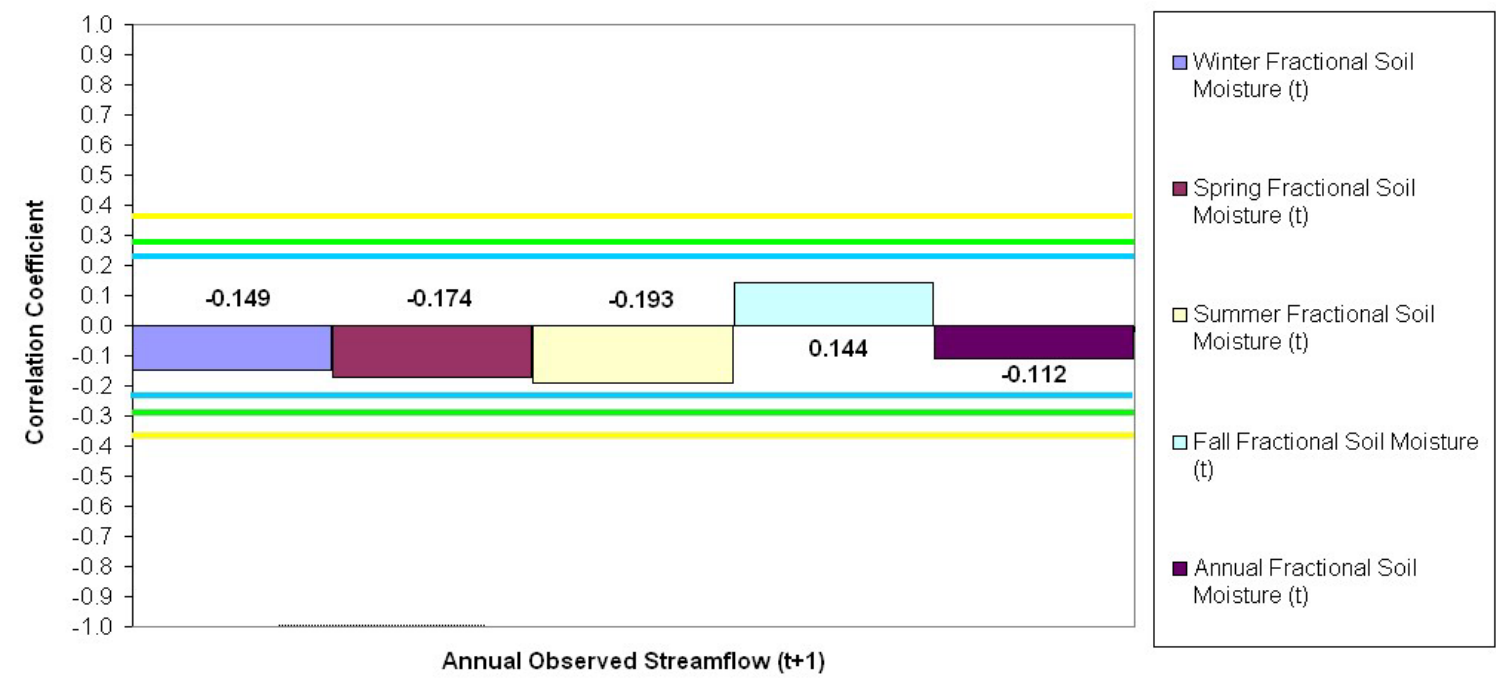

Moisture (t)

Figure 5.16: Annual Aggregate Observed Streamflow Correlations with 1-Year Lag

Another trend found from the correlation analysis was statistically significant correlations obtained between soil moisture and streamflow in subsequent seasons (Figure 5.17). This type of correlation is useful for seasonal lead-time applications. The only exception to this trend is the poor correlation of Winter fractional soil moisture to Spring observed streamflow (0.189).

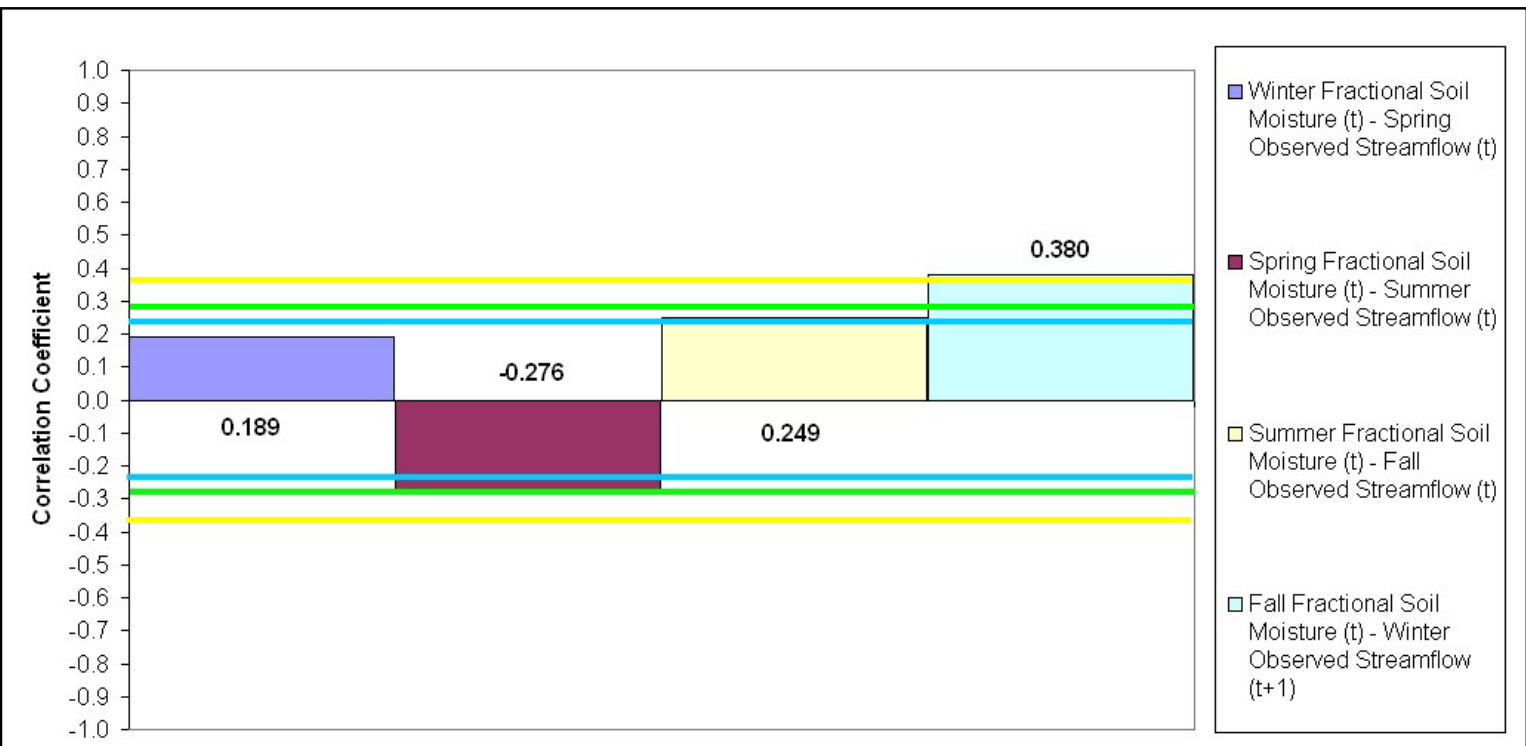

Figure 5.17: Consecutive Seasons Soil Moisture Correlations 
There also existed a statistically significant correlation between all seasons (except Summer) to the Summer seasons following them. As shown in Figure 5.18, Fall, Winter, and Spring fractional soil moisture exhibited significant correlations with Summer observed streamflow. Summer (and annual) fractional soil moisture did not correlate as well with Summer observed streamflow as the other seasons. In general, the Summer season did not present itself as a suitable period for the correlation of fractional soil moisture to observed streamflow. However, Summer fractional soil moisture had a statistically significant correlation (-0.342) with the following year's Spring observed streamflow (see Figure 5.13).

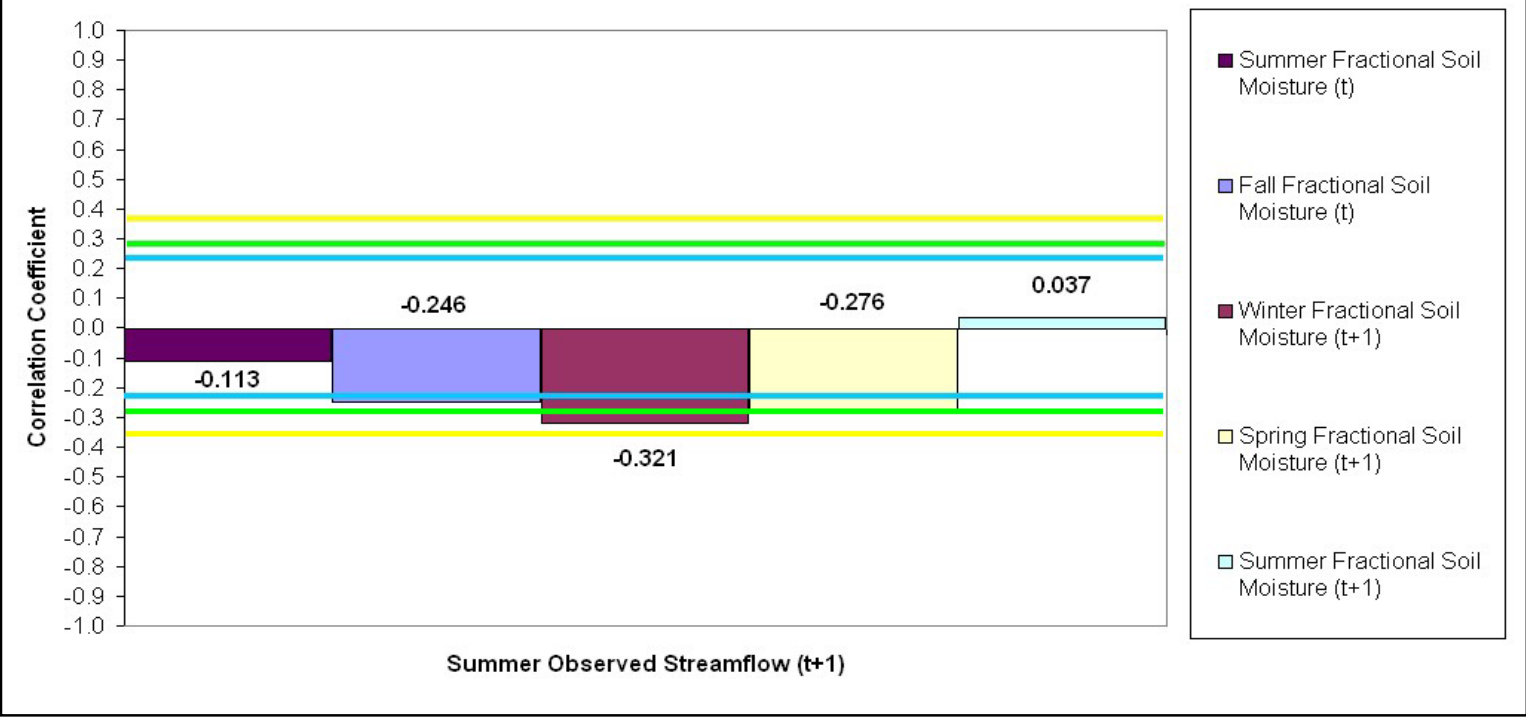

Figure 5.18: Summer Aggregate Observed Streamflow Correlations

Although significant correlation coefficient values exist for fractional soil moisture and observed streamflow for the same temporal period, as lead-time between fractional soil moisture and observed streamflow correlation increases, the value of the associated correlation coefficient decreases rapidly. Thus, for water managers of the LCRA to utilize these coincident correlations, accurate soil moisture forecasts must be available. For example, a forecast of next season's soil moisture could be used in predicting next 
season's streamflow. The soil moisture forecasts used in this manner need to be skillful and reliable in their application. Use of these forecasts would capitalize on the sameseason and same-year correlations, since 0-lags represent the highest correlation available between fractional soil moisture and observed streamflow for the LCRA watershed region. Unfortunately, current soil moisture forecasts and outlooks have not reached a degree of precision necessary to be used in a dependable way, although positive steps have been taken in that direction (e.g. NOAA CPC forecasts). Water managers should ideally be able to use these soil moisture forecasts to predict soil moisture at a given period, and then with the correlation results found in this study predict the upcoming annual streamflow depending on the value of that correlation. The use of soil moisture forecasts will provide the necessary lead time in predicting streamflow that is needed for timely water resources management decisions. The preferred result for the decision making process is to have very high correlation between soil moisture and streamflow with long lead times. Forecasts of soil moisture could provide the lead time needed to assist water managers in their decision making process. In comparison to previous work and findings (O'Connell, 2002), the results regarding the use of soil moisture as a streamflow indicator are promising but also hinges on the progress of future work. This future work would look at the incorporation of soil moisture forecast into the streamflow prediction process as well as possibly recalibrating the VIC-3L model to the specific watershed of interest. Future work is discussed further in section 6.3.

Equation Chapter 6 Section 1 


\section{Summary and Conclusions}

This final chapter summarizes the thesis and provides final conclusions based on the results performed in the previous chapter. Suggested future work is also outlined as the next step in the overall project.

\subsection{Summary}

The objective of this study was to evaluate soil moisture's potential as a viable climate indicator and predictor of streamflow over the Lower Colorado River Basin in central Texas. Future research will use soil moisture in conjunction with other climate indicators to be incorporated in a decision support model of the Highland Lakes multi-reservoir system. The goal is to assist water managers who sign annual interruptible water contracts to better project water supplies and needs for the coming year.

In order to assess the value of soil moisture as a climate indicator and predictor of stream flow, a couple of data sets were used. Along with historical observed streamflow data, modeled fractional soil moisture and runoff data from the Variable Infiltration Capacity (VIC) Retrospective Land Surface Data Set were utilized in this study. The common time period and the study period between the observed and modeled data sets was 1950-1999. The VIC modeled data was extracted from its NetCDF format by MATLAB into ArcView so that it could be manipulated.

Prior to correlation analysis, a sensitivity analysis was performed to check if changes in the VIC-3L model domain would affect the values and range of the attributes within the LCRA. If any changes occured with respect to soil moisture, attribute variability would have to be accounted for. A streamflow-runoff analysis was then done to observe how VIC modeled data and historical observed data would compare to each other. Climatology was then established for all different seasonal and annual combinations of fractional soil moisture and streamflow. Trends were viewed as deviations from a temporal average, denoted as anomalies. The next stage of the research was the correlation analysis, which determined the correlation values between fractional soil 
moisture and streamflow for various annual and seasonal temporal combinations. This analysis was used to verify the potential skill in soil moisture as a predictor of streamflow over the LCRA watershed.

\subsection{Conclusions}

The results of the sensitivity analysis concluded that there were no significant changes in the average fractional soil moisture values in the LCRA watershed to justify a change in the VIC-3L model domain. Therefore, attribute variability was not an issue since no exterior watersheds or tributaries outside of the Highland Lakes reservoir system affected the physical properties within the watershed. The streamflow-runoff analysis verified that the modeled streamflow from the VIC Retrospective Land Surface Data Set tracked well with the observed historical streamflow data (correlation of about 0.75 ). This gives confidence in the choice of the VIC Retrospective Land Surface Data set as a data source for the study purposes. Visual comparison of the VIC modeled fractional soil moisture and observed historical streamflow time series confirmed the potential of soil moisture as a hydrologic indicator over the LCRA region.

Some correlation patterns were found from the correlation analysis, with varying degrees of statistical significance. Significant correlation was apparent between all seasons (except Summer) to the Summer season that followed them. Also, there was significant correlation between subsequent seasons with the exception of a statistically- insignificant correlation between the Winter and Spring seasons. Besides these two trends, seasonal fractional soil moisture was found to be a good indicator of seasonal streamflow for coincident and subsequent seasons over the LCRA region. Also, seasonal and annual soil moisture were good indicators of annual streamflow for coincident years over the LCRA region. The analysis also showed that correlations between fractional soil moisture and streamflow decreased rapidly as the lead-time increased. Comparing fractional soil moisture and streamflow correlations at different lag times has demonstrated that a correlation between the two parameters was significantly higher for 0-year lag than for 1year lag. The same can be said for correlations between seasons. This finding highlights the value and need for accurate soil moisture forecasts. 


\subsection{Future Work}

The VIC-3L Model used to obtain the VIC Retrospective Land Surface Data Set was calibrated to represent the continental United States. It is possible to obtain better correlation and analysis results using a VIC-3L model calibrated specifically for the Lower Colorado River Basin. Applying an LCRA-calibrated VIC-3 model would give more information on the sensitivity of the results to the calibration of the VIC-3L model. To reduce the overestimation of modeled runoff through this calibration, a few physical parameters can be adjusted accordingly. Parameters such as infiltration rate and the amount of storage in the soil layers can be increased. The water diffusion between the soil layers can be increased in capacity and thus increase the amount of baseflow.

Correlation analysis between soil moisture from the VIC Retrospective Land Surface Data Set and observed streamflow demonstrated the need for coincident (0-lag) soil moisture and streamflow temporal combinations to obtain significant correlation. Thus if soil moisture is to be used as a climate indicator and predictor of annual aggregate streamflow, then reliable forecasts of seasonal-to-annual soil moisture are needed. This leads to the necessary evaluation of the usefulness of applying National Oceanic and Atmospheric Administration's (NOAA) Climate Prediction Center (CPC) forecasts of soil moisture anomalies for predicting streamflow for the LCRA watershed region.

NOAA CPC climate forecasts or outlooks focus on portraying information of average temperature, total precipitation, and soil moisture (see Figures 6.1-6.3). Climate forecasts and outlooks provided by the CPC online include frequently updated evaluations that are easily accessible to users and indicate probability anomalies that are organized into discrete categories (e.g. wet, dry, normal). CPC outlooks are available in lead-times of 12 weeks, monthly, and 3-month seasonal time periods. 


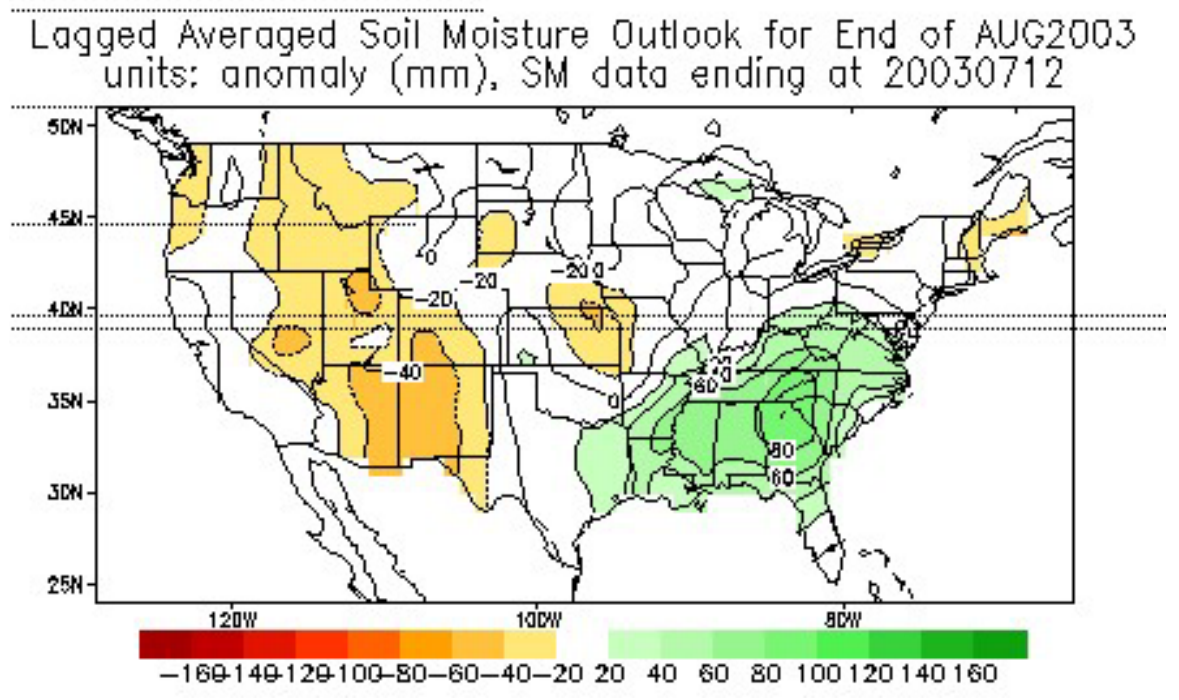

Figure 6.1: Example of NOAA CPC Soil Moisture Outlook (Climate Prediction Center, n.d.)

Lagged Averaged Precipitation Outlook for ASO 2003

-....unifts: anomaty (sdxto0), SM data ending at 20030712

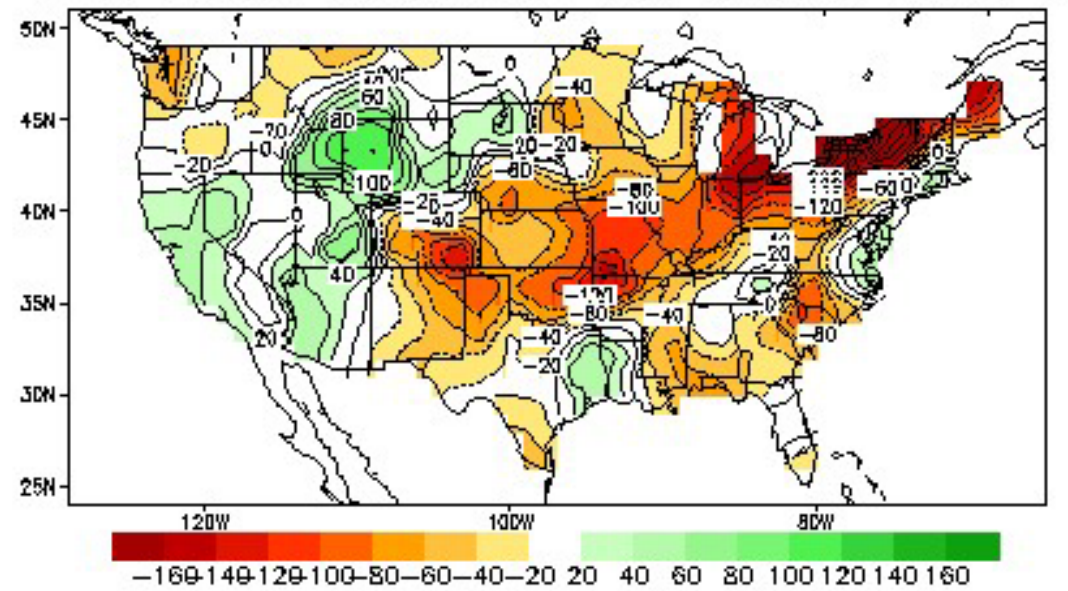

Figure 6.2: Example of NOAA CPC Precipitation Outlook (Climate Prediction Center, n.d.) 
Logged Averaged Temperature Outlook for ASO 2003

units: anomaly (sdX100), SM data ending at 20030712

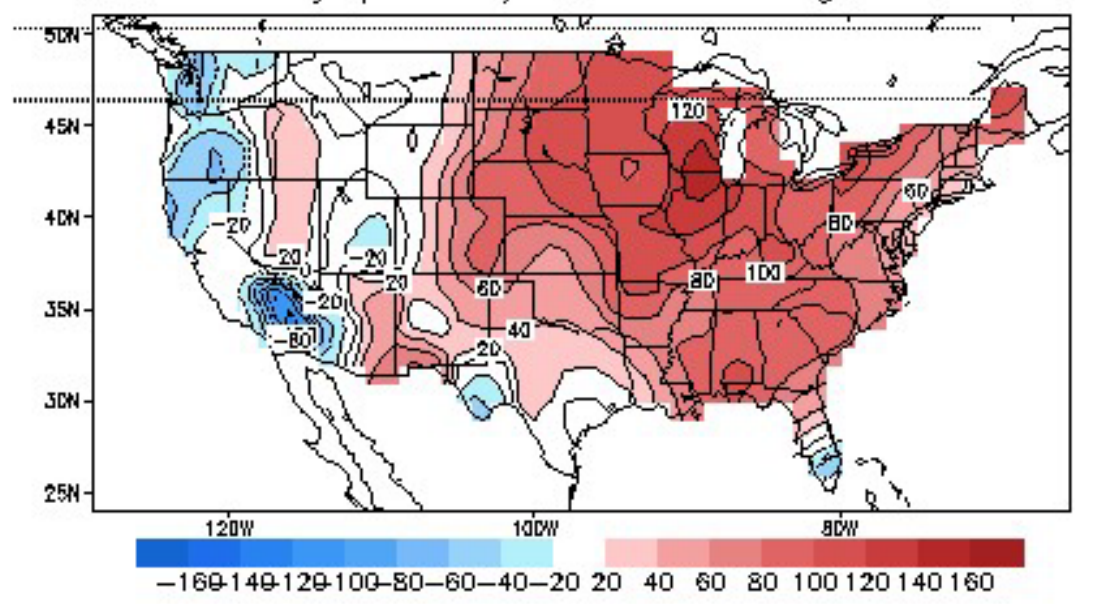

Figure 6.3: Example of NOAA CPC Temperature Outlook (Climate Prediction Center, n.d.)

NOAA CPC seasonal climate outlooks have shown greater predictive skill than forecasts that project climatological probabilities based on historical data and have shown a skillful ranked probability score (over 20\% improvement on climatology) for Southwest and Gulf Coast regions with long lead times (Hartmann et al., 2002). Furthermore, the need for forecasts to take into account user input (Stern and Easterling, 1999) in creating accurate, easy, and user-friendly outlooks is evident by the misinterpretation of CPC outlooks by even water and resource managers with technical backgrounds (Pagano et al., 2001). A common misinterpretation is mistaking probability anomalies on the CPC outlooks for actual quantities. Future research is needed to assess the usage of CPC forecast and outlook products to improve upon the findings of this work. This future research would also provide insight for the research community on the necessary skill and lead time required to make soil moisture forecasts useful in water resources management applications. 


\section{References}

Bou-Zeid, E., and El-Fadel, M. (2002). "Climate Change and Water Resources in Lebanon and the Middle East.” J. Water Resour. Plng. \& Mgmt., 128(5), 343-355.

Changnon, S.A. (1990). "The dilemma of climatic and hydrologic forecasting for the Great Lakes." Proc. Great Lakes Water Level Forecast and Statistics Symp., Ann Arbor, MI, Great Lakes Commission, 13-25.

Chenlai, C.-L. (Dec. 1990). "Evaluation of extended streamflow prediction runoff forecasts using a simple water balance model" M.S. Thesis, Dep. Of Civ. Eng., Univ. of Wash., Seattle.

Chiew, F.H.S., Piechota, T.C., Dracup, J.A., and McMahon, T.A. (1998). "El Niño/Southern Oscillation and Austrailian rainfall, streamflow and drought: Links and potential for forecasting." J. Hydrol., 204, 138-149.

Conley, J., Eakin, H., Sheridan, T.E., and Hadley, D. (1999). "CLIMAS ranching case study: Year 1. CLIMAS CL3-99, Institute for the Study of Planet Earth, The University of Arizona, Tucson, AZ, 27 pp.

Day, G.N. (1985). "Extending streamflow forecasting using NWSRFS." J. Water Resour. Plng. \& Mgmt., 111(2), 157-170.

Fernandez, P.C., Fattorelli, S., Rodriguez, S., and Fornero, L. (1999). "Regional Analysis of Convective Storms." J. Hydrol. Eng., 4(4), 317-325.

Grygier, J.C., and Stedinger, J.R. (1990). "SPIGOT, A Synthetic Streamflow Generation Software Package.” Technical Description, Version 2.6. Ithaca: School of Civil and Environmental Engineering, Cornell University.

Gutiérrez, F., and Dracup, J.A. (2001). "An analysis of the feasibility of long-range streamflow forecasting for Columbia using El Niño-Southern Oscillation indicators." J. Hydrol., 246, 181-196.

Hall, W.A., and Dracup, J.A. (1970). Water Resources Systems Engineering. New York: McGraw Hill.

Hamlet, A.F., Huppert, D., and Lettenmaier, D.P. (2002). "Economic Value of LongLead Streamflow Forecasts for Columbia River Hydropower." J. Water Resour. Plng. \& Mgmt., 128(2), 91-101.

Hamlet, A.F., and Lettenmeier, D.P. (1999). "Columbia River streamflow forecasting based on ENSO and PDO climate signals." J. Water Resour. Plng. \& Mgmt., 125(6), 333-341. 
Hartmann, H.C., Paganoi, T.C., Sorooshian, S., Bales, R. (2002). "Evaluating Seasonal Climate Forecasts from User Perspectives" Bulletin of the Amer. Meteor. Soc., May 2002.

Institute of Hydrology (1985). Models for operational control, 1, Rainfall-runoff models for subcatchments, report, Thames Water, Inst. Of Hydrol., Wallingford, England, Feb. 1985.

Institute for the Study of Planet Earth (2000). "The Implications of La Nina and El Nino for Fire Management." Tucson, AZ, CLIMAS, ISPE, and the Laboratory for Tree Ring Research, The University of Arizona, 45 pp.

Ji, M., A. Kumar, and A. Leetmaa (1994). "A multiseason climate forecast system at the National Meteorology Center." Bulletin of the Amer. Meteor. Soc., 75(4), 569577.

Kracman, D.R. (2002). "Stochastic Optimization of the Highland Lakes System in Texas." M.S. Thesis, Engineering, University of Texas at Austin, Austin, TX.

Lower Colorado River Authority (1999). Water Management Plan for the Lower Colorado River Basin. Austin, Texas, Lower Colorado River Authority. http://www.lcra.org/water/wmp/

Lee, D.H. (1999). "Institutional and technical barriers to risk-based water resources management: A case study." J. Water Resour. Plng. and Mgmt., ASCE, 125(4), 186-193.

Liang, X., Wood, E.F., and Lettenmaier, D.P. (1996a). "Surface soil moisture parameterization of the VIC-2L model: Evaluation and modification." Global and Planetary Change, 13, 195-206.

Liang, X., Lettenmaier, D.P., and Wood, E.F. (1996b). "One-dimensional statistical dynamic representation of subgrid spatial variability of precipitation in the twolayer variable infiltration capacity model." J. Geophys. Res., 101(D16), 2140321422.

Liang, X., Lettenmaier, D.P., Wood, E.F., and Burges, S. J. (1994). "A simple hydrologically based model of land surface water and energy fluxes for general circulation models." J. Geophys. Res., 99(D7), 14415-14428.

Lohmann, D., Raschke, E., Nijssen, B., and Lettenmaier, D.P. (1998) "Regional scale hydrology: II. Application of the VIC-2L model to the Weser River, Germany." Hydrol. Sci. J., 43(1), 143-158.

Maidment, D.R., Ed. (1993). Handbook of Hydrology. New York: McGraw-Hill. 
Manabe, S., Smagorinsky, J., and Strickler, R.J. (1965). "Simulated climatology of a general circulation model with a hydrological cycle." Mon. Weather Rev., 91, 769-798.

Martin, Q.W. (1991). "Drought management plan for Lower Colorado River in Texas." $J$. Water Resour. Plng. \& Mgmt., 117(6), 645-660.

Maurer, E.P. (2002). Monthly Data Sets. From VIC Retrospective Land Surface Data Set: 1950-2000. http://www.ce.washington.edu/pub/HYDRO/edm/VIC_retrospective/

Maurer, E.P., Wood, A.W., Adam, J.C., Lettenmaier, D.P., and Nijssen, B. (2002). "A Long-Term Hydrologically-Based Data Set of Land Surface Fluxes and States for the Conterminous United States." J. Climate, 15(22), 3237-3251.

Mintz, Y., and Serafini, Y.V. (1992). "A global monthly climatology of soil moisture and water balance." Climate Dyn., 8, 13-27.

Nijssen, B., Schnur, R., and Lettenmaier, D.P. (2001). "Global Retrospective Estimation of Soil Moisture Using the Variable Infiltration Capacity Land Surface Model, 1980-93." J. Climate, 14, 1790-1808.

Nijssen, B., Lettenmaier, D.P., Liang, X., Wetzel, S.W., and Wood, E.F. (1997). "Streamflow simulation for continental-scale river basins" Water Resour. Res., 33, 711-724.

O'Connell, S.M. (2002). "The Use of Predictive Climate Signals in Synthetic Streamflow Development for Central Texas Water Management." M.S. Thesis, Michigan Tech Univ., Houghton, MI.

Pagano, T.C., Hartmann, H.C., and Sorooshian, S. (2000). "Climate forecasts: A new tool for emergency management in the southwest U.S." Nat. Hazards Observ., 24, 7-8.

Pagano, T.C., Hartmann, H.C., and Sorooshian, S. (2001). "Using climate forecasts for water management: Arizona and the 1997-98 El Nino." J. Amer. Water Resour. Assoc., 37, 1139-1152.

Pagano, T.C., Hartmann, H.C., and Sorooshian, S. (2002). "Use of climate forecasts for water management in Arizona: A case study of the 1997-98 El Nino." Climate Res., in press.

Piechota, T.C., Chiew, F.H.S., Dracup, J.A., and McMahon, T.A. (2001). "Development of exceedance probability streamflow forecast." J. Hydrol. Eng., 6(1), 20-28.

Piechota, T.C. and Dracup, J.A. (1999). "Long-range streamflow forecasting using El Niño-Southern Oscillation indicators.” J. Hydrol. Eng., 4(2), 144-151. 
Piechota, T.C., Chiew, F.H.S., Dracup, J.A., and McMahon, T.A. (1998). "Seasonal streamflow forecasting in eastern Australia and the El Niño-Southern Oscillation." Water Resour. Res., 34(11), 3035-3044.

Piechota, T.C. and Dracup, J.A. (1996). "Drought and regional hydrologic variation in the United States: Associations with the El Niño-Southern Oscillation." Water Resour. Res., 32(5), 1359-1373.

Redmond, K. and Koch, R. (1991). "Surface climate variability in the western U.S. and its relationship to large scale circulation indices" Water Resour. Res., 27(9), 23812399.

Ropelewski, C.F., and M.S. Halpert (1986). "North American precipitation and temperature patterns associated with the El Niño/Southern Oscillation." Monthly Weather Rev., 114, 2352-2362.

Smith, J.A., Day, G.N., and Kane, M.D. (1992). "Nonparametric framework for longrange streamflow forecasting." J. Water Resour. Plng. and Mgmt., ASCE, 118(1), 82-92.

Stern, P. C., and Easterling, W.E (1999). "Making Climate Forecasts Matter." National Academy Press, $175 \mathrm{pp}$.

Watkins, D.W., Jr., McKinney, D.C., Lasdon, L.S., Nielsen, S.S., and Martin, Q.W. (2000). "A scenario-based stochastic programming model for water supplies from the highland lakes." Intl. Trans. in Op. Res., 7, 211-230.

Wood, E.F., Lettenmaier, D.P., and Zartarian, V.G. (1992). "A Land-Surface Hydrology Parameterization With Subgrid Variability for General Circulation Models" $J$. Geophys. Res., 97(D3), 2717-2728. 


\section{Appendix A ArcView GIS Applications and Visuals}


ArcView GIS was the program used to apply GIS operations on the extracted VIC Retrospective Land Surface Data Set. Besides the tasks performed on the VIC modeled data as explained in Section 4.3 in Chapter 4, other GIS applications are possible such as the visual display of watersheds (see Figure A.1) and the data points of interest (see Figure A.2). Another useful GIS program that performs similar functions to ArcView GIS is ArcMap. ArcMap utilizes the same type of operations available in ArcView for data manipulation. ArcMap also performs visual Kriging of data layers and/or data points (see Figure A.3). This type of Ordinary Kriging is labeled as a Prediction Map because what it essentially does is provide data on a layer in locations where previously there was no data. It is a useful visual to estimate the average of a given attribute over a given area. Kriging is displayed here for visual purposes and was not used as part of this study.

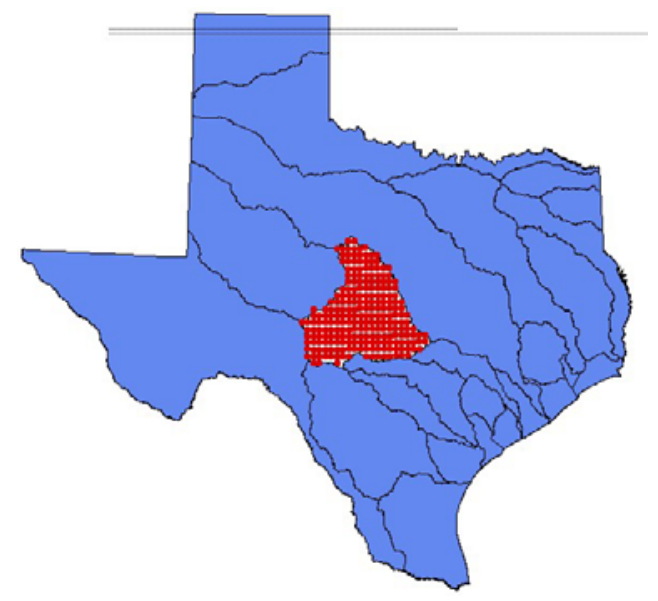

Figure A.1: GIS Visual of the LCRA Watershed and VIC Data Layer on the State of Texas

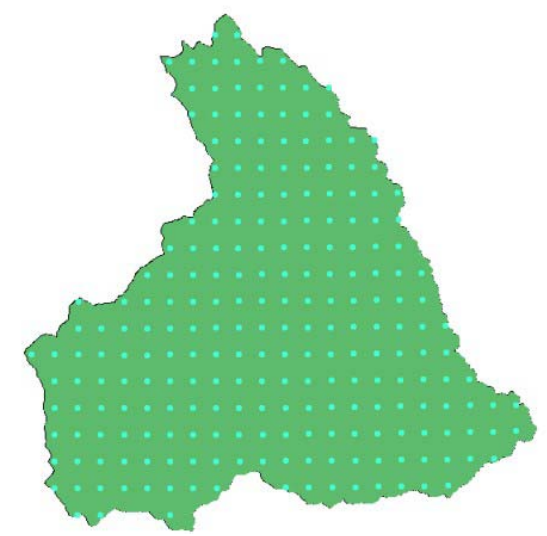

Figure A.2: GIS Visual of the LCRA Watershed and Overlaying VIC Modeled Data Points 


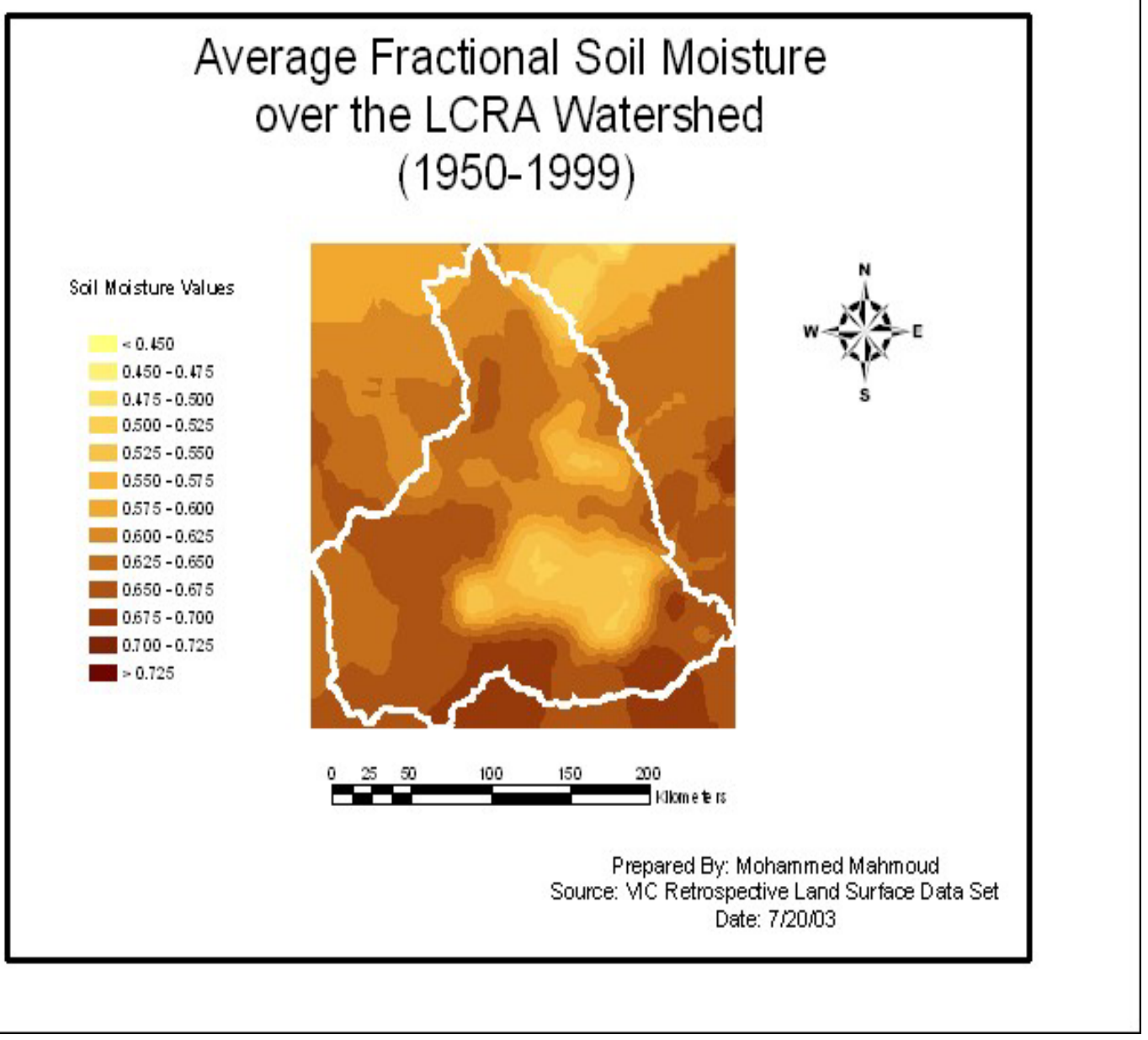

Figure A.3: GIS Visual of Kriging on the LCRA Watershed 


\section{Appendix B Sample MATLAB Code used for VIC Data Extraction from NETCDF Format}

